

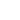

-

$$
\text { . }
$$




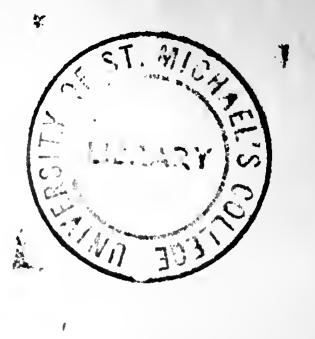

IIR. BALFOUR'S APOLOGEIIICS 



\section{IIR. BALFOUR'S}

\section{APOLOGETICS}

CRITICALIY EXAIINEI)

BY

IV. B. COLUMBINE

[ISSUED FOR THE RATIONALIST pRESS ASSOCIATION, LIMTED]

LoNDON :

WATTS \& CO.,

17, JOHNSON'S COURT, FLEET STREET, E.C. 



\section{CONTENTS}

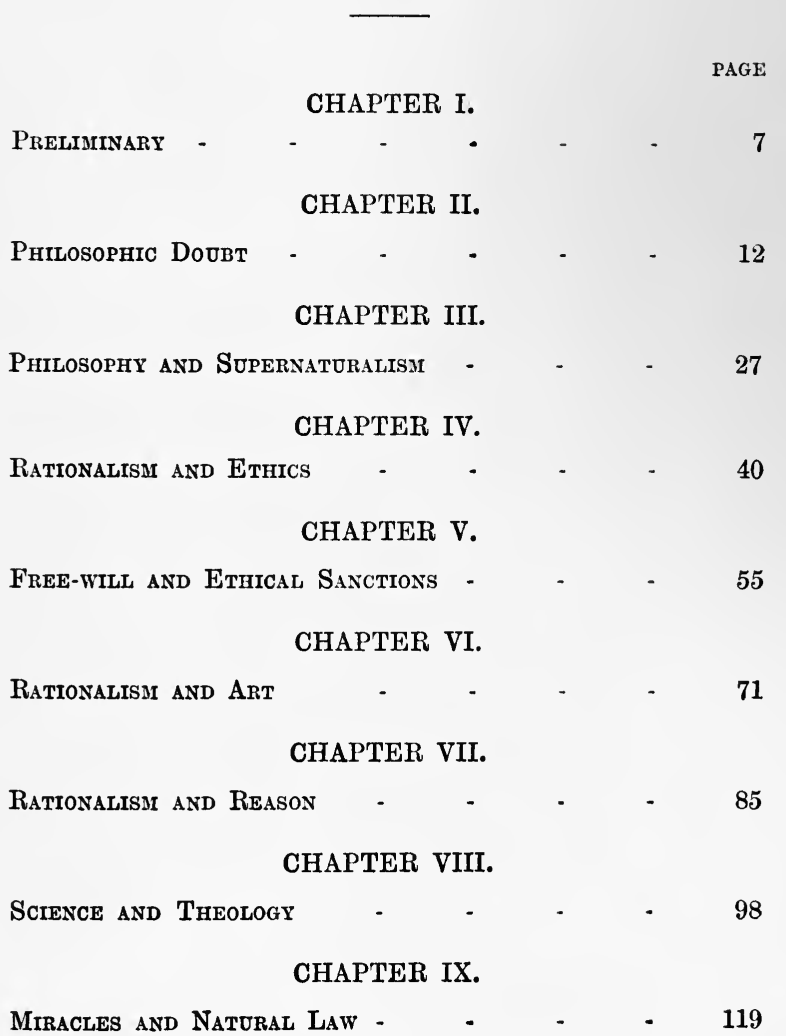




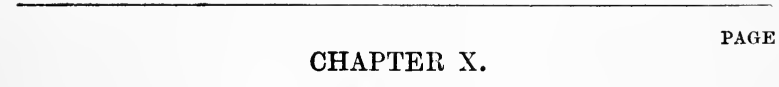

Philosophy and Rationalisi $\quad$ - $\quad$ - $\quad$ - 143

CHAPTER XI.

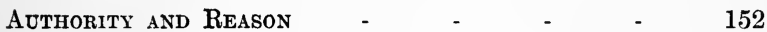

CHAPTER XII.

Mr. Balfour's Provisional Unification - $\quad 166$

CHAPTER XIII.

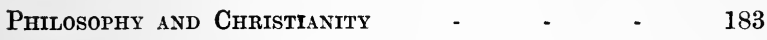

CHAPTER XIV.

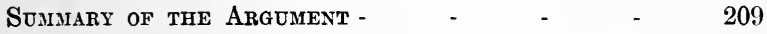

CHAPTER XV.

Mr. Balfour's Personal Position - $\quad$ - 221 


\section{CHAPTER I.}

\section{PRELIMINARY}

ON the great battle-field of the human mind, where, from age to age, the strife is unceasing and the most brilliant victory of any particular school of thought means only that the conflict is transferred to other ground, and, perhaps, higher levels, two great and irreconcilable powers are engaged in a fierce struggle for mastery. One of these combatants is Supernaturalism, under which term we include all the supernatural religions of the world, with Christianity at their head; the other is Rationalism, by which we mean the free and fearless application of reason, regardless of consequences, to all questions of ethics, science, philosophy, and religion. Both alike are children of Evolution; but, while one is hoar with age, and looks back upon a long maturity which stretches far away into the dim abyss of prehistoric time, the other glows with the vigour and promise of youth, and its gaze and expectation are directed towards the present and the future, with all the glorious possibilities which they enfold. 
To the present writer it seems that this struggle can have but one result. Rationalism or Naturalism (the terms are practically synonymous) is swiftly and surely beating back the forces of Supernaturalism at all points, and the day of its final victory-in the Western world at least-cannot be far distant. Armed with the sword of Science, clad in the coat of mail which has been slowly fashioned by human thought and effort during many painful centuries. Rationalism possesses inestimable advantages in the war with the myths and fables of the past, and against the futile longings for the magic and the mystery of a supernatural world. These things have been weighed in the balance of Reason and found wanting; in bold and indelible characters their fate is written on the wall in the sight of all mankind; by all the laws of nature and of human thought they are doomed to extinction.

It is clear that Mr. Balfour has realised with special vividness the overwhelming strength of the Rationalist case against Christianity, and that he does not indulge in any vain hope that the hostile verdicts of science, history, and Biblical criticism may be reversed by further investigations and discoveries. Apparently he accepts these verdicts. In his speech at 
Glasgow, November 4th, 1901, he urged that the "great change in our views of the history of the world," to which " every science has contributed -astronomy, geology, physics, anthropology," carries with it " the need and necessity, not of any change in Christian doctrine, not of any change of religion, but of a change of statement of the thought and setting in which religion is from age to age presented to the people." But if (words are to represent things, and to be something more than empty sounds, a change of statement which is necessitated by " the greatest revolutions in secular and scientific thought of which any record remains to us " must involve some change of doctrine. Mr. Balfour admits that this is the case when, in the same speech, he refers to "the great harm, in some cases the incalculable harm, and the immeasurable loss which has occurred through that being represented as integral and essential which was, after all, temporary and accidental." That is to say, features of the Christian religion which have (been held by high authorities to be of the utmost importance, and, in fact, " integral and essential," may, under stress of criticism and advancing knowledge, be abandoned as "temporary and accidental." This is more than a "change of setting"; it is a change of doctrine, and, 
in some cases, amounts to a change of religion.

Unfortunately, neither in his writings nor in his speeches has Mr. Balfour defined his own theological position with any exactness. It seems clear, however, that while he is something more than a Unitarian he is something less than an orthodox member of, say, the Church of England or the Church of Scotland. He believes in the deity of Jesus, and we may therefore assume that he accepts the gospels as, in the main, historically true. But, apparently, he also recognises the validity of the theory of evolution, and he must, therefore, reject the Pauline scheme of redemption, which is based on the fall of Adam. Here, then, in $\mathrm{Mr}$. Balfour's own case, we have not merely changes of setting or of statement, but far-reaching changes of doctrine.

Is it reasonable to believe in the Christian religion, in the modified form in which it is held by Mr. Balfour? This is the question which underlies both his books, A Defence of Philosophic Doubt and The Foundations of Belief, and the whole of his subtle philosophical arguments and eloquent general pleadings form a coherent and systematic attempt to justify an affirmative answer to the question. Mr. Balfour, however, is too skilful and well-informed to meet 
Rationalism in the open field, and to attempt the hopeless task of refuting its arguments in detail. He prefers to attack them by sap and mine, and endeavours to show that, if the pretensions of Christianity are surrounded by doubt and difficulty, Rationalism, and the science on which it is based, stand in no better position, when viewed from the philosophical standpoint, and, in short, closely resemble castles in the air. He also attempts to show that " the great body of our beliefs, scientific, ethical, theological, form a more coherent and satisfactory whole if we consider them in a Christian setting than if we consider them in a Naturalistic one."

The gauntlet thus thrown down is here taken up with confidence that Truth will be justified of her children, and that all Mr. Balfour's main positions, in so far as they are intended to form the buttress of a decaying creed, will yield to a determined assault. 


\section{CHAPTER II.}

\section{PHILOSOPHIC DOUBT}

Is there a persistent, external world? If so, may we reasonably accept the evidence of our senses respecting it, bearing in mind the fact that our senses sometimes deceive us? Can the law of causation be logically proved? What philosophical ground is there for assuming that uniformity of nature which figures so largely in modern science?

These are some of the questions which $\mathrm{Mr}$. Balfour discusses with great acumen and at considerable length in his Defence of Philosophic Doubt, and, to a less extent, in his Foundations of Belief. He shows with much clearness and success that, from the philosophic standpoint, each of these questions must be answered either in the negative or with a cautious scepticism. The reader at once asks, What is gained for religion by this promulgation of universal doubt? How can the fact that we are uncertain as to everything beyond our own existence, sensations, and ideas form any support for the doctrines of Christianity? Mr. Balfour tells us that his 
practical object is not to produce universal scepticism, which he admits to be impossible, but to aid the cause of religion by showing that Science, which is put forward as the foe and the conqueror of Theology, has no title, in philosophy and reason, to sit in judgment on all systems of belief, and that, in fact, the scientific system "is, as a whole, incapable of any rational defence." Everything, of course, depends on what is meant by the word "rational." Mr. Balfour uses it here in the sense of "philosophical," and he has defined philosophy as " the systematic account of the grounds of belief and disbelief." Now, while Science may not be capable of philosophical defence, it is clearly invulnerable when regarded from the standpoint of the empirical and the practical. And we maintain that this is the only rational standpoint from which it can be examined, and that to relegate these matters of practical importance to the high and rarefied atmosphere of abstract philosophy and pure reason is as irrational as it would be for Mr. Balfour to place himself in the path of an express train, hoping that no evil results might ensue, on the ground that there is no philosophical proof of the reality of the external world.

Take, for example, the questions of the Law 
of Causation and the Uniformity of Nature. Mr. Balfour contends that no enumeration of individual sequences can be sufficient to prove that the law of causation operates throughout all space and time; that, amid the complexity and diversity of nature, it is impossible to determine all the causes of any particular event; and that no satisfactory proof can be given of the doctrine that nature is uniform. All this, from the standpoint of pure logic and abstract philosophy, is undoubtedly true; but what practical bearing has it on the question whether Science, as a system, is valid and rational? Probability, as Bishop Butler said, is the guide of life, and the probabilities that the law of causation is universal, and that Nature is uniform, are raised to the level of practical certainties by the experience of all mankind. Nor is this consideration weakened by the fact that the inference from experience is, in the last resort, an inference from "the immediate and limited experience of each individual." If man can be certain only of his own existence, feelings, and ideas, the basis of individual experience, however narrow, is clearly of unique strength, and empiricism possesses a dignity and power which no other philosophy can claim.

Careful consideration of the objection that we 
are unable to determine all the causes which are necessary to produce any given phenomenon should have convinced $\mathrm{Mr}$. Balfour that his whole line of argument, as an indictment of the foundations of science, is unpractical and beside the mark. The existence of the solar system is, no. doubt, as Mr. Balfour suggests, a necessary concomitant of all the events that take place on our own planet. But, so far as the influences of these distant causes are known, they already form part of the possessions of science; so far as they are unknown, they may, at least, be considered as possible scientific discoveries of the future. A chemist conducting experiments in his laboratory need not, and does not, trouble himself about such facts as the permanent arrangements. of the solar system. Directly or indirectly, these act as causes of all events that take place on the earth; but their operation is on so vast and uniform a scale, and of so fundamental a kind, that in large numbers of instances they are rightly taken for granted in theory and ignored in practice, while in other cases, where their influence is more immediate and clearly defined, it is carefully and accurately enumerated among the causes of any given phenomena. Blot the planet Mars out of existence, and no doubt the course of terrestrial history would be altogether 
changed. But the fact that we cannot accurately estimate the influence of Mars upon the earth, and that we are therefore unable to predict what would happen if he ceased to exist, is not of the least practical importance. It is for the present at any rate a matter of vain and empty speculation. From the standpoint of a perfect philosophy, science may, no doubt, be required to tabulate all the causes of a given phenomenon. But sensible and practical men, while always striving towards higher ideals, recognise that absolute perfection is beyond their reach, and they are quite satisfied that science is a valid and reasonable system when its efficiency and power are demonstrated, over and over again, by successful prediction and experiment.

$\mathrm{Mr}$. Balfour contends that it is impossible to prove the uniformity of nature, and his ground for this contention is that, even supposing the antecedent $\mathrm{A}$ to be always followed by the consequent $B$, we have no means of determining which of the many thousands of phenomena that always co-exist with $\mathrm{A}$ and $\mathrm{B}$ are necessary factors in the operation. What is this but the merest trifling? Is it any wonder that philosophy has fallen into contempt when it raises and elaborates issues so unpractical and preposterous as this? We know that the application 
of heat to water, under certain conditions, will produce steam. Given the conditions, and the result is inevitable and invariable. This is an example of what we mean by the uniformity of nature, and to attempt to destroy our faith in science as a rational system on the ground that we do not know what part is played in the process by the fixed stars may be amusing as an exhibition of philosophical dialectics, but can hardly be expected to produce any practical result.

Dealing with the question of Historical Inference, Mr. Balfour argues at some length that, as more than one cause may be capable of producing the same effect, there can be no reasonable guarantee that the account which is given in outline by science of " the history of the whole human race, of the organic world, of the planet on which we dwell, and of the system to which it belongs," is worthy of credence. Mr. Balfour himself appears to believe that this account is true, but he is unable to find any philosophical grounds for believing it. A collection of flint arrow-heads may be, and no doubt is, the work of pre-historic men, but they may also be "the product of that unknown collection of mechanical causes which in this case, for convenience, we may call accident." Or, we might 
add, they may be the work of the devil, designed to produce unbelief in the Biblical story of the creation of man. Or they may have been fashioned by fairies and hobgoblins in the morning of the world. Or they may have been shot from the volcanoes in the moon. "One version of history," writes Mr. Balfour, "need not be less likely than another, merely because it seems in comparison unnatural and extravagant." That is to say, there is no more philosophical ground for believing that any given collection of flint arrow-heads was the work of man than for believing that it was the work of the devil. If this is all that philosophy can do for us on questions of historical inference, practical men will be inclined to banish philosophy altogether, and to walk with the aid only of clear-eyed science and plain common-sense. Mr. Balfour concedes that probabilities are infinitely in favour of the scientific version of history, and that no human being who need be considered will seriously call it in question. The fact, then, that philosophy is unable to discover logical grounds on which the principles of science may be firmly based proves either the impotence and worthlessness of the philosophy in question, or that, owing to the limitations of the human mind, no satisfactory philosophy of 
science can be framed. It does not in the smallest degree invalidate the general teachings of science, or detract from the value of science as the mightiest instrument of physical and mental progress that has been evolved by man.

Discussing the bearing, on the question of historical inference, of the existence of a " universal first cause, whether that be the unknown $x$ of certain philosophers or the personal God of the theologians," Mr. Balfour affirms that, taking for granted the existence, of such a first cause, "there is no period of history at which creation might not have taken place"; and, further, that "whatever date in the past we select, there are always two causes which are equally likely to have produced the phenomena then existing : the one is the group of phenomena which might have produced them according to known laws ; the other is the First/ Cause."

Now, we submit that this is just the kind of worthless speculation against which science rightly sets its face like flint. Admit that, the universe was produced, is maintained, and may be continued or destroyed, by the operation of some unknown $x$, or by the arbitrary will of \{ a personal God, and the door is opened for all sorts of wild and windy theories and baseless $\uparrow$ 
speculations. Proceeding from the narrow but impregnable basis of experience, Science assumes the universality of the law of causation and the uniformity of nature throughout all space and time, and her assumption is justified by every fresh discovery, and by all the facts of life and history, so far as these have become the common property of mankind. Science knows nothing of the arbitrary intervention of a first cause, whether it be an unknown $x$ or a personal God, in the history of the cosmos or of mankind; to admit any such hypothesis is to destroy the foundations of all exact knowledge, and to render science impossible. Newton, writing his Princinia ; Laplace, formulating his nebular theory which embraces past, present, and future in its comprehensive sweep; Lyell, framing his Principles of Geology; Darwin, studying through many patient years the origin of species-all these leaders of scientific thought either ignored the existence of a first cause, or assumed that, having brought the universe into existence, it immediately became quiescent, and may be left out of account in all scientific theories and investigations. In face of any strange and startling phenomenon, Superstition is ever ready to murmur, "It is the work of the devil," while her twin-sister, Iheology, exclaims, "It is the 
will of God." Science brushes these vain fantasies aside, and, believing firmly in the universality of the law of causation, lays bear the natural causes of all phenomena, thus shattering not only the dreams of the theologian, but the puerile speculations of Mr. Balfour's metempirical philosophy.

In his Defence of Plilosoplic Doulbt, Mr. Balfour lays much stress on the fact that our knowledge of an external world as conveyed to us by the evidence of the senses is corrected and qualified in some important respects by the investigations of science. For example, that which is declared by the senses to be an objective phenomenon, such as colour or sound, is shown by science to be purely subjective, and to have no existence apart from the senses. Colour and sound, in the external world, are merely ethereal or atmospheric vibrations; take away the perceiving subject and the universe consists of uncoloured objects, and there is no such thing as sound. All this is very true; but it is simply a curious speculation, and has neither practical nor philosophical importance. An external world must always be different from what it appears to be to a perceiving mind. But this is not equivalent to saying that the perception of the mind in question is false. 
The senses declare, and declare truly, what the universe is in relation to themselves. That which objectively is vibration, subjectively is colour or sound. But neither the objective phenomenon nor the subjective appearance may be correctly described as unreal or false. We cannot conceive of sight and hearing fundamentally different from our own, and to any being possessing sight and hearing the vibrations in question must become perceptible as colour and sound.

Mr. Balfour observes that, "if our whole ground for believing in the existence of a persistent world be derived from the evidence of the senses, the fact that they deceive us, though only occasionally, casts a suspicion over all the rest of their testimony." But we deny that the senses even occasionally deceive us, in any true sense of the words. Mr. Balfour does not disbelieve or doubt the reality of the objective causes which produce the subjective effects he is disposed to call illusory, and we submit that it is incorrect to call these effects false or illusory, inasmuch as they are instances in which the effect upon the perceiving mind must, of necessity, be different from the producing cause, just as the pressure of a heavy body upon a wounded limb is different from the acute pain which it may 
produce in the person to whom the limb belongs. To attempt, from the philosophical or any other standpoint, to cast doubt on the existence of a persistent world, and to destroy the foundations of science on the ground that the senses occasionally deceive us, is clearly a weak and inconclusive proceeding. Let us, however, look at the matter for a moment in another light. $\mathrm{Mr}$. Balfour maintains, in The Foundations of Belief, that our perceptions " are not merely occasionally inaccurate, but habitually mendacious." What a reflection upon the creating Deity in whom Mr. Balfour believes, and before whom he falls down in worship! God, it seems, has endowed his creatures with senses which perpetually deceive and mislead them as to the character of the universe in which they live. It may be urged that the illusions work for good, and tend to give pleasure and delight. But could not the All-Wise and All-Powerful attain these ends without resorting to the questionable methods of mendacity and illusion? In his anxiety to arraign the foundations of science, Mr. Balfour has succeeded in impeaching his Deity as an Almighty Artificer who has fashioned every one of his creatures to be a living lie.

Enlarging upon the fact that the universe of vibrating atoms which is revealed to us by 
science is altogether unlike " the world which we actually perceive, or can represent by an effort of the imagination," Mr. Balfour observes :-

That knowledge, or what passes for knowledge, soon gets in this way beyond the data of perception and the powers of imagination is a fact which comes to the surface more prominently in theology, perhaps, than in science. I am not aware that this is because there is any essential philosophic difference between these two great departments of knowledge.

To describe theology as a department of knowledge is to beg the whole question at issue between Rationalism and religion. Knowledge, as. distinguished from mere speculation, can be laid upon the logical counter in the sight of all men. It courts the most rigorous investigation ; analysis can do nothing but strengthen its claims on our credence; every additional test brings out in stronger relief the fact that it has the genuine ring of truth. What single fact or statement is there in the realm of theology which can be successfully submitted to these conditions, and which may, therefore, be entitled to rank as knowledge? And to what theology does Mr. Balfour refer? Does he refer to the barbaric theology of Abraham and Moses, or to the gentler Theism of Jesus Christ? Does he mean the theology of the Vedas or of the Koran? of John Calvin or of Theodore Parker? of Martin Luther or of the Pope of Rome? Mr. 
Balfour appears to limit the scope of theology to pure Theism, and he apparently holds that the knowledge which theology reveals to us is a linowledge of God. Let him tell us, not what he thinks or believes; but what he linou's, about the existence and attributes of God. He does not even know that God exists. Does he affirm that to believe in an intelligent first cause of the univere is a necessity of thought? By what logical or philosophical right does he make the infirmity of human thought a ground for believing in so far-reaching a doctrine? Besides, the same necessity of thought which requires us to affirm that the universe had a first cause compels us also to postulate a cause of the first cause. It is just as reasonable to believe in an uncaused universe as in an uncaused first cause. But, granting for the sake of argument that the Deity exists, what does Mr. Balfour know about him? Does he affirm that God is absolute and unconditioned? Then he cannot have created the universe; for, as creator, he must be conditioned by the relations into which he has entered towards' the work of his hands. Does Mr. Balfour say that God is all-wise, allpowerful, and all-good? Every fatal shaft of lightning, every earthquake, every disastrous storm, every loathsome epidemic, every sin 
and woe and wrong, gives the lie to this statement.

The argument may be pressed home from another quarter with results which are equally fatal to Mr. Balfour's position that theology is a department of knowledge. The fabric of science is based on the evidence of the senses, and on inferences which are drawn therefrom. If, in the last resort, this evidence and these inferences are incapable of philosophical proof, science still remains firmly planted on the impregnable ground of experience. But theology has no such immediate contact with the evidence of the senses. The so-called knowledge which is given to us by theology consists mainly of doctrines and speculations which are based on imagination or on vain desire, and, to a less degree, on inferences illogically drawn from the inferences which form part of the foundations of science. Thus Mr. Balfour, like a blind Samson, in philosophically uprooting the fabric of science, destroys the only reasonable foundation on which his temple of theology could be built. 


\section{CHAPTER III.}

\section{PHILOSOPHY AND SUPERNATURALISII}

IN conformity with his assumption that theology is a department of knowledge, Mr. Balfour refers to the "claim on our beliefs" which is possessed alike by science and theology, and he puts forward this "claim" as the "sole practical foundation on which our convictions ultimately rest." This claim he describes as " a kind of inward inclination, or impulse," which leaves the reason unsatisfied, but amounts " to a practical cause of belief." It is not true, as $\mathrm{Mr}$. Balfour contends, that in the case of a large number of persons this impulse is as strong in regard to matters of religion as it is in regard to matters of science. The "I think, therefore I am," of Descartes is not more universally and irresistibly felt to be true than the "I see, and hear, and feel, therefore I believe," which forms the bed-rock of the practical convictions of every member of the human race. The impulse to believe in the doctrines of science springs from the irresistible impulse to accept the facts which are given to us by the testimony of the senses 
as ultimate and irrefragable truths. But for the infinitely weaker and less universal impulse to believe in religion there is no such firm basis. Mr. Balfour writes of "the need for religious truth, rooted as it is in the loftiest region of our moral nature," and it is in this "need" that he finds the origin of the impulse to believe in religion. But is such a "need" general, or even widely spread? If by "religious truth" be meant the doctrines of the existence of God and of human immortality, we think it would be difficult to show that there is any general " need" to believe in these things. The speculations on these subjects are too vague and too remote to enter as important factors into the daily life and thoughts of the average man or woman. Nor, with all deference, can we think that $\mathrm{Mr}$. Balfour and the "indefinite number of $A$ other persons" for whom he speaks feel any $\chi$ deep-rooted, imperious "need" to believe in $x$ these doctrines. In so far as such a need exists, $\alpha$ it is the direct result of early training and $\wedge$ the mental habits thus formed, combined with a feeling of helpless ignorance as to the origin and destiny of the universe and of man.

It is probable, however, that in this instance by "religious truth" Mr. Balfour means what might more appropriately be called ethical truth. 
The human heart has a deep reverence for justice, love, and mercy-a reverence which in higher natures is instinctive, and which has been <engendered in the whole race, in varying degrees of strength, by millions of years of family and isocial life. But the impulse to cling to ethical truth is certainly not an exclusive characteristic of believers in the supernaturalism for which $\mathrm{Mr}$. Balfour pleads. If Rationalism may be said to include a religion at all, one half of it at least consists of ethical truths and ideals, and no impartial observer would deny that leading Rationalists have been distinguished by an intense devotion, both in conduct and in precept, to the great moral principles which embody the highest wisdom and the loftiest aspirations of the race.

While declaring that science is defective in its premises, in its inferences, and in the general relation of its parts, Mr. Balfour avows that he shares the "implicit and indestructible confidence" which is felt by all men in the truth of science. His doubts and arguments are not of a practical kind, and have no relation to common-sense; they are merely philosophic and academic. Yet he hopes by the use of these airy and fantastic weapons to prove that religion has claims on our credence not less strong than 
the claims of science. Our final answer to Mr. Balfour's line of argument takes the form of a demand that the trial of this cause shall be removed from the rarefied atmosphere of the court above to the invigorating air of the court below. The discoveries of science and the dreams and doctrines of supernaturalism; the facts of astronomy and the fancies of astrology; the theory of gravitation and tales of witchcraft and demoniac possession; the religion of Jesus and the fetish-worship of an African savage-all these, from a philosophical point of view, may be equally destitute of any logical foundation, and equally credible or incredible. So far as this is true, it merely proves the impotence of philosophy and the imperfections of philosophers; or, to take a wider and more charitable view, it proves the limitation of human faculties when brought face to face with ultimate truths.

But, after all, the question whether science and supernaturalism have equal claims on our credence is a question of immense practical importance, which must be decided on practical grounds, and apart from the finely-spun dialectics of a philosophy which is hopelessly entangled in questions of the absolute and unknowable, and which confesses that it is unable to discover 
reasonable grounds for any belief whatever. The court in which this futile philosophy presides cannot possess real influence over the minds of men, and may be safely left to its own devices. We turn to the court of practical reason, and here we find three arguments from popular philosophy which are discussed and dismissed with philosophic contempt by Mr. Balfour in the seventh chapter of his Defence of Plilosophic Doubt, but which have great weight with all mankind. These are, the argument from general consent, the argument from success in practice, and the argument from common sense. While these arguments may be open to the philosophical objections which Mr. Balfour urges against them, it is certain that any system which they unite in supporting may be accepted as indubitably true in the absence of any positive evidence to the contrary. The facts and theories of science receive daily and overwhelming confirmation from general consent, from success in practice, and from common sense. But the same thing cannot be said of supernaturalism. There may be a more or less general consent that the supernatural exists, but there is no sort of general agreement as to what the supernatural includes, and this shows that the belief rests on fear and imagination, and not on 
knowledge. Besides, the belief has no success in practice. A man may call spirits from the vasty deep, but his voice dies away unheeded on the waters of the dim unknown, and Nature proclaims both by her silence and by her myriad sweet voices that the fancies which have peopled the universe with gods and ghosts are idle and vain. And the voices of nature are supported by the voice of common-sense. Portents and omens, visions and miracles, deities and devils, are the baneful offspring of times and hours of ignorance and darkness, of weakness and despair. They vanish in the golden sunlight; they cease to press like nightmares on the healthy mind and body; they wither away at the touch of advancing knowledge, and before the sturdy commonsense of daily life and daily thought.

Thus it is that, strange as it seems to $\mathrm{Mr}$. Balfour, thinkers like Professor Huxley and Sir Leslie Stephen have laid down " the principle that science is the one thing certain; that everything which cannot be proved by scientific means is incapable of proof; and that everything which is inconsistent with science is thereby disproved." For all practical purposes the philosophic doubts raised by $\mathrm{Mr}$. Balfour may be, and must be, as he himself confesses, treated as a negligeable quantity. Of what 
practical concern is a philosophy which demonstrates that all beliefs are equally false, equally incredible, and equally absurd? Men might as well try to nourish their bodies on the east wind as expect to feed their minds on Mr. Balfour's barren negations. His philosophy is aptly summarised in one line of Byron :-

"All we know is, nothing can be known."

$\mathrm{He}$ leaves all things exactly where he found them. His philosophic doubt strikes with equal force at the roots of all systems; and therefore, like an elector who divides his votes equally between opposing candidates, he neutralises himself, and can have no voice in the decision of the questions at issue. When face to face with the problems of life men have always ignored the philosophy which thus proclaims and proves its own impotence, and have recognised that practical questions must be approached from the standpoint of the relative, and without reference to the metaphysical conundrums which lie coiled like snakes around the bases of human thought. Science is the one thing certain, because science embraces all knowledge-and knowledge is the only staff on which man may lean with safety, the only weapon which will not break in his hands when he confronts the mighty forces of the universe. All faith which is not an 
inference from knowledge should be regarded with suspicion and distrust, and may be a delusion and a snare. No methods of investiga. tion save those of science are admissible, because the experience of the race has proved beyond the shadow of a doubt that knowledge can only be gained by means of observation, corrected and verified by experiment. If any such knowledge of the supernatural can be shown to exist, it must take rank as scientific truth. But if statements are made respecting the supernatural which are not the result of observation, and which cannot be verified by experiment, or shown to be legitimate inferences from the known, and, in short, for which no evidence can be given, such statements must be condemned as inconsistent with science, and can have no claims on the credence of reasonable men. Mr. Balfour may show to his own satisfaction that, from the standpoint of his philosophy, religion is just as valid or invalid as science. But, when he has proved this, he has proved nothing. The real battle remains to be fought on other fields, and with other weapons. And when the direct issue is presented, Is this statement or this religion true or false? Reason declares, with overwhelming force, that " everything which cannot be proved by scientific means is incapable of 
proof," because no other means of proof is known. And if the statement or the religion be inconsistent with science, it is thereby disproved, because that which is inconsistent with knowledge cannot be true.

In the thirteenth chapter of $A$ Defence of Philosoplic Doubt Mr. Balfour discusses, with characteristic subtlety and cleverness, "The Evolution of Belief," and, with some plausibility and much self-satisfaction, attempts to reduce to absurdity the doctrine of evolution and the methods of science. Starting from the evolutionist position that beliefs, like all other things, are developed according to law, he asks whether the belief in evolution is likely to be destroyed by future development, and, if the answer be in the negative, he desires to know what grounds exist for thinking that this belief will escape the fate which has overtaken the opinions and beliefs of the past. The dilemma is ingenious; but, however real and perplexing it may seem in the realm of abstract philosophy, it will not form a stumbling-block to the practical thinker who aims at grasping firmly the truth within his reach, and who is unwilling to waste time and energy on empty speculations as to the kind of truth which mankind may be able to apprehend in a million years to come. A belief which 
corresponds with fact cannot be modified or destroyed by the process of development. The belief that the moon revolves around the earth is not likely to be changed or disturbed by any evolution of the human mind. And so also with the theory that beliefs are developed according to law. If this theory be true of the present and the past, it will also be true throughout all future ages, because the time will never come when man will have fathomed all the secrets of the universe and can no longer add to his stores of knowledge. Opinions and beliefs which are untrue or partially true must be destroyed or modified by the process of evolution. But the theory that beliefs are developed according to law stands in the same category as the theory of gravitation; it is true yesterday, to-day, and for ever, and a whole eternity of evolution cannot change or undermine the fundamental truths which these theories express.

Applying the same reasoning to the methods of science, Mr. Balfour contends that they "land us in contradiction," because they imply that scientific and all other beliefs "are the result of the operation of natural causes, and of these alone," and he thinks' it is certain that " these causes are of a kind to throw doubts on the beliefs they produce." Mr. Balfour is so thoroughly con- 
vinced of the mendacity of the human senses and of the general untruthfulness of the universe that he deems it improbable, if not impossible, that man can arrive at the knowledge of any truth, except perhaps by some legerdemain process of religious introspection. We deny the accuracy of the premises which weigh so heavily on his mind, and we dispute the reasonableness of the conclusions involved in his extraordinary thesis of a lying universe which has been created by a God of truth, and wisdom, and love, before whom he invites us to prostrate ourselves in worship. That beliefs are due to the operation of non-intelligent forces may account for the fact that no beliefs are wholly false; that, however encrusted with error and misconception, there is some kernel of truth in every belief; for the non-intelligent causes of belief do not and cannot lie. False beliefs are the result of man's ignorance and dimsightedness; his opinions and beliefs are erroneous, not because the universe is unveracious, but because he does not hear or read its message aright, or misinterprets the language in which it speaks.

It would be superfluous to point out that there is nothing new in the metaphysical subtleties and difficulties which are raised with so much pertinacity and zeal by Mr. Balfour. Some of 
them are as old as the time of Aristotle, and were debated with portentous elaboration by the schoolmen. All of them, in their modern form, take rise from the works of Descartes, Berkeley, Hume, and Kant, and are nowhere stated more forcibly and profoundly than in the writings of these philosophers. The point that is new in Mr. Balfour's books is that he presses these difficulties to their logical conclusions against modern science, and in the interest of theology . But, as we have already shown, and, indeed, as Mr. Balfour himself admits, his philosophical objections are just as fatal to theology as they are to science. Briefly, his position seems to be that theology has little or no case on the plane of the empirical, and that whenever, on this plane, it comes into collision with science it is discredited and thrust aside. $\mathrm{He}$, therefore, carries the discussion into the subtle region of metaphysics, with the object of showing that, if the doctrines of theology are indefensible, the foundations of science are equally insecure; that no philosophical grounds can be adduced for any belief whatever; and that true philosophers, with all who choose to follow them, may believe anything which they feel a strong impulse to believe, whether it be the teachings of science or the doctrines of the Christian religion-and, 
we may add, the fables of the Book of Mormon, or the stories of the Arabian Nights. Mr. Balfour must be convinced that theology has reached its last gasp when he endeavours to find fresh support for it in such a line of argument as this. When his philosophic doubt may be urged in a court of justice on behalf of one litigant and against another, or as nullifying the claims of all litigants; when it may be introduced into the discussions of a legislative assembly, and advanced for or against some piece of legislation, or against all legislation whatsoever; when, in short, it may be reasonably brought forward to decide any question of concrete fact and common-sense, then, and not till then, may it be admitted as an important factor in the decision of the controversy between Rationalism and Supernaturalism, between Science and Religion. 


\section{CHAPTER IV.}

\section{RATIONALISM AND ETHICS}

Mr. Balfour devotes the first chapter of his Foundations of Belief to a discussion of the destructive effects upon morality and the moral sentiments which, he thinks, will be the inevitable consequence of the full and frank adoption of Rationalist modes of thought. Pointing out that the professors of all creeds, theological and anti-theological, are practically agreed "as to what morality teaches, and as to the sentiments with which its teaching should be regarded," Mr. Balfour remarks that this "suspicious harmony" appears to suggest that " they have taken current morality for granted, and have squared their proofs to their conclusions, and not their conclusions to their proofs." We fail to see that there is anything "suspicious" in this harmony, or that there is any sign of logical weakness in the fact that, while men differ widely as to the origin of morality and the moral sentiments, they are practically agreed as to what constitutes right conduct, and as to the claims 
which the moral law possesses upon our reverence and obedience.

The whole of the reasoning in this chapter is vitiated by the fact that Mr. Balfour views his subject through a cloud of prejudice. $\mathrm{He}$ is fatally hampered by the preconceived notions, born of his religious training and doctrines, that the moral law comes direct from God, and that its majesty and sanctions are derived solely from the belief that God has ordained the law, and that, in a world to come, he will punish all who disregard it, while upon those who reverence and obey it he will lavish everlasting rewards. Holding this barbarous view of the origin of morality, Mr. Balfour is naturally at a loss to understand how the Rationalist who rejects it root and branch can yet be at one with him in regarding the observance of the moral law as the matter of supreme importance in human life, and why the Rationalist should be as ardent as the theologian in his love and admiration for ethical ideals. The explanation of the phenomenon which puzzles Mr. Balfour may be found close at hand. It lies in the simple fact, which he passionately rejects as an outrage upon our highest feelings, that the moral law has grown out of the needs of man, and springs from the human heart. That man should do justice, love 
mercy, speak truth, and help his needy and suffering fellows, are injunctions which are valid, binding, and beautiful because, if they are set at naught, human society becomes impossible, while the observance of these laws produces the highest, most durable, and most widely-spread forms of human happiness. In these injunctions we have the sum and substance of the moral law. What have they to do with the speculations of Theism or Atheism? Mr. Balfour will hardly deny that, whether there be a God or not, injustice, cruelty, and falsehood are ignoble and harmful ; and, despite his theological prepossessions, he will not be prepared to contend that, should Theism be destroyed, these things cease to be wrong, and the moral law falls to the ground like a pricked balloon.

The connection of ethics with theology is purely adventitious, and it is no more remarkable or suspicious that Theists and Agnostics should be in agreement as to the essential points and the binding character of the moral law than that they should agree as to the fundamental principles of architecture or of mathematics. (Is there a civilised man in existence who will $x$ dare to say that if the command, "Thou shalt xnot kill," was not given by God, and if, in fact, there be no God, it is right or permissible for 
any man, apart from the terrors of the civil law, $x$ to commit as many murders as he pleases ? Such a position could only be taken up by a monster or a savage, and this consideration should be sufficient to bring home to every mind the fact that the stability and grandeur of the moral law do not depend upon the belief that $x$ there is a God from whom it emanates, and who $x$ will distribute to men, according to their deeds,, rewards and punishments in a life beyond the $x$ grave. It is true that there is an average current morality which is taken for granted by thinkers of the most diverse schools, but this fact forms no ground for the suggestion that "they have squared their proofs to their conclusions, and not their conclusions to their proofs." Morals, like politics, and all other matters connected with sociological science, are of immense practical importance in daily life. But apart from the social life of man they have no importance whatever. Therefore, however men may differ as to the origin of morality, they tacitly unite in subjecting all ethical maxims to the test of practice, and in judging them by the standard of results. While current morality is largely taken for granted by all men, it may be safely affirmed that there is no generally-accepted ethical maxim which cannot be justified on the 
ground that it produces happiness, and that to disregard it would produce misery. That the moral law rests, not on supernatural voices and divine mandates, but on the facts and needs of human life, and that it finds therein sufficient basis and sanction, has been conclusively demonstrated by Mr. Herbert Spencer in his Data of Ethics.

Mr. Balfour, however, lays down two propositions:-(1) That no moral code can be effective which does not inspire emotions of reverence; and (2) that the capacity of any code to excite elevated emotion cannot be wholly independent of its supposed origin. In these propositions Mr. Balfour falls into the fatal error of inverting cause and effect. He assumes the depravity of human nature to be so great that men will not follow right and refrain from wrong unless the one is expressly commanded, and the other is expressly forbidden, in a code of laws which, by virtue mainly of their origin, and partly of their intrinsic character, are calculated to excite awe and reverence. We hold, on the contrary, that $x$ moral codes are the result, and not the source, $\chi$ of moral sentiments; that a code is the formulated Xexpression of the average morality of the people xamong whom it finds favour, and that it is $x$ reverenced and obeyed, not because of its origin, 
but because its observance is recognised as $x$ indispensable to individual and collective well- $x$ being. Does Mr. Balfour think that men refrain from murder, from theft, and from bearing false witness only because they are told that God thundered forth his mandates against these things from Sinai to the wandering tribes of Israel three thousand years ago? Nothinge could be further from the truth. To the averagex citizen these crimes are naturally abhorrent. $x$ His social feelings and sympathies rise up in hot rebellion against them, and he sees instinctively that they are destructive of the foundations of human society and happiness. On the other $f$ hand, to the man who is predisposed to the commission of crime, the fulminations of a moral code, no matter what he may be told or may. believe as to its origin, are of less weight than a grain of dust in the balance against his evil inclinations.

Pointing out that the incentives to human action are "appetite and disgust, pleasure and pain, instinct, reason, and morality," Mr. Balfour observes that it is hard to see why, on the naturalistic hypothesis, "morality should be put above appetite, or reason above pleasure." All alike are natural agents, and we are asked whence anyone of them is to "derive a dignity 
or a consideration not shared by all the others." We answer that morality and reason are higher than appetite and pleasure, and that they derive from their intrinsic merits a dignity and a consideration which appetite and pleasure can never claim. No word need be said against appetite and pleasure when kept within proper bounds. They are right, and useful, and necessary within their own sphere. And it is precisely because morality and reason step in to regulate appetite and pleasure, and, by restraining them within due limits, prevent them from becoming a menace to individual and general happiness, that they are universally regarded by men of all shades of thought as possessing an authority and a dignity which no one dreams of ascribing to the lower passions and desires.

But does Mr. Balfour seriously mean to argue that things which have a common origin must therefore be equally base or equally valuable? To state the proposition clearly is to stamp it as preposterous. Gentle William Shakespeare and Palmer, the Rugeley poisoner, both sprang from the English nation, but no subtle dialectician has yet come forward to maintain that both men are, therefore, equally deserving of love and veneration. Men, and things, and qualities are judged, not by their origin, but according to 
their individual merits. The artist who had produced a beautiful landscape painting might also cover a deal door with a single coat of paint. Yet even Mr. Balfour would not find it hard to see whence one of these performances could derive a dignity and a consideration not shared by the other. If it is necessary to discriminate between the productions of man, why may we not, with equal reason, discriminate between the productions of nature?

Mr. Balfour, however, cannot see the matter in this light. He urges that, from the point of view of biology, we are " bound to consider the coarsest appetites, the most calculating selfishness, and the most devoted heroism, as all sprung from analogous causes and all evolved for similar objects"-namely, the preservation, firstly, of the individual, and, secondly, of the race. Granted that it is so, how does the fact alter the essential and respective characters of these various human attributes? Does it transform selfishness into sacrifice, or heroism into a coarse appetite? Incredible though it may seem, $\mathrm{Mr}$. Balfour apparently thinks that some transformation of the kind is thereby effected, for he inquires, a few sentences further on, " Have the words 'noble' and 'base' a meaning for us at all ?" and he adds, "If so, it is from no essential 
and immutable quality in the deeds themselves." Is it not astounding that a man of Mr. Balfour's intellectual attainments should be capable of taking up such an extraordinary position as this? A democratic statesman mav arrive at sovereign power by means of the suffrages of a free people. A victorious general may, by means of his conquering troops, become king or emperor of a nation which hates and fears his tyrannical rule. Yet, according to $\mathrm{Mr}$. Balfour's logic, there can be no essential difference between the two methods, because both achieve the same end-namely, supreme power. Heroism and selfsacrifice, he tells us, are, from the naturalistic standpoint, neither nobler nor baser than the most calculating selfishness and the coarsest bodily appetites. All have been evolved for the same purpose, and if, in their best moments, men hate selfishness and love sacrifice and duty, it is only " because, in the struggle for existence, the altruistic virtues are an advantage to the family, the tribe, or the nation," and nature, therefore, surrounds the idea of unselfishness with august sentiments in order to counteract the self-regarding instincts and appetites which we inherit from our animal progenitors, and " to trick us into the performance of altruistic actions." Again we say, granted that it is 
so, how does the fact render selfishness less ignoble, sacrifice less beautiful, duty less binding? Indeed, it is the struggle for existence which gives these things all their force and meaning, and which alone makes possible the existence of vice and virtue. Mr. Balfour tells us that, on the naturalistic hypothesis, courage and selfsurrender, duty and heroism, cannot be noble and august because they grow out of the same soil as selfishness, anger, and lust. We answer that they could not grow from any other soil at all. If there were no struggle for existence, no imperious bodily appetites, no cruel selfishness, there could be no self-sacrifice and no heroism, and the word "duty" would have no meaning. If earth were transformed into the fabled Christian heaven, and sorrow and tears were banished, and all human beings were freed from bodily wants and the selfishness which springs therefrom, what, in such a world, would be the meaning of the phrase, "the majesty of the moral law"? How, in such a world, where each person had all that he required, and where peace and happiness constantly reigned, could there be any room for the exercise of courage, heroism, and self-sacrifice?

Mr. Balfour thinks that, on the naturalistic hypothesis, the moral law ceases to be sublime, 
and may be appropriately compared with the "protective blotches on the beetle's back." Both the "blotches" and the moral law, he suggests, may be pronounced ingenious. But, he asks, "how on this view is the "beauty of holiness' to retain its lustre in the minds of those who know so much of its pedigree?" Mr. Balfour's criticisms remind us of the ancient carping question, "Can any good thing come out of Nazareth?" He seems to think that no good or holy thing can come out of nature by the process of evolution, although we may presume that he believes nature to be the work of God and the visible expression of the mind of God. By "holiness" we mean high moral character, and, re-affirming the position taken above, that morality could be developed only under such chequered conditions as this world affords, we hold that altruism or holiness loses none of its beauty when we discover that its origin may be found in the instinctive yearnings of lowly parent organisms towards their helpless offspring, and that it forms part of the machinery of natural selection which aims at the preservation and elevation of the race. We know nothing, and we take leave to say that $\mathrm{Mr}$. Balfour knows nothing, of the holiness of gods and angels who are without sin. The only holiness known to 
man is that which has grown up on this earth from a soil of selfishness and suffering, and in an atmosphere of temptation and strife. It is beautiful by reason of its contrast with sin and crime, and because of the peace and happiness which it sheds around. Does the beauty of holiness suffer any diminution because we may trace its pedigree to the rude family circles of anthropoid apes, dwelling in the forests of the primeval world, or even to a darker and earlier time, when dragons wrestled together and "tare each other in their slime"? We might as well. say that the orations of Demosthenes lose their eloquence and power, that the plays of Shakespeare cease to be grand and beautiful, that the poetry of Tennyson loses its music and sweetness, if it can be shown that human speech has slowly evolved from a few guttural sounds and simple cries perhaps not distinguishable from the chatter of a crowd of monkeys.

Mr. Balfour contends that much of the efficacy of moral teaching will be destroyed if, while men

"are being taught the supremacy of conscience and the austere majesty of duty, they are also to be taught that these sentiments and beliefs are merely samples of the complicated contrivances, many of them mean and many of them disgusting, wrought into the physical and into the social organism by the shaping forces of selection and elimination."

First, let it be noted how, in this passage, Mr. 
Balfour contrives to bring a grave indictment against his God. It is surely no light thing to say that a being who is all-wise and all-powerful, and to whom, therefore, an infinite number of other courses were open, has chosen to effect his purposes by the agency of mean and disgusting contrivances. On the naturalistic hypothesis, of course, this difficulty does not arise. And the answer to Mr. Balfour's main objection lies in the fact which he persistently ignores, that while one contrivance may be mean and disgusting, another contrivance may be noble and beautiful as well as ingenious. We do not mean to imply by the use of the word "contrivance" that there is a purpose behind or in the phenomena of nature. Evolution implies adaptation and adjustment, but not purpose. Whatever analogy there may be between the evolution or gradual adjustments of man's moral nature and the evolution of physical organisms, it cannot and does not in the smallest degree detract from the value of moral principles, impair the efficacy of moral lessons, or sap the strength of moral sentiments. Some of the contrivances of nature may be mean and disgusting, and many of them are very cruel; but this does not alter the facts that selfishness is base and unselfishness is noble, that cowardice 
is despicable and courage and heroism are grand, that to do wrong knowingly is degrading and contemptible, while to follow duty with unshrinking and fearless devotion calls forth the admiration of every cirilised man and woman.

Another answer, from a different standpoint, may be offered to $\mathrm{Mr}$. Balfour's objection. If moral sentiments and beliefs have been wrought into man's mental nature "by the shaping forces of selection and elimination," how can the knowledge of their origin help to diminish their strength? Whatever the Christian Scientists may say, that which has been wrought into man's nature cannot be eliminated from it by the simple process of taking thought. "Can the Ethiopian change his skin, or the leopard his spots?" Which of us, by taking thought, can add a cubit to his stature? The processes of nature are slow but sure, and they cannot be reversed by the whims of man. The moral ground which has been slowly and painfully won from the tiger, the ape, and the savage is not likely to be lost except by means of some physical cataclysm, and the moral evolution of man is not bound up with the supremacy or permanence of any one ethical or religious system. Physical adaptations have their roots deep down in physical needs and the physical 
environment, and, in like manner, the evolution of morals has its causes in man's mental, social, and physical needs and environment, and neither the one process of evolution nor the other can be seriously affected by the human will. The evolution of society involves a steady advance towards higher moral levels. Individuals may lag behind, but the main current of human life and thought flows ever onward, and the irresistible "forces of selection and elimination" are ceaselessly preserving and multiplying those who are fittest morally to survive, while they are destroying the vicious and the criminal, and placing increasing difficulties in the path of all whose moral sentiment falls below the current ethical standard. 


\section{CHAPTER V.}

FREE-WILL AND ETHICAL SANCTIONS

IN discussing the question of Rationalism and Ethics, Mr. Balfour finds it impossible to avoid some brief references to the old problem of Determinism and Free-will. He observes that all mankind, including necessitarian philosophers themselves, suffer from the ludicrous delusion that in their moral decisions "they are free, when, as a matter of fact, they are nothing of the kind"; that, according to the determinist hypothesis, man and his proceedings are "as absolutely determined by their antecedents as sticks and stones "; that, on the same hypothesis, it is thoroughly irrational to feel righteous indignation either at our own misconduct or that of other people; and that the moral feelings are likely to be weakened "by the effective spread of sound naturalistic doctrine." Let us glance briefly at each of these positions.

In what sense does the ordinary unphilosophical man believe his moral will to be free? $\mathrm{He}$ believes that he is free to perform any given 
/ moral or immoral act, just as he believes that he is free to perform any non-moral act. A man is free to spend a holiday as he pleases. He may stay at home, or take country walks, or go to the lakes or to the seaside. Within the limits of his purse, he feels that he is absolutely free to spend his holiday as he likes. Yet, under such circumstances, the most ardent advocate of free-will would be annoyed if he were told that his choice was undetermined by reasons or motives. To use such language to him would be equivalent to calling him a lunatic. Even Mr. Balfour would admit that the idea of freedom in such a case is an illusion, and that a man's choice is wholly determined by circumstances and motives over which he has no control. If we knew the man's character, antecedents, and environment, together with the motives presented to his mind, we could predict his choice as accurately as a chemist can predict the result of any particular combination of acids, alkalies, or gases. Yet, in making such a choice, his sense of freedom would be as complete as when he is making some more momentous decision between right and wrong.

In truth, the notion that man believes his will to be free, except in a rigorously limited sense of the word, is itself a delusion. A man may 
believe himself to be free to perform any kind of physical antics, either in private or in public, but he will not exercise his freedom in this direction without a sufficient motive. And every sane man knows that this is the case, and thus clearly recognises that his will is caused, or, in other words, that it is the inevitable result of the co-operation of internal and external factors. When we enter the realm of morals the same considerations apply with equal force. A man may fancy that he is free to do right or wrong just as he pleases, but a very little reflection will show him that he knows and recognises by his conduct and by his habits of thought and speech that the idea is a delusion. The habitually temperate man is not free to become a drunkard; the peaceable and merciful man is not free to become a murderer; the honest man is not free to become a thief; the sincere and truthful man is not free to become a hypocrite and a liar. Only by slow degrees can the virtuous man sink into vice. And the converse of all this. is equally true. The immoral man and the $x$ criminal are not free to become virtuous and lawabiding members of the community at any moment when some passing whim or feeling of remorse may impel them in this direction. The habits of their lives hang around them like chains, 
and, even though they may feel a strong desire for moral reformation, years of struggle and discipline must elapse before they can be finally and effectually raised out of the slough of vice and crime. In practice, these truths are recognised by all men, and they form the basis of social intercourse. It is only in theory that men are ready to commit themselves to the absurdities of the free-will doctrine which implies that we may gather grapes from thistles, that the morally weak and the morally strong are equally able to resist temptation, and that good and evil deeds may be expected with equal uncertainty from moral and immoral characters.

Over and over again Mr. Balfour shows in his writings a lack of the discrimination which is an essential characteristic of the philosophic intellect. His statement, that according to the determinist hypothesis man and his proceedings are "as absolutely determined by their antecedents as sticks and stones," seems to carry with it the suggestion that from the necessitarian standpoint there is no material difference between the history of sticks and stones and the sequence of events in human lives. Yet the merest dabbler in the subject must know that such a suggestion has no foundation in fact. Even on the determinist hypothesis, what resemblance can 
there be between the manner in which the career of a stick or stone is determined by its antecedents and surroundings, and the manner in which the lives of human beings are determined by their antecedents and surroundings? The difference between the two orders of necessity which govern the two cases is as immense as the gulf which separates a stick or stone from conscious, sensitive man, who is capable of feeling pleasure and disappointment, sorrow, hope, and remorse.

When Llewellyn slew his noble wolf-hound, Beth-Gelert, because he thought the dog had killed his child, was the Welsh prince carried away by an overwhelming flood of indignation which was "thoroughly irrational" except on the hypothesis that his dog possessed free-will? The truth is that when we feel indignation at our own conduct, or at that of other people, or at the conduct of animals, our indignation is directed against particular actions, and against the nature from which they spring. We do not argue, explicitly or implicitly, that this person or this creature was free to take a course exactly opposite to that which has excited our wrath./ The question of freedom does not enter our minds at all. Our feeling is rather that there must be a strain of vice or wickedness in the 
nature which has produced this evil fruit, and our indignation is intended to discourage future exhibitions of a similar kind.

Time alone can show whether there is any ground for Mr. Balfour's fear that the moral feelings will be weakened "by the effective spread of sound naturalistic doctrine." So far, the verdict of history is that such a fear is altogether groundless. The ages of faith were ages of ignorance, immorality, and crime. The growth of civilisation is dependent upon the growth and spread of Rationalism, and few persons will deny that the modern rise of the rationalistic spirit has been accompanied by a slow but sure uplifting of the manners and the morals of the people. Sound rationalist doctrine has a wider and firmer hold of the human mind than at any previous period in the history of mankind, and we think no well-informed observer will deny that in the Western world the average ethical standard is higher than it has ever been before. If necessitarian doctrines be true, the moral feelings cannot, of course, be injured by the spread of rationalist opinions. Conduct, whether moral or immoral, is not determined by a man's belief or disbelief in the freedom of his will. That this is the case may be demonstrated by every individual for himself. Let any man, 
on the ground that his will is not free, determine to give the rein to passion and inclination. $\mathrm{He}$ will find that the mere consideration that his will is not free produces no change whatever in his conduct or in his mental attitude towards good and evil. He finds himself following the ordinary impulses of his nature, and in the hour of temptation, when the inevitable conflict takes place between his higher and lower feelings, he is swayed by motives, and his conduct is determined by the motive which happens to be strongest. The resolution to disregard the moral law on the ground that his will is not free has no influence upon his actions, and is of importance only as showing that his nature is predisposed to evil courses.

Mr. Balfour contends that, on the rationalistic theory, " the ends prescribed by morality" are not consistent, because the Rationalist creed "refuses to admit that the deeds done and the character formed in this life can flow over into another, and there permit a reconciliation and an adjustment between the conflicting principles" of egoism and altruism "which are not always possible here." Both as an objection to Rationalism and as an argument in favour of personal immortality this contention seems to us to be without value. The reconciliation and adjust- 
ment between egoism and altruism are going on all round us, and have been going on since the dawn of moral feeling in far-off brutal times. With every advance in civilisation and every improvement in ethical standards, the adjustment becomes closer, and the reconciliation more complete. It will perhaps never be perfect, but in the golden future for which reformers hope and work the adjustment will probably be so close as to render it unnecessary to postulate a life after death in which vice will be punished and virtue will meet with its due reward. The Rationalist hopes and believes that while, at present, the reconciliation between egoism and altruism may not be possible in the case of each individual, it will one day be effected for the race. His view is that evolution will run its course, and reach its climax, on this earth, and this seems to us a much saner position than that which is taken up by Mr. Balfour, who, apparently, holds that a process of evolution which has begun in a world of material beings can only be continued and completed in a shadowy world of ghosts who have been divested of every feature, except consciousness, which gave character and distinctiveness to their life on earth.

But we may inquire, How do "the ends 
prescribed by morality" become more adequate on the theory of personal immortality? Mr. Balfour cannot admit that "the greatest happiness of the greatest number" is the right end of action. Yet he postulates a future life in order that the "greatest happiness" may be conferred upon all who have been virtuous, and that punishment may be meted out to the wicked. What is this but an extension to heaven of the utilitarian principle which he refuses to recognise on earth? The ends of morality are the same in both cases, except that on Mr. Balfour's theory they are to be attained in some dim and shadowy world of ghosts, while Rationalists hold that they can be reached only in this life with an ever closer approximation to perfection as the cycles of evolution move slowly onward.

Mr. Balfour, however, holds that rationalistic ethics are emotionally inadequate, even though we assume that "the perfection and felicity of the sentient creation" are the all-inclusive objects "prescribed by morality for human endeavour." His grounds for this contention are that on the Rationalist theory man is no more than "a natural object among other natural objects"; that "his very existence is an accident, his story a brief and transitory episode in the life of one of the meanest of the 
| planets"; and that in the distant future the sun will be darkened, the earth will no longer tolerate our race upon its bosom, and " man will go down into the pit, and all his thoughts will perish." Mr. Balfour devotes the four concluding pages of his chapter on "Naturalism and Ethics" to an eloquent protest on these grounds against the emotional adequacy of rationalistic ethics. He holds that, as we more clearly measure the relative importance of man and his performances, " our practical ideal gets relatively dwarfed and beggared," and he asks

" whether so transitory and so unimportant an accident in the general scheme of things as the fortunes of the human race can any longer satisfy aspirations and emotions nourished upon beliefs in the Everlasting and the Divine."

That is to say, Mr. Balfour considers that no race which is not immortal, and which does not occupy a large place in the universe, can excite sentiments and emotions of a high ethical order in the minds of its members. The practical ideal of working for the perfection and felicity of a sentient creation which may exist for ten million years to come is " dwarfed and beggared" by the reflection that in fifteen million years to come that sentient creation will probably have been extinguished for ever along with the light of the sun. We suggest that in connection with practical ideals it is well to take relatively short 
views, and that the possible ten million years of existence to which the human race may look forward should furnish sufficient scope for the emotions and ideals of the greediest seeker after endless life.

Even if it be granted that the human race is a transitory and unimportant accident in the general scheme of things, the adequacy of the fortunes of the race to furnish an emotional foundation for ethical ideals must be measured by the relations of the race to its members, and not by a comparison between the size and duration of the race and the size and duration of the universe at large. From this standpoint it is ludicrous to find individual man, whose life at most extends to a hundred years, complaining that his practical ideal gets dwarfed and beggared if it be concerned with so transitory and unimportant a thing as the fortunes of a race which has already existed for probably two million years, and which may exist for ten million years longer. In this section of his argument Mr. Balfour seems to have lost all sense of proportion.

Is the sunshine less beautiful now because in $\downarrow$ some distant future the sun's glory will be dimmed? Is life less delicious to the young and healthy because a hundred years ago they $x$ 
were not in existence, and in a hundred years to come they will have passed away for ever? Is unselfishness less beautiful, is love less sweet, is kindness less needed and less worthy, is vice less ugly and cruelty less despicable, because in the far-off night of Time man and all his works and thoughts and feelings will have vanished from the face of the frozen earth? And why is "the perfection and felicity of the sentient creation" less worthy to be worked for because it cannot be expected to endure throughout all eternity?

Here, as elsewhere, Mr. Balfour's argument is vitiated by the prejudice which underlies it. $\mathrm{He}$ was trained to believe that the moral law has no foundation other than the will of an Eternal God, and that only in the happiness and perfection of an everlasting life beyond the grave can be found ideals worthy of the human heart, and capable of satisfying its deepest emotions. By the side of these fantastic visions, the truths and theories of rationalistic science seem poor and prosaic indeed. Yet, to the unprejudiced mind, the history and the probable destiny of the human race furnish stimulus and ideals sufficient to engross the ardent hopes and life-long labours of the greatest, most heroic, and most self-denying of the sons of men. And 
there is infinitely greater satisfaction in working for ideals which may be, and will be, realised on earth than in living for a visionary happiness and perfection which are supposed to lie beyond the dark portals of the grave in

"The undiscover'd country from whose bourn

No traveller returns."

It is true, as Mr. Balfour says, that

" after a period, long compared with the individual life, but short indeed compared with the divisions of time open to our investigation, the energies of our system will decay, the glory of the sun will be dimmed, and....man will go down into the pit, and all his thoughts will perish."

But all these considerations have no more bearing on ethics than they have on politics, or on questions of international policy, or of political economy. To some minds it may be saddening to reflect that the human race has been evolved from shapeless protoplasm, and that in the distant future humanity will find an everlasting grave in the earth from which it sprang. But why should these speculations fill us with melancholy? We might as well waste our time in weeping over the facts that each one of us has been developed from an egg 1-240th of an inch in diameter, and that the day will surely come when our lives will be extinct and we shall be masses of senseless clay. No healthy-minded person troubles himself or herself about these 
things. Besides, the fate which is in store for the race as a whole has already overtaken and is daily befalling the individuals of the race. Countless thousands of millions of men and women have gone down into the pit, and all their thoughts have perished. Whole nations have lived and died, and what they thought and did makes no ripple on the surface of the world to-day. Of the men and women who lived in the days of George the Second, how many are remembered now? Of the men and women who are living at the present time, how many will be remembered in the year 2050? Why should we be appalled or depressed or influenced in any way by the thought that in, say, ten million years to come the oblivion which has already wrapped the vast majority of the human race within its impenetrable folds will have devoured the few individuals whose deeds and words have lifted them above the crowd, and that throughout the universe there will remain no memory of man, his victories and defeats, his joys and pains?

It is difficult to see that ethical motives are weakened by the thought that the human race is doomed to perish. We might as well try to assuage the pangs of toothache or reconcile ourselves to going without dinner by the reflection 
that a hundred years hence it will be all the same to us whether we have led painful or happy lives, whether we have dined regularly or endured semi-starvation, as attempt to undermine ethics with speculations upon the origin and destiny of mankind. Tell a man that he need not trouble about getting his dinner to-day because in the year 2000 it will not matter whether he has dined or not, and if he is charitable he may conclude that you are a sort of philosophical lunatic. Yet what real difference is there between such solemn trifling as that and Mr. Balfour's contention that our practical moral ideal is " $d$ warfed and beggared" by the realisation of the fact that the human race is not eternal? Mr. Balfour observes that in that far-off time when the human race will have perished, nothing

" that is will be better or worse for all that the labour, genius, devotion, and suffering of man have striven through countless generations to effect."

That is true, but what does it matter now? And what will it matter throughout the æons of existence which remain in store for man? "The labour, genius, devotios , a. 1 suffering of man " have already borne rich fruit. The harvest of human effort is reaped in this world, and by the human race itself. To live for others is noble, 
but to permit ourselves to be paralysed by the thought that our labours, like our lives, are mortal, and that, when the solar system has passed away, there may be races of intelligent beings, say, in the constellation of Orion, who will be neither better nor worse for anything that man has done and suffered, is to bury altruism beneath a vanity which is little short of madness. 


\section{CHAPTER VI.}

RATIONALISM AND ART

In the second chapter of The Foundations of Belief Mr. Balfour contends that, from the standpoint of Naturalism, no satisfactory explanation can be given of the origin and development of æsthetic sentiments. He assumes that these sentiments, "being (at least in any developed stage) quite useless for the preservation of the individual or species, must be regarded, upon the naturalistic hypothesis, as mere by-products " of the machinery of natural selection. But anything which produces happiness or pleasure must tend to the preservation both of the individual and of the species, by deepening and strengthening the hold upon life. Thus the development of the æsthetic sentiments may be explained as one of the inevitable results of the operation of natural selection, and these sentiments need not be regarded as "mere byproducts" and "natural accidents." Other things being equal, the individual or race which, possessing the widest range of emotion, has, 
therefore, the greatest capacity for enjoyment, will succeed best in the battle of life, and will, in the long run, supplant the individuals and races which are deficient in æsthetic sentiment. "To him that hath shall be given." Nature smiles on and befriends the joyous and the happy, and bids them multiply both in numbers and in power. But for the sad and miserable nature has no love and no mercy. Often she piles suffering upon suffering, and slowly or swiftly, as the case may be, but always surely, she exterminates those to whom, by reason of their limitations or their misfortunes, life has become a burden instead of a perpetual joy.

Mr. Balfour thinks the question of the origin or causes of the æsthetic sentiments must form an insoluble problem to the Rationalist. $\mathrm{He}$ asks, "What are the causes...... which enable us to derive æsthetic gratification from some objects, and forbid us to derive it from others?" and he puts the further question :-

"Is there any fixed and permanent element in Beauty, any unchanging reality which we perceive in or through beautiful objects, and to which normal æsthetic feelings correspond?"

Without attempting to dogmatise on a subject which is surrounded with difficulty, we may be permitted to suggest that æsthetic sentiments have their origin in the fact that the normal 
exercise of all bodily functions is agreeable. If it be asked, Why is this exercise pleasurable? we can only say that here we are face to face with one of the ultimate facts of the universe for which no explanation can be given. In the organic world the ultimate fact is Feeling. Given beings who can feel, what is there strange in the fact that all normal feeling is pleasurable, that some feelings are more pleasurable than others, that an excess of feeling in one direction produces pain, while in another direction it produces happiness? In the presence of ultimate facts, philosophers and thinkers of every school, whether Rationalist or Christian, are as dumb and helpless as the veriest clown. To explain why the facts are thus, and not otherwise, the human mind would require to transcend itselfa mental feat which is as impossible as the physical feat of escaping from the control of gravitation. We start, then, with the proposition that the normal and moderate exercise of all bodily functions is agreeable, that it is pleasant to use the senses of sight and hearing, apart from any consideration of the particular objects in connection with which they may be used. From this root have sprung the widely-extended æsthetic sentiments which now characterise the human race. The growth of these sentiments 
is a question of variation and environment, of heredity and education.

Mr. Balfour takes the case of music as being by far the most convenient of the fine arts for the purpose of this discussion, and he asks, What is the cause of our delight in music? To the suggestion, that it originated through the action of sexual selection, he answers that this is impossible, because "sexual selection can only work on materials already in existence," and he contends that the capacity for making or enjoying music (or noise) " must have existed in a rudimentary state before matrimonial preferences can have improved either one gift or the other." This is true, and the "rudimentary state" referred to is merely an example of the general fact that the normal and moderate exercise of all bodily functions is agreeable. But, inquires Mr. Balfour, "how does the fact that our ancestors liked the tom-tom account forl our liking the Ninth Symphony?"'

The three essential elements in the gratification of the æsthetic sentiments are variety, harmony, and symmetry. The craving for change which is so deeply rooted in humant nature is probably an aspect of the larger fact that the whole universe is constantly undergoing $x$ movement and change. Life is essentiallyt 
motion and change, and man's senses imperiously demand variety, and persistently rebel against the sameness and monotony which, in an extreme form, culminate in the stagnation of death. Herein, we think, lies the explanation of the fact that our savage ancestors took delight in noises which to us are hideous. To use the organs of speech and of hearing was pleasurable to them in itself, but on special occasions, and in order to derive a more intense delight from these organs, it was indispensable that they should be exercised in a manner as widely different as possible from that of ordinary life. Variety of a pronounced type was the first requisite in the "music" of primitive man, to whom melody and cadence were unknown. Hence the gratification which he found in the tom-tom, and in all kinds of noise and discorda gratification which was the parent of the delight felt by moderns in the exquisite compositions of the great masters. From mere continuous noise to the first rude harmonies of music was a long step, which probably occupied ages; but it was inevitable that the step should be taken by an intelligent race in the course of evolution. The same love of change which caused men to take delight in noises, combined with the inventive faculty which enabled them 
to fashion tools, led them along the path of musical progress. Perhaps the pre-historic mother crooning over her restless child discovered rudimentary cadences in her efforts to hush the infant to sleep. The tendency to imitation, which is so strong in savages, would lead man to attempt to reproduce all the sounds and voices of nature, from the roar of the lion to the peaceful murmuring of the brook, from the singing of birds to the whistling of the wind among autumn leaves. Along with this would naturally proceed the invention and improvement of such rude instruments for producing noise or music as were possible with the limited materials at the disposal of primitive man. Helmholtz has shown that there is a mathematical correspondence between the atmospheric vibrations which produce exquisite harmonies and the physical effects of these vibrations on the nervous system. Thus, in all his musical developments, man has done little more than lay bare the natural correspondences which exist between himself and the universe.

These considerations may, perhaps, throw some light on the fact that, as Mr. Balfour points out, despite the enormous advance in musical art, we moderns derive no more pleasure rom music than did the ancients in the days of 
Plato. To each of the ages that is past "its music has been as adequate as ours is to us," and

"Compositions which for us have lost their magic, and which we regard as at best but agreeable curiosities, contained for them the secret of all the unpictured beauties which music shows to her worshippers."

The Rationalist, as such, is not bound to give any explanation of this phenomenon. The only solution offered by Mr. Balfour is that "in this. particular art a steady level of æsthetic sensation can only be maintained by increasing doses of æsthetic stimulant." We are unable to accept this explanation, and may, perhaps, be allowed to make one or two suggestions.

Does not the child derive as much enjoyment from fairy tales as the youth finds in the perusal of Robinson Crusoe, and is the pleasure of either exceeded by the delight and interest which are felt by the grown man in Vanity Fair or The Bride of Lammermoor? It may be that the child and the youth derive keener gratification from fairy tales and romance than adults can find in the soberer fiction suited to their years. But this does not show that increasing doses of stimulant are necessary in order to maintain the level of æsthetic sensation. It shows (1) that for higher intellectual capacity a higher order of æsthetic gratification is required, and 
(2) that, when once a higher level of artistic enjoyment has been reached, it is impossible to find in lower spheres the zest and delight of former days. We do not suggest that Plato was not as capable of appreciating the beauties of Wagner as the average man of the twentieth century. If Plato had listened to modern music and modern instruments, he would probably, after the shock of novelty had worn off, have turned to them with ever-increasing delight, and might, perhaps, have learned to regard as merely "agreeable curiosities" the compositions which at an earlier time had given him exquisite pleasure. Whether he would have found greater felicity in the new music than in the old, who can say? Touch human emotion at any point, and, if the touch be effective, no matter by what instrument or in what fashion it may be made, the response will be sure and deep. The boy who has grown to love Treasure Island and Iranhoe better than the crude stories of blood and murder in which he formerly delighted may or may not derive greater pleasure from the new romances than from the old. While he was under the spell of the penny dreadful, its power over him was complete. His interest was roused, his blood was stirred; he was keenly excited as to the fate of the various characters 
in the story. But, having reached a higher level of rsthetic enjoyment, he looks back with indifference, perhaps with disgust, upon these stories, and wonders how he could have found delight in "curiosities" which have no longer" any power to move him.

Dealing with the general question of art, Mr. Balfour contends that beauty has no existence apart from the perceiving organism. This is no doubt true, just as it is also true that without eyes there could be no such thing as sight, and without ears there could be no hearing. Mr. Balfour thinks that beauty is nothing more than

" the name for a miscellaneous flux of endlessly varying causes, possessing no property in common, except that at some place, at some time, and in some person, they have shown themselves able to evoke the kind of feeling which we choose to describe as æsthetic."

There is some truth in this, but it is truth of a general and unimportant kind. To the healthy individual, whether savage or civilised, all natural objects are more or less beautiful. As the æsthetic emotions take rise in the fact that the normal exercise of all bodily functions is pleasurable, it is not wonderful that, within certain wide limits, the element of beauty is subjective rather than objective. But that it is. objective as well as subjective there can be no reasonable doubt. No sane persons, of any 
country or epoch, have ever found beauty in the chaos and devastation produced by fire or flood, by an earthquake or a volcanic eruption. To excite æsthetic emotion there must always be variety, but there must also be harmony and symmetry. All the rest is a matter of taste, education, and environment. Mr. Balfour himself shows that this is the case when, speaking of " the immortality we glibly predicate of departed artists," he says that, if we would still hold familiar intercourse with them, we must train ourselves " to penetrate the veil which, in everthickening folds, conceals them from the ordinary. gaze."

The vagaries of fashion to which Mr. Balfour refers as presenting "instructive and interesting" phenomena arise, no doubt, mainly from the passion for variety which is deeply rooted in the human breast. From a purely artistic standpoint the change may be for the better or for the worse, but the demand for a change of some kind is imperative. In the case of fashions there is no permanent objective standard of beauty, and, while the leaders of fashion no doubt aim at making articles of clothing as beautiful as possible, variety is, after all, the main consideration. And during the same season people wear the same kind of hats and bonnets, because the 
average man or woman, while liking change, dislikes to be thought odd or uncommon, and is ready to follow the fashion as blindly and implicitly as sheep will follow their leader through a hedge. Mr. Balfour's conclusion on the subject of æsthetics is that

"We must believe that somewhere and for some Being there shines an unchanging splendour of beauty, of which, in Nature and in Art, we see, each of us from our own standpoint, only passing gleams and stray reflections."

But how, on this theory, can we account for the fact that, while our ancestors liked the tom-tom, we like the Ninth Symphony? Do we, in the tom-tom, see a passing gleam and stray reflection of the unchanging splendour of musical beauty which shines for ever in the presence of God? And why must we believe in Mr. Balfour's theory at all? It explains nothing. Instead of removing some of the difficulties which surround the subject, it adds mystery to mystery. Mr. Balfour's only ground for accepting it is that, when he looks back on rare moments of deep æsthetic feeling, he cannot accept any explanation of them "which confines itself to the bare enumeration of psychological and physiological causes and effects." Yet what does he know of the wondrous possibilities which lie hidden in these causes and effects? There is nothing in the universe more wonderful than life and its 
concomitant, feeling; and, impossible as it may be to explain the ultimate nature of these things, we know that such explanation of them as we may hope to obtain lies wholly within the realm of "psychological and physioiogical causes and effects." If life and feeling may be accounted for satisfactorily, in their relative aspects at least, by physical science, there is no depth of æsthetic emotion, there is no state of exalted mental vision, which we may not hope to adequately explain by an appeal to the same chain of causes and effects. Given life and feeling, and everything else, from the flint knives of the stone age to the poems of Milton, from the honest, plodding labour of the workman to the rapt devotion of the artist and the saint, follows in the natural order of the process of evolution.

Prejudice, and not reason, is the guide which Mr. Balfour finally accepts in this, as in all other matters connected with religion. He will not "assent to a theory which makes a good composer only differ from a good cook in that he deals in more complicated relations, moves in a wider circle of associations, and arouses our feelings through a different sense." To state the theory in this crude and inexact form only serves to obscure the truth. Mr. Balfour knows very well that Rationalists do not hold, and are not 
logically committed to, the theory that cookery is a branch of æsthetics, and that a good musical composer does not rank higher than a good cook. The two orders of things-music and cookerycannot, of course, be compared with each other, and a philosophic training which does not inculcate the importance of discriminating between such totally different things is not of much value. Mr. Balfour evidently thinks that the man who does not assent to the doctrine of the Trinity cannot, in logic or in practice, hold the genius of Beethoven or of Handel in higher esteem than he holds the talent of a French cook.

How is it that Mr. Balfour dreams such vain and foolish dreams? The Rationalist discriminates between an opera and a dinner; between a landscape by Turner and a whitewashed wall; between a poem and a table. The emotions which are aroused within us by music, by contact with the glorious freshness and beauty of Nature, by the skill of the sculptor, the poet, and the novelist, do not depend for their depth and permanence on the belief in "some Being" for whom "there shines an unchanging splendour of beauty." Whether we hold such a belief or not, whether there be such a "Being" or not, our æsthetic feelings remain the same. 
Rationalists do not profess to be able to solve all the problems of the universe. But, at any rate, they endeavour to bring an open and candid mind to the consideration of all evidence that may be laid before them in connection with these problems, and they do not willingly shut their eyes to any light, no matter from what quarter it may come. But when, instead of tentative suggestions or cautious investigation, or an appeal for suspension of judgment, Mr. Balfour attempts to decide an obscure and difficult question by the aid of a speculation which is logically incoherent, which has no basis outside his own fervid imagination, and for which there is no recommendation other than the eloquent language in which it is conveyed, Rationalists decline to exchange the solid ground of science and common-sense for the quagmires of dogma and supernaturalism over which $\mathrm{Mr}$. Balfour vainly pursues the ignis fatuus of a dead faith. 


\section{CHAPTER VII.}

\section{RATIONALISM AND REASON}

The paradoxical character of Mr. Balfour's general method of argument is nowhere better illustrated than in the third chapter of The Foundations of Belief, in which he discusses the subject of "Naturalism and Reason." In the interests of theology he endeavours at one and the same time to exalt Reason to the throne of God and to degrade it below the level of the humblest instincts.

$\mathrm{He}$ tells us that some Rationalists "find a compensation for the general non-rationality of Nature in the fact that, after all, reason, human reason, is Nature's final product." What Rationalist troubles himself about the nonrationality of Nature? What does it matter to man whether Nature be rational or not? So far as human convenience and happiness are concerned, the orderly, unvarying sequences of a non-rational Nature are infinitely preferable to Nature controlled by what Mr. Balfour calls "discursive Reason," which, in its arbitrary 
wisdom, might occasionally decide to advance or postpone the rising of the sun, and possibly to conclude that on some days it would be well that it should not rise at all. The believer in the non-rationality of Nature can look upon such a calamity as the destruction of St. Pierre with deep and unutterable sympathy for its victims, but without any feelings of loathing and hatred for the powers which caused the catastrophe. But, in the presence of such an event, what does Mr. Balfour think of his doctrine of the rationality of Nature? How can he believe that such a Nature has been framed, is upheld, and is controlled by a Divine Reason? It is an outrage on human reason, and a blasphemy against the divine being himself if he exist, to assert that a God of infinite wisdom and goodness and power was the author of the devastation in Martinique. If this be the work of God, his goodness is indeed unfathomable, and in prostrating himself before such a being $\mathrm{Mr}$. Balfour displays an unreasoning superstition not altogether unlike the abject folly of the savages who cringe before the brother cannibal who has been made their god, crying, "We are thy meat."

But why should man constitute himself the standard by which the universe must be 
measured? No folly could be more preposterous than this. Man's reason is of supreme importance to him, but it is ludicrous to find him declaring that the universe must be a failure or a horror unless it can be shown that it is the work of a being who possesses reason similar to his own. Within the narrow circle of our knowledge and experience, reason is Nature's highest product; but, after all, what does man know of the capacities of Nature and the contents of the universe? As Mr. Herbert Spencer has suggested, there may be in existence forms of energy as far transcending will and intelligence as these in turn transcend mechanical contrivance.

Mr. Balfour points out that, on the theory of evolution, reason has been developed for utilitarian ends, and that under these circumstances it is not surprising that human faculties should be " imperfectly fitted to satisfy that speculative curiosity which is one of the most curious byproducts of the evolutionary process." We have here an admission that the facts of the case are on the side of the Rationalist. The capacity of the human intellect is in conformity with what we might expect, on the theory that it has been evolved for practical purposes by the process of natural selection. It is adapted for the needs 
and the labours of social life; but when, by its help, we attempt to penetrate the inner mysteries of the universe we soon discover that for this kind of work we need a keener and more subtle instrument, with a far wider range of power. When Mr. Balfour speaks of "speculative curiosity" as a "curious by-product" of the evolutionary process, he probably means to imply that this is something which cannot be explained on Rationalist theories, and that this "speculative curiosity" is a sign of man's divine origin, a testimony in favour of the belief that he is a child of God. Yet, on reflection, it will be seen that this so-called "by-product" is the inevitable outcome of intelligent self-consciousness when it has attained to a high degree of development. The reason which is adequate to the demands of daily life must also be capable of asking questions as to the origin and destiny of man and the universe. There is nothing in this inconsistent with the theories of Rationalism, nor is it surprising that within certain narrow limits man should be able, by the aid of faculties developed on the utilitarian lines of natural selection, to acquire considerable knowledge as to the present condition and the history of himself and the universe.

$\mathrm{Mr}$. Balfour also lays stress on the inadequacy 
of the senses, apparently with the object of showing that there is a great deal more in the universe than is dreamt of in our philosophy. There is much force in his remarks on this subject. We know that the senses fail in delicacy and range, but we doubt whether there is ground for Mr. Balfour's contention that they fail also in variety, and that "there must be an indefinite number of aspects of Nature respecting which science never can give us any information, even in our dreams." But, in any case, the facts are once more on the side of the Rationalist. The senses are what we might expect them to be on the theory of evolution-rough-and-ready instruments adapted to the practical purposes of daily life. They are not what we might expect them to be on the theory that man was created by an all-wise, benevolent God, who would, presumably, have equipped his creature with a perfect sense apparatus, so that no aspect of Nature should be hidden from his view. $\mathrm{Mr}$. Balfour says "we must conceive ourselves as feeling our way about this dim corner of the illimitable world, like children in a darkened room, encompassed by we know not what." Even if this be true-and it is certainly true in some degree-is it consistent with Mr. Balfour's theology? Would a loving father place his 
children in a darkened room, leaving them togrope about as best they could, and to stumble over objects which he himself had placed in their way? "On the naturalistic theory," writes Mr. Balfour, " reason is not the final result of a great process, the roof and crown of things." It is "no more than one of many experiments for increasing our chance of survival." Here again we have the fatal error of ascribing the same dignity and worth to different faculties on the ground that they subserve the same general ends. On any theory of human affairs, whether Rationalist or Supernaturalist, reason must be deemed "the roof and crown of things," the highest faculty possessed by man. It is the faculty of self-adjustment, the power of co-ordination which enables man to bend all his energies in a given direction for the accomplishment of a particular purpose. Take away sight, or hearing, or any other single faculty, and a man may still live a successful life, and play a great part in the world. But take away his reason, and it were better that he should be laid in his grave.

In pursuance of his strange and self-imposed task of disparaging the human intellect, Mr. Balfour observes :-

"The management of the humblest organ would be infinitely beyond our mental capacity were it possible for us to be 
entrusted with it; and, as a matter of fact, it is only in the simplest jobs that discursive reason is permitted to have a hand at all; our tendency to take a different view being merely the self-importance of a child who, because it is allowed to stamp the letters, imagines that it conducts the correspondence."

Thus, according to Mr. Balfour, man is little better than an automaton. In the main work of life his intellect takes no active part. $\mathrm{He}$ imagines he is conducting the correspondence when he is merely stamping the letters, which are written without his aid, and largely without his knowledge. If Mr. Balfour's reasoning on this point be sound, he has destroyed at one blow his doctrine of the freedom of the will, and all his eloquence on the subject of human responsibility, and the disastrous consequences which may be expected to follow the spread of Rationalism, becomes the emptiest mockery. It is true that Mr. Balfour is referring to "the difficult and complex work connected with the maintenance of life," but moral and mental decisions have certainly a close connection with the maintenance of life, and the context shows that Mr. Balfour includes them in his survey. How, then, can man be held responsible if, instead of conducting the correspondence, he merely stamps the letters, and if it is only in the simplest jobs that his reason is permitted to have a hand at all? 
Mr. Balfour's contentions on this point are, in truth, partly right and partly wrong. In the actual physical processes of life man's intellect has and can have no share. But indirectly he can influence them, can mould, hinder, or accelerate them to a very great extent. Reason is, in fact, enthroned as king over all the vital processes, and within narrow limits can bend them to its will. Even in purely physical matters Reason superintends, if it does not altogether conduct, the correspondence, and, in some dread instances, puts a stop to it altogether. Reason, in short, may be compared to the manager of a great business. All the threads of government are retained in its hands, but details are left to the care of subordinates.

It is somewhat of a paradox that, after reducing the scope and the capacity of reason within the narrowest possible bounds, Mr. Balfour should remark that he is

"left sensibly poorer by this deposition of Reason from its \& ancient position as the ground of all existence, to that of an expedient among other expedients for the maintenance of organic life."

But Mr. Balfour is not acquainted with any reason other than human reason, and if man's intellect be so weak and limited a faculty that he is able to declare instinct to be "incomparably the better machine in every respect save one," how 
can he, or any other man, pretend to believe that reason is "the ground of all existence"? Why should he, or any other man, be left sensibly poorer if he is no longer able to hold the puerile belief that "the ground of all existence" is something akin to the faculty which leads man to imagine that he "conducts the correspondence," when he is merely "allowed to stamp the letters"? The "ground of all existence" should surely be something firmer and more reliable than this faculty which, according to $\mathrm{Mr}$. Balfour, unites with signal impotence for good an extraordinary capacity for producing selfdelusions. He may tell us that the reason which $<$ he would postulate as " the ground of all existence" is something infinitely greater and more powerful than human reason; but we would urge, with all deference, that he is using words which have no meaning, and that to talk of such a "reason" is to overstep the bounds of the merely improbable, and to enter the region of the impossible. From the human standpoint, reason is "the roof and crown of things"; it is the final result of a long process of natural selection. To affirm that it is the foundation of the universe is something like attempting to fix a pyramid on its apex. And if it be said that this is affirmed of divine, and not of human, 
reason, we answer that a God who is omniscient and all-wise, who knows the past, the present, and the future, cannot possess reason in any intelligible sense of the word. Reason implies limited intelligence; it involves logical steps from premises to conclusions, progress from the known to the unknown: the use of reason is accompanied by a constant advance in knowledge. To a God who knows everything all this is impossible. Applied to such a God the word "reason" has no meaning whatever, and when Mr. Balfour speaks of "a rational author of Nature" he is, perhaps unconsciously, reverting to an anthropomorphism not less gross than that of the Pentateuch.

But Mr. Balfour professes to be shocked at the spectacle of degradation presented by "an irrational universe which accidentally turns out a few reasoning animals at one corner of it," and he says we might well despise this universe "if we did not ourselves share its degradation." That the universe is irrational should be no reproach in the eyes of Mr. Balfour, who rates rationality so low that he can only consent to pay respect to it on the vain supposition that it is a dim reflection of some incomprehensible divine intellect which forms " the ground of all existence." We fail to see that any degradation is involved in 
belonging to a universe which, despite all its faults of irrationality, is capable of turning "out a few reasoning animals at one corner of it." Let the universe, at least, have full credit for all the wonders which it has performed. $\mathrm{Mr}$. Balfour's sense of degradation on this point seems to bear a close resemblance to the absurd feeling of false pride which, in the early days of the theory of evolution, caused some persons to shrink with disgust from the teachings of Darwin, because, if they accepted these teachings, they could not escape the conclusion that their far-off ancestor was an anthropoid ape.

On the subject of Reason, as on all other fundamental topics with which theology is concerned, Mr. Balfour displays great reluctance to regard facts with a candid and unprejudiced gaze. If the universe be the work of a rational author, he is ready to laud reason as man's most glorious attribute and the "roof and crown of things." But if the universe be the outcome of non-rational forces, he is ready to pour contempt on man's reasoning powers and the limited sphere of their operations, to place reason below instinct in efficiency and value, and to regard it, in so far as it involves self-consciousness, as the sign and seal of the degradation of the universe. The Rationalist turns with pity and disgust from 
these specimens of unedifying paradox and selfstultification. Let reason be judged on its merits. Let it stand or fall according to its actual value, and not because it may or may not be supported by the superstitious fancy that it is the adumbration of an attribute which is possessed in all its fulness by the Creator of the universe. Mr. Balfour will probably admit that he can never know that reason is the ground of all existence; he may speculate, and dream, and perform wonderful intellectual feats on metaphysical tight-ropes; but on this subject he must for ever remain agnostic in fact, whatever he may be in theory. He may indeed be certain that reason, in anything like its human form, is not the ground of all existence; that, in fact, such a notion is as baseless and grotesque as would be the speculation of a minnow in its creek that the "ground of all existence" must be the power of the Creator to live in water and to swim against the stream.

Mr. Balfour is thus precluded by his theological speculations from coming to any definite conclusion as to the value of reason. As, in this world at least, he can never hope to verify these speculations, he will never know whether to regard reason as a glorious or as a contemptible attribute. He is committed to a ludicrous and 
perpetual game of see-saw. He says, in effect: "If my theology be true, reason is man's noblest faculty; if your Rationalism be true, it is a mere expedient among other expedients for the maintenance of organic life, and, of these, by no means the most important or the most enduring." However valuable such methods as this may be in the region of abstract philosophy, few persons will be disposed to regard them with favour when introduced into the realm of the concrete. The value and position of reason amongst human faculties does not depend upon the truth or falsehood of any speculations or theories as to its origin. Whether there be a God or not, whether the universe be irrational or not, Reason stands before us as the crowning fact in the world of man, and mutely demands to be judged, not by its origin, real or supposed, but by the glorious services which it has rendered to mankind. 


\section{CHAPTER VIII.}

\section{SCIENCE AND THEOLOGY}

Perhaps it is not too much to say that the question of the relations between science and religion forms the central point of the argument in both Mr. Balfour's books. If on this question he is able to hold his own, it may be admitted that his general line of attack and defence is fairly sound; but if he fails to maintain his positions on this branch of the subject, it must be said that his whole case falls to the ground.

In Chapter III., Part IV., of The Foundations of Belief, Mr. Balfour endeavours to show that there is, or need be, no real conflict between science and theology, and that there is, in fact, a fundamental agreement between these two departments of activity, inasmuch as both are "compelled to $x$ postulate a Rational Ground or Cause of the world, $\chi$ who made it intelligible and us in some faint y degree able to understand it." At the outset of $t$ his argument he is careful to distinguish between science and naturalism, affirming that, while the latter is irreconcilable with theology, it is also 
in itself "incoherent and inadequate." When Mr. Balfour asserts that naturalism or rationalism is incoherent, he means only that it is impossible to frame a systematic account of the principles of naturalism which might successfully withstand the onslaught of the philosophic doubt which, as we have seen, is fatal to the fundamental principles, not only of science, but of theology, and of every system of philosophy that the world has seen. This, however, is not a point that need detain us here. Mr. Balfour's theology is not only philosophically incoherent, but it is encumbered with practical difficulties and contradictions from which Rationalism is free; the latter, indeed, being, as $\mathrm{Mr}$. Balfour admits, distinguished "by the inevitableness of its positive teaching."

The inadequacy of Naturalism, we are told by Mr. Balfour, is " covered by the, as yet, un. squandered heritage of sentiments and ideals which has come down to us from other ages inspired by other faiths." But Rationalism claims, and justly claims, a share in the "heritage of sentiments and ideals" which has been bequeathed to us by the past, and it is not likely to squander any of these that are of value. On the contrary, it will preserve and cultivate them. Rationalism is essentially eclectic. It is 
broad as humanity itself, and there is no great sentiment or lofty ideal which it is not anxious to include among its sacred treasures. Rationalists are not so foolish as to reject wisdom because it comes down to us in the name of Buddha, or love and tenderness because they may be stamped with the name of Christ. The "heritage of sentiments and ideals" now in the world is not the sole bequest of the Christian Church. What Christian sentiment or ideal is there of permanent value which cannot be traced to other sources? What did not Christianity owe to Judaism, to the religions of Egypt and India, to the philosophy of Plato? If Christianity, which professes to have been a revelation from heaven, might, without reproach, borrow its ethics and its ideals from older systems, why may not Rationalism enter, without sneer or question, upon that "heritage of sentiments and ideals" which is the common property of all mankind, and which Rationalism, at least, will not squander, but perpetuate?

It is not surprising that $\mathrm{Mr}$. Balfour, with his passion for abstract philosophy, should suggest. that the discrepancies between religion and science are less in number and importance than those which exist within the two departments themselves. But such a remark is little better 
than an attempt to evade the real difficulties of the case. It is of no avail to tell us that the same philosophical perplexities lie at the root of both science and religion. However great these difficulties may be, from the standpoint of philosophy, they must be left out of account when we are dealing with the practical questions of the relative credibility and mutual consistency of science and theology.

\section{Mr. Balfour observes :-}

"Science is in no way concerned to deny the reality of a world unrevealed to us in sense-perception, nor the existence of a God who, however imperfectly, may be known by those who diligently seek Him."

Neither, we may add, is science concerned to deny the existence of fairies, or of devils with whom men and women may form unholy compacts, or of wondrous regions where space may be of only two, or of as many as four, dimensions. Science does not trouble to deny these things; she leaves them severely alone, and they die of inanition in the atmosphere which she has created. Have we the right to assume that any marvel is true which science is not concerned to deny? Mr. Balfour talks of "the reality of a world unrevealed to us in sense-perception"; does he mean to affirm that there are channels of knowledge other than the senses and the intellect, and that through these channels he has been 
assured of the reality of the world in question? If so, this knowledge must itself come within the boundaries of science, for science is knowledge verified and reduced to system. But if this other world be a figment of imagination, if nobody has any knowledge of it other than that which is acquired in dreams, science, it is true, does not directly deny the reality of such a world, but she excludes it by implication, and the whole of her teaching discountenances the indulgence in such airy and fantastic visions.

The same considerations apply to the attitude of science towards the question of the existence of God. Science neither affirms nor denies the existence of God ; she has no need to trouble herself about any such hypothesis. So long as it remains a mere hypothesis-unintelligible in its terms, incredible in its assumptions, and unsupported by facts-it is altogether excluded from the domain of science, which can recognise nothing that is not based on knowledge. If, as Mr. Balfour affirms, God "may be known, however imperfectly, by those who +diligently seek Him," this knowledge must x form an actual or potential part of science, for \& science includes all knowledge. But, in such a t case, science can no longer remain indifferent or neutral. The so-called knowledge must be 
submitted to the tests of observation and experi- $x$ ment; if it is knowledge at all, it is capable of verification, and the verdict of science on the subject must be final. This method of procedure, however, would not meet Mr. Balfour's views or suit the exigencies of his case. $\mathrm{He}$ would have us believe, apparently on no better ground than that it is necessary for the stability of his argument, that there are two separate departments of knowledge-namely, science and theology, and that the means of acquiring knowledge in these two departments are not merely different from each other, but diametrically opposite. We decline to acknowledge any such distinction between the two departments, or to grant the validity of a contention which would elevate the sickly dreams and mystic visions of theology to equal rank with the solid discoveries of science.

But Mr. Balfour goes further than the mere statement that "science is not concerned to deny the existence of a God." He thinks the doctrine that there is a rational and supernatural ground, "on which the whole system of natural phenomena depends," renders the scientific view of the natural world less " beset with difficulties than it is at present." But how can any single difficulty, whether metaphysical or practical, be 
removed by the assumption, for it is nothing more, that there is a rational and supernatural ground of all existence? Such a doctrine, instead of helping to solve the mysteries already before us, presents a still greater mystery for solution. It reminds us of the Eastern story in which the world was said to be supported by an elephant. That seemed feasible, but what did the elephant stand on? The unsupported elephant was as great a puzzle as the unsupported world. It is a mockery to pretend that the mysteries which we can see, and hear, and feel may be explained by some other mystery which we cannot see, which may not even exist, and which is altogether incomprehensible to us. Granted, for the sake of argument, that there is a rational and supernatural power which is the ground of all existence, by what, may we ask, is this power supported? Mr. Balfour would, no doubt, reply that it is self-supporting; but if a fact so stupendous and incomprehensible may be predicated of a power whose very existence is a matter, not of knowledge, but of speculation, why may we not, with as little difficulty, predicate it of this universe of matter and energy, whose effects we know and feel, but whose ultimate nature is for ever hidden from our gaze?

Mr. Balfour, however, is prepared to carry the 
argument in favour of theism further than this metaphysical stage. He affirms that, "broadly speaking and in the rough, the facts" of Nature harmonise with the theory of design, and that this theory "gives a unity and a coherence to our apprehension of the natural world which it would not otherwise possess." Whether speaking in a broad or in a narrow sense, it seems to us that there is no real evidence of design in the universe, and that if it be the work of a rational architect he is limited both in goodness and in power. Consider, first, the waste of energy which has taken place within the comparatively narrow confines of the solar system. If we assume, in accordance with Christian theories, that the object of the Creator in forming the sun and his attendant planets was to produce worlds capable of maintaining large numbers of sentient creatures in a high condition of intelligence and happiness, the whole scheme must be pronounced a clumsy failure. Millions of years were spent in the slow condensation of the original nebula into the separate masses of sun and planets. Millions of years more elapsed before any of these bodies had cooled sufficiently to be capable of bearing life, and even now, when the sun is probably half spent as a source of light and heat, only three 
planets-the Earth, Mars, and Venus-appear to be fitted for the habitation of creatures of a moderately advanced type. Some of the planets, such as Uranus and Neptune, are so far off the parent orb that the most brilliant sunshine which visits their frozen surfaces can be no stronger than twilight on the earth, while Mercury is so near the sun that it must be impossible for organic life to endure the intolerable heat of his surface. Jupiter and Saturn appear to be still in a state of youthful incandescence, while our own moon hangs aloft, a dead and worn-out world, the dreary forecast of the fate which will befall the earth in some far-distant future. If there be design in the structure and development of the solar system, it is marked by waste, by clumsiness, and by all the features of imperfect arrangement and unfulfilled purpose which characterise the most disastrous failure of schemes evolved by man.

Take, next, the history of the earth and of man. The object of the Creator here, we are told both explicitly and implicitly by Christian theorists, was to produce a race of perfect beings who should reign in peace over all the inferior inhabitants of the earth. But, instead of immediately forming such a race, the designer elected to proceed by the slow and tedious process of Evolution. He starts with a speck 
of protoplasm, and takes millions of years to work up to man, by the bloody and toilsome way of the jelly-fish, the reptile, the quadruped, and the ape. Myriads of individuals and many species are trampled out of existence in the fierce fight for life, which this designer imposes upon his creatures, and which forms the chief tool whereby he seeks to fashion a race of perfect human beings. Numbers of species can only live by killing and eating other species, while the designer has also been careful and thoughtful enough to create parasites whose only mission is to prey upon and torture beings immeasurably superior to themselves. And even now, when the dominance of man on earth is assured, there is no peace, and the end is yet remote. It seems probable that man's reign will be marked by the destruction of all the inferior species of land animals, except such as may be of service to him, while between the different races of men the same struggle for existence grinds along its eternal way. And all this, Mr. Balfour tells us, has been designed by a God of infinite goodness and power! All this chaos and waste, all this confusion and suffering and death, become intelligible only, he tells us, if we assume that a rational and supernatural power is the ground of all existence! 
But Mr. Balfour apparently holds the doctrine that the end justifies the means. He affirms that " in the region of design it is only through the later stages that the earlier can be understood," and that "the most unlovely germ of instinct or of appetite" is consecrated by the higher sentiments which have proceeded from them. First, let it be noted that if this argument is good for the Christian it is also good for the Rationalist, and that it entirely destroys Mr. Balfour's previous contention that all the virtues and the whole body of ethical $x$ sentiments and ideals will be brought into contempt by the adoption of the naturalistic theory that they are the distant offspring of unlovely instincts and bodily appetites. If, on the Christian theory, the sweetness and beauty of the ripened fruit may be held to consecrate the unloveliness of the seed, why may they not also be held to consecrate it on the theory of Rationalism? Rationalists, however, are not concerned to palliate the ugliness of the germs from which some of the noblest human sentiments have grown. They are content to take the facts of evolution as they find them, and will leave to Mr. Balfour the task of canonising a brute because his descendant is a saint.

We cannot, however, admit that the end 
justifies and consecrates the means, whether the scheme we are considering be that of man or of God. To the designer whose plans involve the use of brutal lust, savage and endless conflict, and wholesale murder, we say: Forego the end at which you aim, no matter how high and worthy it may be, or take with you the undying execration of all humane souls. The tyrant who is prepared to "wade through slaughter to a throne" becomes an angel of wisdom and love when compared with an almighty designer who plans the evolution of a race of perfect beings from a speck of protoplasm by the tedious, wasteful, and agonising process of natural selection.

Mr. Balfour, however, draws from scientific knowledge a "more important argument" in favour of theism than the argument from design. This is based on the "mere fact that we knowa fact which, like every other, has to be accounted for. And how is it to be accounted for ?" $\mathrm{Mr}$. Balfour continues :-

"Whatever be the part played by reason among the proximate causes of belief, among the ultimate causes it plays, according to science, no part at all. On the naturalistic hypothesis, the whole premises of knowledge are clearly due to the blind operation of material causes, and in the last resort to these alone. On that hypothesis we no more possess free reason than we possess free will."

The connection between Mr. Balfour's premises 
and his conclusion is not clear, but his argument is, briefly, the old one that reason cannot proceed from unreason, and that our knowledge of "the ordered system of phenomena" is inexplicable unless we assume for that system a rational author. We are unable to see the force of this contention.

Life is one of the ultimate facts of the universe, like matter and energy, and no man can define its nature or explain its origin. What is life, indeed, but a special form of force, like electricity, heat, and light, all of which may be identical in their nature, and, therefore, transmutable into each other, if we only knew the process by which the change may be effected? But force, in all its forms, defies explanation, and is one of the ultimate mysteries of the universe against which the puny waves of the human intellect dash themselves in vain. Given the ultimate fact of life and the whole of Mr. Balfour's difficulty disappears, and the argument he has based upon it crumbles into dust. Life in its lowest forms involves relations and correspondences with the surrounding world, and what are these but incipient knowledge? From these humble beginnings a rudimentary nervous system is built up; at a later stage of development nervous centres are added; and 
then we have the slow but sure formation of a supreme nervous centre in the shape of the brain. All these forms of life exist around us, and we have thus living illustrations of the fact that reason has proceeded from non-reason. Starting with life in its lowest form, that of mere shapeless tissue, possessing a certain amount of irritability, and, under such conditions as have existed on the earth, its evolution from the primitive stage to that of civilised man is a process which is bound to take place.

But even if this be accepted as a tentative explanation of the fact that we are capable of knowing, Mr. Balfour will no doubt insist on the further difficulty that in a world which is not the work of a rational author it is strange there should exist an " ordered system of phenomena." Has it never occurred to Mr. Balfour that all the order which exists in the universe arises from the simple fact that, in the absence of disturbing causes, things and their qualities remain the same? There is nothing supernatural in the fact that a stone which is hard to-day will also be hard to-morrow, unless, by some external agency, its nature be altogether changed. If we were face to face with a collection of phenomena that were not ordered-if that which exhibited the qualities of a stone on 
one day exhibited the qualities of a feather on the morrow, if the law of gravity was sometimes in force and sometimes suspended-there would be some ground for supposing that the universe lies in the grasp of a personal being or beings who guide it for their own ends, or in accordance with the whims and caprices of their will. But it is not surprising that what Mr. Balfour calls an "ordered system of phenomena" should exist in a universe of which the two cardinal facts are the indestructibility of matter and the persistence of force.

Thus we are able to comprehend, to some extent at least, why the universe contains a large amount of what we call order, and why man is capable of acquiring some knowledge of that order; and Mr. Balfour's great argument in favour of theism falls to the ground. The same considerations enable us to see that there is nothing remarkable or degrading in the fact that "the whole premises of knowledge are clearly due to the blind operation of material causes," and that there is no such thing as "free reason." The most reasonable man is he who frames his judgments and his conduct in accordance with facts, and it is the closeness of his adherence to fact, and the clearness and depth of his insight into fact, that measure the extent to which 
any man is entitled to be thought reasonable. If by "free reason" be meant reason which is free to work in independence of, or in opposition to, the material facts which form its indispensable data, and without which, indeed, it could not exist, then the phrase is an absurdity, a contradiction in terms. Reason is not free to declare that black is white, that two and two make five, that light and darkness are the same, or in any other way to contradict the ascertained premises of knowledge. Such reason as this would be indistinguishable from the unreason of lunacy. But in what other sense does Mr. Balfour hold, or desire to hold, that man possesses "free reason"? And if, as he intimates, there is some mysterious degradation involved in the fact that man's knowledge and reasoning processes are determined by material causes independent of himself, how is this degradation lessened if he is allowed to assume that these causes have themselves been produced by a rational creator? Man's relation to the material causes of knowledge remains exactly the same whether they are the work of a rational author, or whether they form part of an eternal, uncaused universe.

Mr. Balfour, however, affirms that the conclusions of Rationalism on this subject are 
"absolutely ruinous to knowledge. For they require us to accept a system as rational one of whose doctrines is that the system itself is the product of causes which have no tendency to truth rather than falsehood, or to falschood rather than truth."

Elsewhere he observes that all our knowledge and "all our conclusions are the inevitable product of forces which are quite alien to reason." What does Mr. Balfour mean? Has he never heard of circumstantial evidence? The law has long recognised the unique strength of testimony consisting of a chain of facts which, being dumb, cannot be guilty of perjury, and which can neither be terrorised nor bribed. Such evidence may in itself be " alien to reason," but it forms valuable raw material for reasoning processes. In what valid sense of the words is it true that the material causes of knowledge are "alien to reason," and "have no tendency to truth rather than falsehood, or to falsehood rather than truth"? In no valid sense of the words are these statements true. On the rationalistic hypothesis reason has grown out of the material world, and it cannot be alien to the causes from which it has sprung. Again, a large part of what we call truth consists of records and comparisons of the natural facts which are the material causes of knowledge, and which $\mathrm{Mr}$. Balfour says " have no tendency to truth rather 
than falsehood." He might as well say that figures have no tendency to accuracy rather than inaccuracy. Yet the right use of them in any arithmetical calculation constitutes accuracy. "The forces of nature may be unconscious, and, therefore, in that sense, and in that sense only, " alien to reason "; but they, and the facts which they produce, constitute the truths of the universe, and form the principal raw material on which reason can possibly or profitably be employed, and the only solid foundations of knowledge.

But, leaving aside for a moment the abstract philosophical aspect of the case, even Mr. Balfour will hardly be prepared to deny the reality of natural facts, or that any belief which is based upon them will be an expression of truth. What, then, becomes of his assertion that the conclusions of Rationalism on this subject are "absolutely ruinous to knowledge"? He will scarcely be so fanatical an anti-Gradgrind as to deny that facts are facts, and he must, therefore, be committed to the argument that, if there be a God, the universe is true, and human reason may, by working in its rich fields, acquire a knowledge of truth; but that, if there be no God, the universe may be either true or false, and man can never be certain that he possesses 
anything which may be called truth. His argument for theism thus runs in a circle. Reason tells him that there is a large amount of order in the universe, and that the observation and comparison of natural facts is the basis of knowledge. But as these facts are probably unconscious and non-rational, he assumes, on purely theoretical grounds, that they must be the work of a rational author who has placed them in correspondence with human reason. If he could be led to doubt that the universe has any such rational author, he would also doubt whether the appearance of order in the world is a delusion, and whether man can know that there is such a thing as truth in nature. Mr. Balfour is in the false and utterly untenable position that he attempts to prove the existence of God by the order and truth which he believes he sees in the material universe, while, at the same time, he only believes he sees this order and truth in the universe because he believes in the existence of a God who is its rational author. Conclusions of this sort will do no harm to any rational theory of knowledge, but they are absolutely ruinous to the theism in support of which they are put forward.

Dealing with the question of the relation of God to the world of phenomena, Mr. Balfour 
contends that the difficulties experienced by theology on this point are met in a still more embarrassing form by Rationalism, which has to deal with the same problems in connection with man's relation to the universe.

"Each living soul which acts on its surroundings raises questions analogous to, and in some ways more perplexing than, those suggested by the action of a God immanent in a universe of phenomena."

Is this true? Does it possess any semblance of truth? There is no more analogy between the alleged action of God in the universe and the action of man than there is between the action of man and that of Prospero on his island when he raised tempests and spirits according to his whims and needs. Waiving for the moment any questions as to the nature of the self of man or the freedom of his will, it is clear that, whether he is more or not, he is at least a visible phenomenon amongst phenomena, and that all his action takes place in accordance with natural law. He may bend the laws of nature to his_service, but he cannot contravene them. If $\mathrm{Mr}$. Balfour means no more than that the action of God in the universe is analogous to the action of man-if he means that the force which pervades_space is God, and that the uniformities of nature are the expression of the unchanging will of God-his theism, so far as science. is 
concerned, is reduced to very small and harmless dimensions, and the quarrel between him and Rationalism, on the ground of science, becomes one as to words rather than as to things. Nothing is gained by calling force God, and the laws of nature the will of God. Rationalists prefer to adhere to ascertained facts, and those who seek to add metaphysical mysteries to the physical mysteries of the universe are logically bound to furnish some reason for their proceedings, other than the desire to rehabilitate an exploded theological figment. 


\section{CHAPTER IX.}

MIRACLES AND NATURAL LAW

Havisg searched in various quarters for discrepancies between science and religion, and having proved, to his own satisfaction, that no such discrepancies exist, Mr. Balfour turns at length to the question of Miracles, and admits that it may be "possible to approach the real kernel of the problem" from this side.

$\mathrm{He}$ attempts, first, to evade the objection against miracles which arises from the principle of the uniformity of nature, by once more urging some of the philosophical difficulties which we have already discussed in our second chapter. $\mathrm{He}$ asks what is meant by the statement that nature is uniform, and says if we mean that " the condition of the world at one moment is so connected with its condition at the next that, if we could imagine it brought twice into exactly the same position, its subsequent history would in each case be exactly the same,"

no one, he supposes, "imagines that uniformity in this sense has any quarrel with miracles." He continues :-

"If a miracle is a wonder wrought by God to meet the needs 
arising out of the special circumstances of a particular moment, then, supposing the circumstances were to recur, as they would if the world were twice to pass through the same phase, the miracle, we cannot doubt, would recur also."

Now, it is the "uniformity" of the first of these two passages which wages relentless war against all miracles and the idea of miracles. The "uniformity" of the second passage is a totally different kind of uniformity from that of the first passage, and is, in practice, if not in theory, altogether inconsistent with it. Neither science nor rationalism recognises a "uniformity of nature" which includes the possibility of wonders wrought by God to meet the special needs of a particular moment. There is no evidence that any such wonders have ever been performed. If they took place as the outcome of natural law, they would, of course, cease to be miraculous, however extraordinary they might be. If, on the other hand, they are put forward as possible examples of the arbitrary intervention of a personal being in the course of natural events, they are scouted and excluded by the principles and methods of science.

But, says Mr. Balfour, Nature as a whole is not uniform; the universe never is twice over precisely in the same condition; and we are compelled to fall back on certain working hypotheses, as, for example, that Nature is not merely uniform 
as a whole, but is made up of a bundle of smaller uniformities. As applied to the practical question of miracles, all this is philosophical quibbling of the worst kind. It has no bearing whatever on the subject. All that science means, all that empirical philosophy means, by the uniformity of Nature, is that, if the same conditions be repeated, the same result will follow, and that precisely in so far as the conditions are repeated the result is the same. Indeed, as G. H. Lewes put it in Problems of Life and Mind, the cause and the effect are one and the same thing. The assemblage of causes constitutes the effect, and precisely in so far as the causes vary, so also will there be a variation in the effect. The scale of operations may be limited to a charge of gunpowder in a toy pistol, or it may be as vast as the solar system; the question of size has no bearing on the fact that Nature is uniform in her operations.

Mr. Balfour urges that misconceptions arise in relation to this subject through the use of language which implies that a law of nature is "a sort of self-subsisting entity" which rules with undisputed sway over some department in the world of phenomena, and the most that he will admit as to law is that " in certain regions of nature, though only in certain regions, 
we can detect subordinate uniformities of repetition which, though not exact, enable us, without sensible insecurity or error, to anticipate the future or reconstruct the past."

Adopting Bradlaugh's admirable definition of a law of nature as "observed order of phenomena," $<x$ we would remind $\mathrm{Mr}$. Balfour that many such laws have been tabulated and verified by science, and they cover ground sufficiently wide to enable us to affirm with practical certainty that, so far as the investigations of man have gone, whether with telescope and spectroscope in the distant heavens or with microscope and microphone among the wonders of earth, which, by their smallness, elude the unassisted eye and ear, Nature is everywhere uniform in her operations, and the same or similar causes are always followed by the same or similar effects. Mr. Balfour thinks that "no profit can yet be extracted from controversies as to the precise relation in which miracles stand to the Order of the world"; but we hold, with Hume and J. S. Mill, that this relation lies at the root of the whole matter. Miracles are contraventions of the uniformities of nature which have been observed and verified by man, and thus raised to the rank of complete inductions; and, as Hume said in effect, it is much more likely that a person who declares that one of these unifor mities 
has been infringed is mistaken or is telling a lie than that a law of nature should be suspended. In the words of Mill, "Such an assertion is not to be credited on any less evidence than what would suffice to overturn the law."

Mr. Balfour's arguments on the subject of miracles are simply elaborate and skilful evasions of the points at issue. Leaving the question of miracles in the abstract, let us apply Mr. Balfour's reasoning to some concrete case, as, for example, the raising of Lazarus from the dead. On what ground can it be maintained that miracles of this kind may form part of the uniformity of nature, however broadly that uniformity may be interpreted? Neither Christian nor Rationalist believes in such a uniformity of nature as is implied in the assumption that the world passes more than once through the same phase, and that the circumstances of the first century A.D. in Palestine will recur, and will thus include the raising of a second Lazarus from the dead by a second Jesus as a part of the course of nature. Besides, what were the "special circumstances" of the "particular moment" which made it necessary that the ordinary processes of nature should be reversed, and that this stupendous wonder should be wrought by God? The death of a 
beloved brother did not form a special circumstance or create a special need; innumerable men and women have mourned the untimely death of their nearest and dearest; yet only on two or three occasions in the history of the world has it been found necessary to weave a miracle into the uniformity of nature in order to assuage the grief of sorrowing friends. If it be said that Lazarus was raised from the dead, not for the sake of Mary and Martha, but as a demonstration of the power and divine authority of Jesus, the miracle must be pronounced a complete failure. Nobody but the unknown author of the fourth gospel seems to have been aware that it had taken place. The other three evangelists could not, and would not, have omitted all mention of this wondrous event, if they had heard of it. But even if there was historical foundation for the story of this miracle, it is valueless as testimony to the divine mission of Jesus, because there is no evidence to show that Lazarus was really dead. He may have been lying in a death-like swoon or trance. - Again, what bearing on such a miracle has Mr. Balfour's remark that by a "law of nature" all we ought to mean is that

" in certain regions of nature, though only in certain regions, we can detect subordinate uniformities of repetition which, 
though not exact, enable us without sensible insecurity or errorto anticipate the future or reconstruct the past "?

Once more defining "law of nature" as "observed order of phenomena," we affirm that it is a law of nature that a dead man has never been, and cannot be, restored to life. In all the legends. and history books of the world, including the New Testament, there is no account of any such alleged event that would bear investigation in a court of law by the ordinary rules of judicial evidence. Whether the uniformities of repetition in connection with the phenomena of death be subordinate or primary, they are universal, so far at least as the earth is concerned, and they are so exact as to enable us to anticipate the future and reconstruct the past with absolute certainty. The two great inductions of life and death-(1) all living creatures must die; and (2) no creature once dead has been restored to lifeare complete, and something more than anonymous stories of obscure miracles would be required to overturn them. Mr. Balfour talks. about "subordinate uniformities of repetition" as though the regularities of natural phenomena. were of small importance and could be brushed aside by a wizard's incantation or by the cunning. hands of a juggler. The truth is that the uniformity of nature, in the sense that the same. 
or similar causes are always followed by the same or similar effects, is the primary fact of nature, and no service is rendered to the cause of theology and miracles by attempting to show that man's knowledge of this uniformity is imperfect, and that he has only been able to discover "subordinate uniformities" in certain limited regions of nature. Perhaps the distinguishing characteristic of the twentieth century will be a general and complete realisation of the facts that nature is uniform, and that the law of causation is universal; and we may be certain that when this conviction has once taken firm hold of the human mind it will be as impossible for men to believe that miracles have taken place in the past as to expect that they will take place in the future.

Mr. Balfour disclaims any intention "to suggest that it is as easy to believe in a miracle as not"; yet what else can be the logical outcome of his arguments? If the uniformity of nature may mean anything or nothing; if the "subordinate uniformities" known to man do not preclude the possibility that in other and more extensive regions of nature any effect may be produced by any cause, or by no cause at all ; if there is a Being behind or immanent in the universe who, by the exercise of his will, may at 
any moment produce any event he chooses, it is not only "as easy to believe in a miracle as not," but it is impossible to avoid the conclusion that miracles may be as confidently expected as the rising and setting of the sun. Grant $\mathrm{Mr}$. Balfour's premises, and the aspect of nature is immediately transformed. We are back in the world of primitive man; law and order are scarcely recognised, if recognised at all, in phenomena; in all the wondrous manifestations of nature we see, not the result of the persistence of force and the indestructibility of matter, but the capricious operation of personal will and power. In such a world one event is as possible as any other event, and what we call miracles would be occurrences which every man might hope to see performed on his own behalf if he were clever enough or servile enough to propitiate the genii presiding over natural phenomena. Mr. Balfour's arguments, as usual, prove too much. In attempting, by the aid of a philosophy which is content with nothing short of accuracy and proofs that lie beyond the reach of human faculties, to cut the ground from beneath the feet of science on the subject of natural law, he destroys the only compass by which he, or mankind in general, can thread the paths of nature or cope with the practical 
problems of life. Either, as science teaches, Nature is uniform in all her operations, from the revolutions of sidereal systems to the motion of a pebble in the hands of a child, or we cannot assume that she is uniform at all, and the "subordinate uniformities" which we think we have discovered in certain regions may be overturned by the experiences of to-morrow. On Mr. Balfour's halting hypothesis, why should he not hope some day to walk on the water, to feed the starving victims of an Indian famine with a few handfuls of rice, to turn water into wine, or to raise somebody from the dead? Apart from belief in the uniformity of nature, there is no reason why any man should not expect to perform such wonders as these, and it is thus clear that Mr. Balfour's philosophy, when carried to its logical conclusions, lands us in the world of fairy tales and of the Arabian Nights, instead of in the world of sober common-sense and practical science.

Mr. Balfour thinks he has shown that "no profit can yet be extracted from controversies as. to the precise relation in which miracles stand to the order of the world." That is to say, the question must be left open; we must not conclude that miracles are impossible; every miracle must be judged on its merits; and we must 
assume that, within certain limits, "it is as easy to believe in a miracle as not." Even if every miracle be judged on its merits, the case for miracles falls to the ground, because there is no miracle on record that is established by satisfactory evidence. But a question of this kind cannot be allowed to remain open, and the relation in which miracles stand to the order of the world is the kernel of the problem. Reverting to the definition of natural law as "observed order of phenomena," we hold that the laws of nature have never been contravened within the history of man, and that any contravention of them is impossible. The order of phenomena is never reversed, and is never changed, unless some new element be introduced, when the effect varies in exact proportion to the variation in the causes. Meaning by the miraculous such a contravention of the laws of nature as is implied in the raising of a dead man to life, we affirm that the order of the world excludes miracles, and that, viewed from this standpoint, they are incredible unless supported by sufficient evidence to show that the order of the world does not exist. In other words, miracles and natural law are mutually exclusive. Mr. Balfour must make his choice between them; he cannot have both. That the order of the world is a reality 
has been demonstrated by endless observations and experiments, and we verify it every moment of our lives. If we believe in the order of the world, we cannot believe in miracles, because we are unable to resist the conclusion that it is infinitely more probable that a person should be mistaken, or should be committing a fraud, than that the order of the world should be infringed. From the scientific standpoint, miracles can only be established by such a weight of evidence as would be sufficient to show that the belief in natural law is a delusion.

Mr. Balfour attempts to escape from the force of this argument by flying to his favourite city of refuge-philosophic doubt. He tells us that there is no clear and generally accepted theory as to what is meant by the uniformity of nature and by particular laws of nature, and as to the kind of proof by which each is to be established. The rationalist account of the "natural," says Mr. Balfour, is itself " one which, if interpreted strictly, seems open to grave philosophical objection, and is certainly deficient in philosophic proof." But what has all this to do with the question of miracles? Are we, because we cannot solve all the mysteries of being, to abandon the light of reason, and to give credence to every lying tale of wonder that may be told by any 
juggling charlatan or religious enthusiast? Apart from belief in the uniformity of nature, which Mr. Balfour does his best to discredit, all these tales are equally credible, and there is no it priori reason why any of them should be rejected. The philosophy which destroys the foundations of science and rationalism is equally fatal to common sense, and, if carried into practice, would leave man, like a ship without a rudder, at the mercy of every wind and wave of irrational thought. Mr. Balfour's philosophic doubt does not touch the question of miracles, which can be solved only by practical methods from the standpoint of the concrete. The question whether a man has been, or can be, raised from the dead is one of fact and science, and not of abstract philosophy. There is a general practical agreement as to what is meant by the uniformity of nature, and by particular laws of nature, and as to the kind of proof by which each is to be established. Even if this proof falls short of philosophic perfection, it is sufficient for practical purposes, and there is no proof in any way comparable with it that can be adduced in support of miracles. Indeed, as already pointed out, the evidence required to establish a miracle would have to be strong enough to overthrow our belief in the uniformity 
of nature. Mr. Balfour may well be anxious to show that no profit can be extracted from controversies as to the precise relation in which miracles stand to the order of the world. In evading this question he evades the whole of the scientific aspect of the problem of miracles, and leaves himself free to accept stories of the miraculous on evidence which science pronounces to be altogether inadequate. But in defending and accepting miracles on such grounds he is condemned not only by logic and science, but by the philosophy to which he always turns as a final court of appeal.

Mr. Balfour urges that religion is

" as necessary an element in any adequate scheme of belief \& as science itself. Every event, therefore, whether wonderful $\downarrow$ or not, a belief in whose occurrence is involved in that religion, every event by whose disproof the religion would be seriously impoverished or altogether destroyed, has behind it the whole combined strength of the system to which it belongs."

In the lofty regions of abstract philosophy this may pass for sound logic, but to the uninitiated eye of the Rationalist it looks very much like reasoning in a circle. The religion is to be proved by the miracle, and the miracle is to be proved by the religion. That is a very convenient arrangement, no doubt, but it can hardly be expected to appeal to the sceptic, or even to the candid and thoughtful Christian. 
The assertion that religion is " as necessary an element in any adequate scheme of belief as science itself" begs the whole question at issue. If this be true, why is it necessary to write volumes in support of the statement? If it were true, the fact would be self-evident to every intelligent man and woman. Yet vast numbers of people go through life without troubling themselves seriously about religion at all, and a large proportion of those who devote much time to religious and philosophical questions reject religion altogether. How could this happen if religion were as necessary as science to any adequate scheme of belief? No scientific man, no layman, no philosopher, has found it necessary to write an elaborate treatise in order to convince the world that science is a necessary element of any "adequate scheme of belief." Beliefs that are worthy of the name do not need to be forced in an intellectual hothouse. They grow, without the aid of the human will, out of man's relations to the irrational facts of the irrational universe upon which Mr. Balfour pours the vials of his contempt and scorn. Again, what religion is it that is a necessary element in any adequate scheme of belief? Is it the Christian religion? If so, on what ground is that religion singled out from the religions of the world? Or will 
any religion answer the purpose, from the faith of Confucius or Zoroaster to the sordid cult of Joseph Smith? In that case we have the edifying conclusion that, in $\mathrm{Mr}$. Balfour's opinion, a false religion may be a necessary element in an adequate scheme of belief. His assertion on this point brings out clearly the radical difference between the claims of science and the claims of religion. Science, though it assumes many forms, is essentially one and indivisible; it is systematised knowledge, and speaks with equal authority in every clime and through every tongue. But supernatural religion is the mournful legacy of the barbarous past; it is a medley of dreams and visions born of the hopes and fears and yearnings of ignorant, aspiring man, and hence it varies, in essential points, with climate, and race, and epoch.

But, however vaguely Mr. Balfour may use the word "religion," and however friendly may be his attitude towards the great historical faiths of the world, there can be no doubt that he holds a brief for Christianity, and that his arguments are advanced mainly in the interests of that religion. Let us, therefore, apply his reasoning to the greatest of Christian miracles-that of the resurrection of Jesus himself. Does Mr. Balfour contend that without belief in this "event" 
the religion of Jesus would be "seriously, impoverished or altogether destroyed "? If so, what kind of religion must it be that is dependent for its value and permanence on miracles, and the belief in miracles? There is no connection between wonder-working and ethics, and surely a religion which professes to embody lofty moral and spiritual truth need not rest on a background of supernatural marvels. The maxims which Jesus taught, the spirit which he breathed in his discourses and in his life, could not be affected in the smallest degree by such a miracle as the resurrection. Accepting, for the sake of argument, the non-miraculous portions of the gospels as historically true, how can it be maintained that the words and life of Jesus are rendered more or less valuable and original, more or less true and beautiful, by belief or disbelief in his resurrection? A religion which is "seriously impoverished" if its founder does not rise from the dead is not worth preserving. And if religion be the expression of the highest ethical and spiritual truth, how can its value or existence depend on the proof or disproof of any event, whether wonderful or normal, whether natural or supernatural? If $\mathrm{Mr}$. Balfour means that, but for the renewed hope and courage which the resurrection infused in the hearts of 
the disciples, the religion of Jesus would have died with his death, strangled by the hands which nailed him to the cross, who will dare to say that so weak a religion came down from heaven, or that such unheroic men were the fit bearers of a new evangel to the world? Besides, this contention places Christianity below the level of the other religions of the world. These survived the deaths of their founders, and have held the allegiance of many millions of men and women throughout many centuries, without the aid of such a miracle as the resurrection. Is Christianity weaker, and of less intrinsic worth, than they?

No; miracles cannot be established in this fashion. "On what ground shall one, that can make iron swim, come and declare that therefore he can teach religion?" And, reversing the question, we would ask, on what ground shall one, that can teach religion, come and declare that therefore he can make iron swim? But, says Mr. Balfour, the miracle

\begin{abstract}
"may assume a character of inevitableness; it may almost proclaim aloud that thus it has occurred, and not otherwise, to those who consider it in its relation, not to the natural world alone, but to the spiritual, and to the needs of man as a citizen of both."
\end{abstract}

Taking the "setting" as portrayed by the gospels, there was nothing inevitable in the 
physical resurrection of Jesus. Even though he were God incarnate, it would have been quite natural for his body to remain in the tomb, while, if necessary, he could have appeared in the spirit to comfort and reassure his disciples. The same argument applies with equal force to all the miracles of Jesus. Was it inevitable that, when in the presence of certain needs and suffering, he should turn water into wine, feed the hungry, heal the sick, and raise the dead? As God, he is always in the presence of similar grief, and pain, and need; yet he makes no sign. How can the actions which were inevitable to him as "man" be otherwise than inevitable to him as "God"? Are we to understand that Jesus the man was capable of an overflowing sympathy and affection for his needy and suffering fellows, which are not felt in the same degree by Jesus the God?

On the ground that a miracle "may assume a character of inevitableness," from the nature of its setting, Mr. Balfour urges that no "presumption " may exist against it, and that, therefore, it does not require "the impossible accumulation of proof on proof, of testimony on testimony," before this supposed presumption can be neutralised. Here, again, we have a flagrant example of reasoning in a circle. Who is to 
decide whether, under given circumstances, a miracle is inevitable or not? Apparently, each individual must decide for himself according to his natural bias, his prejudices, and his education. He may hold that the miracles are true because the religion is divine, and that the religion is divine because the miracles are true. If this is the best that can be said on behalf of miracles, the most ardent theologian must be prepared to admit that the case is hopeless. Mr. Balfour may fence, and struggle, and weave metaphysical conundrums, but he cannot evade the force of the scientific argument against miracles, which rests entirely on the granite strength of the inductions which we call laws of nature. These inductions can only be overthrown by other inductions equally wide and equally certain. No doubt whatever is cast upon them by the assertions of an individual, or a body of individuals, who may come forward with wonderful stories of a teacher who has walked upon the sea and has raised men from the dead. The teacher of whom these tales are told may be the incarnation of holiness and wisdom, but, however good and wise he may be, it is not inevitable that the processes of nature should be reversed in accordance with his will. It is infinitely more probable that 
the persons who relate these stories are mistaken, or are trying to deceive others, than that the uniformity of nature has been broken by the fiat of either man or God. The presumption against miracles is overwhelming. It is as wide as the experience of mankind, as deep and far-reaching as the investigations and experiments of science, and it can only be overturned by an "accumulation of proof on proof, of testimony on testimony," which it is impossible to gather, because it would need to be strong enough to overturn the induction which it impugned, and to establish a contrary induction in its place.

Dealing with the objection that, as theological miracles are due to the special action of God, they imply a preferential exercise of divine power, Mr. Balfour points out that this is, from a religious point of view, no peculiarity of miracles. The same preferential action is. implied or assumed by most religious systems even by those which do not advance beyond the: nebulous position that there is a power which makes for righteousness. These considerations. may have weight with the adherents of the religious systems to which $\mathrm{Mr}$. Baifour refers, but they can, of course, avail nothing against. the objections of science and rationalism. Science knows nothing of preferential action on 
the part of God, and is not prepared to accept miracles on the ground that they form merely one phase of this kind of action. If it be alleged that there is a special Providence that whispers warnings to the hearts of men at times of crisis, and guides them through the shoals and quicksands of life; or that the general course of history is directed by God; or that God is, at least, using his influence and power on the side of righteousness, Science can only declare that she is not concerned with such matters at all. If the propositions which they involve are presented in a definite and intelligible form, and can be supported by evidence, they come within the jurisdiction of science; but so long as they remain mere speculations, shadowy in outline, indefinite in terms, and unsupported by facts, science can take no cognisance of them.

But, contends Mr. Balfour, on the question of the preferential action of God science has come to the aid of theology in an unexpected manner. If the existence of God be assumed, it is clear that by means of the process of evolution the Author of the world is slowly working out a purpose which involves something in the nature of preferential action on his part. $\mathrm{He}$ is selecting and strengthening some parts of his creation, and is rejecting and eliminating other parts. If 
miracles and the general thesis of the preferential action of God can find scientific support only in the theory of evolution, even theologians will be prepared to admit, on reflection, that, so far as: these matters are concerned, they had better dispense with the aid of science altogether. Assuming theism to be true, what kind of preferential action on the part of God does the theory of evolution imply? It implies that he has produced large portions of the universe only to reject and destroy them. Is this consistent with the theory that God is all-wise, all-powerful, and all-good? Mr. Balfour's argument suggests that God resembles an amateur carpenter, who, having tried his 'prentice hand at making various articles, condemns some as bad and destroys them, selects others as temporarily passable, and then proceeds to try his hand again. Or, perhaps, he more nearly resembles a gardener or cattlebreeder who aims at producing certain ideal forms of vegetable or animal life, and who shows preferential action towards this end by killing off the weak and unfit. Such preferential action may be necessary and moral on the part of man, but it is altogether inconsistent with the alleged holiness, wisdom, and power of Mr. Balfour's God. Judged by human standards (and there are no other standards known to man), the God 
who, possessing infinite wisdom and power, produces sentient creatures only to destroy them as imperfect and unfit to survive, is clearly an immoral being. He marches along a pathway strewn with the bones of men and beasts towards an ideal which omnipotence could have reached without shedding a single drop of blood, or inflicting a moment's agony upon any living thing. Thus, by invoking the aid of the theory of evolution on behalf of the doctrine of the preferential action of God, Mr. Balfour commits himself to that "idea of an immoral creator governing a world peopled with moral, or even with sentient, creatures," which he describes as " a speculative nightmare," and which, if clearly realised and believed in, would, he affirms, ultimately destroy morality. We leave him facing the consequences of this dilemma. Either he must abandon the argument that science, by the theory of evolution, affords some countenance to the doctrine of divine preferential action, and, by implication, to the miracles which are only a more obvious and striking form of such action, or he is committed to the "speculative night-" mare" of an immoral creator, which, if generally realised and accepted, would banish ethics from $x$ the face of the earth. 


\section{CHAPTER X.}

\section{PHILOSOPHY AND RATIONALISII}

Discussing the question of "Philosophy and Rationalism " in the third chapter of the second part of The Foundations of Belief, Mr. Balfour contends that "we have at the present time neither a satisfactory system of metaphysies nor a satisfactory theory of science." If by "metaphysics" he means what G. H. Lewes aptly styled "metempirics"- speculations on matters which are beyond the range of experience and logical inference-it is not surprising that we have no "satisfactory system" of thought in relation to these questions. Experience may, as Mr. Balfour affirms, form a deceitful and insecure standing ground, but it is the sole ultimate source of knowledge, and if we leave experience and logical inference therefrom behind, and launch our intellectual bark upon the sea of speculation, we cannot expect to arrive at any satisfactory port. We are more likely to play the part of a Flying Dutchman, doomed to an eternal cruise which has no useful purpose, and 
can have no tangible result. We might as well expect to reduce the dreams and visions of the night to a "satisfactory system" as expect to derive logical coherence and mental satisfaction from the speculations of metempirics. Mr. Balfour finds it " difficult to believe that" metaphysical "opinions have been elements of primary importance to the advancement of mankind." Clearly, from the Rationalist standpoint, it is impossible that they should be of any importance, except as indications of mental energy which has been diverted from legitimate to illegitimate channels. The utmost that Mr. Balfour can claim for them is that they are a department of poetry which deals with " the abstract and the supersensible instead of the concrete and the sensuous," and that they possess historic value, although they may not "have brought us into communion with eternal truth." These claims are hardly worth discussing, and we may pass to the more important question as to whether or not we possess a "satisfactory theory of science."

Here, after all, we are merely face to face with Mr. Balfour's haunting spectre, philosophic doubt. We are unable to prove the existence of the external world, or the universality of the law of causation; and even if these gigantic difficulties were overcome, we should still be unable to 
determine to what extent the account of the universe given to us by the senses is inaccurate. From facts like these Mr. Balfour draws the conclusion that " no scheme of knowledge exists, certain in its first principles, and coherent in its elaborated conclusions"; and it is in this sense that he holds we have no " satisfactory theory of science." Let it be noted that the theory of science which Mr. Balfour would deem "satisfactory" is one that would require to transcend experience. His ideal theory would include proofs, apart from experience, that the testimonies given by experience are valid-an achievement which is clearly beyond human reach. Therefore, we must be content to dispense with philosophical perfection, and must restrict ourselves to the practical and the relative. But, writes Mr. Balfour,

"if faith be provisionally defined as conviction apart from or in excess of proof, then it is upon faith that the maxims of daily life, not less than the loftiest creeds and the most farreaching discoveries, must ultimately lean."

Thus, by one clever but suicidal stroke of the pen, Mr. Balfour destroys the foundations of knowledge and reason, and places the grossest absurdities of imagination or of superstition on the same level of credibility as the sober facts of daily life. The cardinal error in this sentence lies in the sense in which he uses the word 
"proof." He means the kind of proof which is required to allay his philosophic doubt, and which, as we have already seen, is beyond the reach of the human mind. He may, of course, claim that, as he is discussing this question from the abstract philosophic standpoint, he is entitled to use the word "proof" in a philosophic sense. But, in that case, the word " faith" also requires extension or modification. $x$ The maxims of daily life are based upon faith in the validity of our own experiences. It is absurd to pretend that there is no essential difference between faith of this kind and that which forms the basis of the beliefs that there is a personal devil, that the book of Mormon is a revelation from God, and that men are destined to live for ever in heaven or in hell.

Mr. Balfour observes that if his argument on this point be sound, "it is plainly a fact of capital importance. It must revolutionise our whole attitude towards the problems presented to us by science, ethics, and theology. It must destroy the ordinary tests and standards whereby we measure essential truth."

But his argument on this point is not sound. All human knowledge is relative, and it is futile and confusing to write as though we may advance from the relative to the absolute. "Faith" and "proof" are relative terms, and the only significance they have or can have for man is derived 
from their association with the facts of experience. To attempt to place the affairs of daily life, the discoveries and experiments of science, and the dreams of theology and metempirics, in the same category of credibility or incredibility on the ground that, in the last resort, all are equally destitute of philosophic proof, is just as foolish and unavailing as it would be to impugn the verdict of a court of justice, or the accuracy of a scientific observation, on the ground that we are unable to prove the reliability of the senses or the existence of an external world. Mr. Balfour's "fact of capital importance" thus dwindles to a fact of no importance at all, and, so far as questions of rationalism and theology are concerned, becomes altogether irrelevant. But even if his argument were sound, what "tests and standards" of truth would he give us in place of those which he has destroyed? Plainly, there are none, and he can give us none. He has thrown overboard the compass of reason and the rudder of experience, and he would leave us afloat on the ocean of life with no guide save impulse, and would reassure us with the suggestion that we are just as well off without helm and compass as with them, since we cannot prove that they are reliable, and the ports of Truth and Certitude may lie in any direction or in no 
direction at all. If this is the logical outcome of Mr. Balfour's "fact of capital importance," we think the world will do well to remain in ignorance of his great discovery, and to plod steadfastly along the lines of mere vulgar empiricism. If theology can be rehabilitated only by the destruction of reason, most people would prefer that theology should perish rather than that the whole race should be reduced to a state of philosophic lunacy.

Having, as he thinks, demolished the bulwarks of science and rationalism by undermining the foundations of all belief, Mr. Balfour proceeds to. assert the claims and the dignity of theology. He observes that, in the light of his "fact of capital importance," we can no longer be content with the view that " every theological statement, if unsupported by science, is doubtful ; if inconsistent with science, is false," and he asks :

"Are we arbitrarily to erect one department of belief into a if law-giver for all the others?"

If we accept Mr. Balfour's premises that all beliefs are equally incapable of proof, and may, therefore, be equally true or equally false, it is, of course, illogical " to erect one department of belief into a law-giver for all the others." On Mr. Balfour's theory, the stories of Gulliver and of Baron Munchausen are entitled to as much 
credit as the narratives of Humboldt and Livingstone. But Rationalists hold that science, being knowledge, is thereby constituted a "law-giver" for all departments of belief which deal with matters of fact. If theology makes any statements bearing on matters of fact, they come within the jurisdiction of science, and we are entitled to hold that, if unsupported by science, such statements are doubtful, and, if inconsistent with science, they are false.

Mr. Balfour, however, exclaims against this method of procedure on the ground that it accepts or rejects beliefs precisely as they square or do not "square with a view of the universe based exclusively upon the prevalent mode of interpreting sense-perception." What is this but darkening counsel with the multiplication of words? Mr. Balfour adds :

"Through the greater portion of the world's history, the ' ordinary mode of interpreting sense-perception' has been perfectly consistent with so-called 'supernatural' phenomena. It may become so again."

The simple facts of the case are that senseperception is the sole foundation of knowledge; that throughout the world's history it has been interpreted in the same way as now ; and that, if at some periods that interpretation has been consistent with so-called supernatural phenomena, it was owing to the limited character of man's 
sense-perception, and not to any difference in his mode of interpreting it. It is, of course, impossible to prove that a view of the universe based upon sense-perception is true; but, apart from sense-perception, we have no knowledge whatever, perfect or imperfect, of the universe, and we may be excused for declining to modify our interpretation of sense-perception in order to make room for the vagaries of metempirics and the dogmas of theology.

But, contends Mr. Balfour, "it would be an act of mere blundering unreason to set up as the universal standard of belief a theory of things which itself stands in so great need of rational defence." By "rational defence" Mr. Balfour means philosophic defence, and it is no reproach to Rationalism that it shares the fundamental limitations of all human systems, and is incapable of producing on its own behalf proofs which lie for ever beyond the reach of human faculties. Mr. Balfour objects further that "this creed, which so arrogantly requires that everything is to be made consistent with it, is not consistent with itself"; but here again he is speaking from the standpoint of philosophic doubt, and we may reply that Rationalism is less inconsistent with itself than theology, while it also has behind it the support of experience, or, in other words, the 
undivided testimony of the facts given in sense- ? perception.

It may seem hard to $\mathrm{Mr}$. Balfour, as a theologian and metaphysician, though it should not seem hard to him as a rational philosopher, that science and rationalism should be constituted judges of theology, and should presume to discountenance every theological doctrine which is inconsistent with their standards. But, considering that man is the denizen of a universe which can only be known to him through senseperception, this result is inevitable. As man's knowledge of the universe grows and deepens, it is unavoidable that he should get rid of the fancies and doctrines that were born of his ignorance and inexperience. And we need not, like Mr. Balfour, take a pessimistic view of the ultimate outcome of this process. Supernatural religion may perish at its touch, but the religion of duty and virtue will become more virile, and will acquire a firmer hold upon the human heart. The moral ideal of Rationalism is truth, and on no other foundation than truth can any lofty or durable system of ethics be reared. 


\section{CHAPTER XI.}

\section{AUTHORITY AND REASON}

IN dealing with this subject in Chapter II., Part III., of The Foundations of Belief, Mr. Balfour displays his customary love of paradox, combined with a characteristic tendency to devote much space and energy to the demonstration of propositions which nobody seriously disputes, and which carry with them no practical consequences of any importance.

He takes first the popular assumption that every man has a right to adopt any opinions he pleases, and he points out that, if each member of any given community deliberately and systematically exercised this right, the result would be chaos and destruction. That is perfectly true, but we need have no fear of disaster on such a score, because, unfortunately, the majority of people do not, and will not, think for themselves at all, and are only too ready to adopt the opinions of others. At the same time, the right of every man to adopt any opinions he pleases, coupled with the duty of critically examining the 
reasons by which they may be supported, is indisputable. In practice, this resolves itself into the right of the intellectual hero to make innovations in thought, and to declare his convictions to all who may care to listen to him, while on the part of the majority of mankind it represents the right to hear any or all sides of any question, and to adopt those principles which most commend themselves to their judgment. The decision may be erroneous, but at least it will be free in the sense that it is not imposed by an arbitrary, unreasoning power against the will of the individual.

$\mathrm{Mr}$. Balfour asks us to picture the consequences that would ensue if every individual of every successive generation were to devote his energies to an impartial criticism of the traditional view of morality. He is convinced that amid the wild chaos of opinions which would emerge from such a process all that we mean by the word " morality" would perish, and he finds comfort in the thought that mankind will refrain from embarking on such an adventure, not because of its danger, but because of its impossibility. For the majority of men such an undertaking is, no doubt, impossible. Law reigns supreme in the affairs of men as in the movements of the solar system, and schemes of ethics, philosophy, and 
$x$ religion cannot be set up, or destroyed, according to the passing whims of man. They are growths, and possess all the tenacity and vigour of natural products. Man can no more overturn $\chi_{\text {by critical analysis the ingrained results of ages }}$

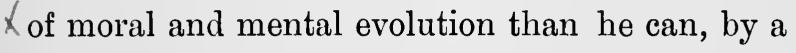
$\downarrow$ similar investigation, change the physical charac$\chi$ teristics which have been wrought into his bodily frame. But if the critical examination of the foundations of morality be a task repugnant and impossible to the average man, it is right that it should be undertaken by those who think themselves capable of performing it. Some of them will fail, but their mistakes may form stepping-stones over which others will advance to success. The fact that this undertaking is impossible for the bulk of mankind induces $\mathrm{Mr}$. Balfour to note " the immense, the inevitable, and, on the whole, the beneficent, part which authority plays in the production of belief." All this must, of course, be admitted, but we would add the proviso that the only authority whose claims can be recognised by Rationalism is that which, on demand, is ready to show facts and reasons other than the arbitrary exercise of personal power for the belief which it produces.

$\mathrm{Mr}$. Balfour proceeds to attack the view that "reason is a kind of Ormuzd doing constant 
battle against the Ahriman of tradition and authority," and he affirms that the "identification of reason with all that is good among the causes of belief, and authority with all that is bad," is a gross yet prevalent delusion. Here, again, the Rationalist is in partial agreement. with Mr. Balfour. Many beliefs which have been produced by authority are true, while others. which have been reached by processes of defective reasoning are false. But no authority can be acknowledged by Rationalism which is not prepared to show that its claims and teachings. are consistent with fact and reason. We agree with Mr. Balfour that reasoning plays an insignificant part in " the complex processes, physiological and psychical, out of which are manufactured the convictions necessary to the conduct of life." Reason is itself the outcome of these: processes, and its special function is to determine whether beliefs, no matter how caused, are consistent with the facts of the universe as revealed in sense-perception. Reason is thus the supreme: judge of all beliefs, though it may be the cause of only a comparatively small number of them.

$\mathrm{Mr}$. Balfour observes that "the power of authority is never more subtle and effective than when it produces a psychological 'atmosphere' or 'climate' favourable to the life of certain 
modes of belief, unfavourable, and even fatal, to the life of others." But is he not here confusing things which are essentially different? By "authority" we mean the influence of persons, or organisations, or systems of thought, and, although these must react to some extent upon the psychological climate, they are clearly the result of the same complex processes which have produced the "atmosphere" in which they exist.

Urging that Rationalism is "a form of authority," inasmuch as it constitutes a psychological climate which is favourable to some forms of belief and fatal to others, $\mathrm{Mr}$. Balfour contends that, although as such a climate "it produces beliefs, it is not on that account a rational cause." We do not think that Rationalism or any psychological climate can, with accuracy, be styled an authority, and we would point out that the whole strength of Rationalism lies in the fact that it appeals to reason and experience, and is thus broadly distinguished from theology and metempirics, which appeal to imagination and faith, and base their claims on the authority of dogma and speculation. It is, therefore, hardly correct to say that Rationalism is a non-rational cause of belief. $\mathrm{Mr}$. Balfour instances the case of witchcraft, which died a natural death in the atmosphere of Rationalism, without having occasioned 
any controversy worth mentioning. But is it not clear that witchcraft was slain by the actual growth of reason and the spread of rational methods of thought? The advance of medical science has shown that ailments which ignorance formerly attributed to the agency of evil spirits are due to physical causes, and the general advance of civilisation has made men less ready to impute malevolence and communion with devils. to friendless women who happen to be old and perhaps somewhat unsocial in their habits.

Mr. Balfour, however, draws a sharp distinction between beliefs which are the result of reasoning, and intellectual changes, such as the decay of the belief in witcheraft, which have not. been produced by the use of logic, but are the indirect effects of a general growth of knowledge and the expansion of reason. That some distinction should be drawn between the two is perfectly justifiable, but we do not think Mr. Balfour is entitled to describe the indirect action of reason as that of authority. The word " authority" should be limited to the statements. and doctrines which any person or persons may seek to impose upon others by the mere weight of their name or position. That the majority of men accept, without question, the customs and beliefs which have been handed down from past 
generations does not imply that on all these points they give up their right to reason and yield to authority as authority, but that they naturally shrink from the impossible task of discovering afresh all the principles of knowledge and reason which have been gradually acquired by their forefathers throughout ages of struggle with the forces of the universe. It is sufficient that these customs and beliefs should, in the main, harmonise with the social needs and general intellectual equipment of the average man, or that, at least, they should not be seriously inconsistent with them.

Further, the popular assent to many beliefs and statements is based, as Mr. Balfour points out, on the fact that these beliefs and statements are supported by persons of repute in their respective departments of knowledge, who are held to be reliable authorities on the subjects of which they treat. The majority of us who are not geologists accept the facts and theories of geology on the authority of those who, by long and assiduous study, have acquired great knowledge and skill in this science. But this does not mean that on geological questions we forego the right to use our own reason. It means that we recognise the enormous value of expert knowledge, and that, while in the main we take for 
granted the statements of geologists, we reserve the right to suspend our judgment on any points we please, to weigh the evidence on matters in dispute, and to decide whether we shall attach ourselves to any particular school of geological thought or to none.

Perhaps Mr. Balfour would say that he is in substantial agreement with the positions here laid down, and, indeed, there are passages to a similar effect in his chapter on "Authority and Reason." The real objection to his line of argument in this chapter is that, taken as a whole, it is an attempt to discredit reason in the interest of what he calls authority. He tells us that by "authority" he means "that group of nonrational causes, moral, social, and educational, which produces its results by psychic processes other than reasoning." An author is, of course, entitled to use a general term of this kind in any sense he chooses, provided he follows $\mathrm{Mr}$. Balfour's example in furnishing us with a definition of the sense in which he is using it. But we think the meaning which he attaches to this word is of too sweeping and unqualified a kind, and that, as used by him, the term is calculated to obscure rather than to elucidate the question of the relations between authority and reason. It is clear that reason has played an active part 
in the formation of the "non-rational causes, moral, social, and educational," which now produce a large proportion of human beliefs; and it is also clear, as Mr. Balfour himself admits, that reason is entitled to call in question any belief which has been produced in this manner, and to. refuse to recognise it as valid unless it can be shown to be based on fact and logic. To authority of this kind, which is always ready to submit its statements to the test of fact and reason, the Rationalist has no objection. Reason is, indeed, at all times, nothing more or less than such authority in the process of formation; for, as Mr. Balfour observes, to reason is largely due the growth of new and the sifting of old lnowledge; and, in the last resort, it is from knowledge only that the " group of non-rational causes" which he designates authority can derive their power. But, in the opinion of Mr. Balfour, the effects of reason are trifling compared with the all-pervading influences which flow from authority :

"At every moment of our lives, as individuals, as members of a family, of a party, of a nation, of a Church, of a universal brotherhood, the silent, continuous, unnoticed influence of authority moulds our feelings, our aspirations, and, what we are more immediately concerned with, our beliefs."

This is true, but it does not follow, as $\mathrm{Mr}$. Balfour's line of argument seems to imply, that 
authority is of more worth and consequence than reason. In the wide sense in which Mr. Balfour uses the term, authority means largely reason which has become crystallised into the various "moral, social, and educational influences" which are always at work around us. We cannot admit that reason, when crystallised into authority, has claims upon our respect and allegiance which are not shared by reason when it exists in its primary state of reasoning. The silent, all-pervading influence of authority constitutes a permanent danger to society. It is a constant menace to intellectual freedom and social progress. Authority, in Mr. Balfour's sense of the word, tends always to degenerate into a tyranny which presses like a dead weight upon the human heart and mind, crushing individual thought and enterprise, and barring man's path in all directions. It becomes tolerable and beneficial only when its wheels are kept in motion by the lubricating and disintegrating forces of reason.

John Stuart Mill's essay, On Liberty, should be read side by side with Mr. Balfour's chapter on "Authority and Reason." The disastrous effects of undue regard for authority have never been pointed out with more clearness and eloquence than in that famous book, and Mill's statement of the case for liberty forms an effective 
antidote to Mr. Balfour's exposition of the beneficial results which flow from the influence of authority. That authority should wield immense and universal sway over human thought and human affairs is inevitable, but it needs to be tempered and chastened by the perpetual challenge of reason. Authority is the mould into which our thoughts and habits, and our very lives, are cast; it is imperative that reason should stand above this non-rational and unconscious mould, modifying and reshaping it in accordance with the advancing knowledge and changing needs of man. Left to the influence of authority alone, human energies would of necessity slacken; life would become a dreary level of stagnant uniformity; and man would sink into a state of general apathy and ignorance.

It may be objected that Mr. Balfour does not attempt to exalt authority at the expense of reason, but that he has merely endeavoured to indicate the relative positions which they occupy in the world of thought. We answer that from the beginning to the end of his argument he assigns to authority an intrinsic worth which it does not possess, and that the motive underlying this portion of his work is a desire to minimise the value and importance of the reason which boldly assumes that church, and creeds, and 
scriptures, no less than matters of science and the practical affairs of daily life, are legitimate objects of its criticism and survey. In the concluding sentence of his chapter on this subject Mr. Balfour suggests that,

"if we would find the quality in which we most notably excel the brute creation, we should look for it, not so much in our faculty of convincing and being convinced by the exercise of reasoning, as in our capacity for influencing and being influenced through the action of authority."

But in so far as our obeisance to authority is laudable, it is dictated by reason on the ground that, within certain limits, we shall do well to defer to a knowledge and experience which are greater than our own. The "capacity for influencing and being influenced" by authority is the natural result of the possession of reason, and cannot exist apart from the processes of reasoning which Mr. Balfour relegates to so subordinate a position in human life. No sane man yields to the influence of authority except on the ground that such a course commends itself to his reason. If it were otherwise, if we followed our elders and leaders blindly, unconsciously, and without question, it is difficult to see how in this respect we could be said to "notably excel" a flock of sheep, which has quite as brilliant a capacity for following its leader wherever he may go. 
Great, then, as is the share of authority in the production of belief, we must not lose sight of the fact that, in the last resort, its power and influence are based upon reason. Nothing is to be gained, and much harm may be done, by dilating, as Mr. Balfour does, upon the "comparative pettiness of the rôle played by reasoning in human affairs." The elevation of the race depends upon an increased use of the faculty of reason on the part of its individual members, and our aim should be not to induce a servile obedience and conformity to existing customs and beliefs by exaggerating the value and influence and potency of authority, but to encourage men to think freely and intelligently for themselves. We see the baleful effects of unquestioned authority in the arrested civilisations of the East; while, on the other hand, Europe and America, with all their drawbacks, present innumerable illustrations of the mighty and beneficent influence of discursive reason.

Mr. Balfour's argument on this subject serves incidentally to emphasise the fact, so constantly insisted upon by Rationalists, that human affairs and the human mind are as completely subject to the reign of law as the earth on which we live. But if under the head of authority we group one set of natural causes which perform a great part 
in the production of beliefs, we must also, under the head of reason, group the set of causes which, through the unfettered play of the individual intellect, proceed also according to law, and are of more intrinsic value and importance than authority in the preservation and increase of human well-being. We owe much to authority, but as authority is, at most, the crystallisation of reason, we owe infinitely more to reason. And however venerable and powerful, and apparently beneficent, authority may be, Rationalists hold that it must ever be subject to the scrutiny and veto or correction of reason. There is no opinion so ancient, no faith so sacred, no church so infallible, no book so authoritative, that it may not be required to submit its credentials at the bar of reason, where every man may, if he pleases, sit as judge. In all matters of custom and belief the court of reason is the final court of appeal, and it has the supreme merit that it is always ready, on due cause being shown, to reconsider its decisions. We acknowledge the might of authority; the strongest must often bow, consciously or unconsciously, before its influence; but we claim that the power of reason is greater still, and that on its exercise and growth depend the welfare and progress of the human race. 


\section{CHAPTER XII.}

IIR. BALFOUR'S PROVISIONAL UNIFICATION

IN the fourth part of The Foundations of Belief $\mathrm{Mr}$. Balfour reaches the goal towards which he has been striving throughout the whole of his two books. That goal is the unification of science and religion by means of a philosophy which shall recognise the claims of both, and which shall furnish a series of first principles as the logical foundation on which the "whole circuit of belief " may harmoniously rest. Mr. Balfour does not venture to say that he is able to formulate a complete and satisfactory philosophy of this kind. Indeed, his general line of attack has been so destructive, from the philosophic standpoint, of the foundations of all belief, whether scientific or theological, that it is difficult to see how he could construct any philosophy at all without re-introducing some of the presuppositions which he has so rigidly ruled out of court. Under these circumstances, it is not surprising that he should content himself with mere "suggestions towards a provisional unification," and it is 
perhaps inevitable, from the insuperable difficulties of the case, that these suggestions should be of a somewhat elementary and tentative character. As, however, they form what theologians would call the final cause of $\mathrm{Mr}$. Balfour's books, we propose to examine them in detail, and we think it will be found that here, as elsewhere, his case breaks down, and that, instead of building a solid foundation on which theology may rest secure and unmoved by the storms of Rationalism, he has merely erected a castle of sand which vanishes at the touch of logic and common-sense.

Mr. Balfour holds that some such presupposition as the belief in a "living God" is " not only tolerated, but is actually required by science," and that when we realise " the scientific truth that at the root of every rational process lies an irrational one," we are driven to hold that

"behind these non-rational forces, and above them, guiding them by slow degrees, and, as it were, with difficulty, to a rational issue, stands that Supreme Reason in whom we must thus believe if we are to believe in anything."

As we have previously pointed out, the difficulty thus brought forward by Mr. Balfour has no real existence, and arises only on the false and vicious theory that we are entitled to measure the universe by the standard of human reason. But 
let us look at the matter for a moment from the standpoint of Mr. Balfour's philosophic doubt. Granted that we are unable to demonstrate the reality of the external world, that the moment we attempt to get behind phenomena, and to lay down first principles which shall bind them into a coherent whole, we find ourselves involved in endless contradictions and in problems for which we can find no solutions, how can there be any justification for the large assumption which Mr. Balfour puts forward as the foundation both of theology and science? If we cannot be certain of the reality of what we hear and see; if at most we can only be sure, each one of us, of his own existence; what possible ground can there be in philosophy or common-sense for the invocation of this phantom of a Supreme Reason as the foundation and source of all cosmic processes? The only conceivable justification for such an assumption is the negative argument that, as we are unable to prove anything at all, all things may be equally true or equally false; that fairytales are as worthy of credence as the most prosaic accounts of every-day occurrences which are published in the newspapers; and that, as one presupposition is not less grotesque or incredible than another, we may adopt any 
presupposition we please in accordance with the needs of the theory which we wish to uphold. In short, Mr. Balfour's practical applications of philosophic doubt involve the abandonment of common-sense, and, having cut the ground of science from beneath his feet, he is left floating in mid-air, the helpless sport of every gust of opinion and sentiment. But we deny his right to apply the results of his philosophical speculations in this manner. If philosophic doubt is fatal to the presuppositions of science, it is equally fatal to Mr. Balfour's presupposition that there is a Supreme Reason who is the source and cause of all things. $\mathrm{He}$ has raised a spectre which cannot be dismissed at his bidding. On the very threshold of his attempt to found a new philosophy his "provisional unification" is strangled by the Frankenstein of philosophic doubt which he has urged with so much zeal against the foundations of science.

Mr. Balfour's presupposition of a Supreme Reason stands in no better position when examined in the light of science. Science has no need of any such presupposition. The only presuppositions necessary to science are that the external world is a reality, and that, within the limits of their capacities, our senses give us a truthful account of the phenomena of the 
universe. All the facts and theories of science are based on these presuppositions, and there is no practical need to lay bare some greater reality in which these two great realities inhere. Theoretically, it may be desirable that we should possess a satisfactory philosophy of science, but, as Mr. Balfour has shown us, this may be impossible, and, in any case, science does not stand in such dire need of presuppositions that she is compelled to accept Mr. Balfour's crude, anthropomorphic conception of a Supreme Reason standing at the helm of nature. What is this "Supreme Reason" but the magnified reflection of man himself thrown by the light of imagination on the background of the universe? With or without any presuppositions, except the two we have named, the work of science goes steadily forward, and its practical scope and results are not affected in any degree by the philosophical struggles that rage around assumptions which may or may not lie at its base.

But, apart from the teachings of religion, there is no reason to suppose that something analagous to human intellect stands above the non-rational forces of nature, guiding them slowly and with difficulty to a rational issue. To what conceivable issue are these forces being directed? There is no glimmering of evidence that any 
such issue is the goal towards which the universe is moving, and, apart from man's vain though natural craving that he, and his loved ones, and his works, shall endure for ever, it is probable that no such idea would have arisen in the human mind. Nothing can be clearer than the fact that the forces of nature are as. impersonal and motiveless as they are nonrational, and their character and relations to each other and to the sentient universe proclaim in trumpet-tones that they are not subject to the guidance of a Supreme Reason. In the words of Matthew Arnold:-

"Nature, with equal mind,

Sees all her sons at play,

Sees man control the wind,

The wind sweep man away;

Allows the proudly-riding and the founder'd bark."

Do not let us pretend that we can discern amid the warring forces of nature a purpose which exists only in the imaginations of men. What. was the rational purpose that was aimed at in the destruction of Herculaneum and Pompeii? or in the earthquake at Lisbon? or that. breathed through the suffocating gases and hellish flames which so recently overwhelmed the inhabitants of Martinique? Whether it be: in the life of individuals, in the history of nations, or in the almost endless cycles of the 
planets, there is no sign of the beneficent and ordered influence of a Supreme Reason which aims at a rational issue, and whose tender mercies are over all its works.

But even Mr. Balfour is obliged to say that the Supreme Reason, which he presupposes, guides the forces of nature " by slow degrees, and, as it were, with difficulty." This is an admission that the state of the universe is inconsistent with Mr. Balfour's presupposition, for how could an omnipotent Supreme Reason have difficulty in guiding the forces of nature in any direction whatever, and why should omnipotence move slowly rather than swiftly towards "a rational issue"? Yet Mr. Balfour tells us that "we must believe" in this Supreme Reason "if we are to believe in anything." That is to say, we must accept a presupposition which, as we have seen, is philosophically untenable, is unnecessary to science, and is at variance with the facts of the universe, or we cannot reasonably believe in anything at all. Most thoughtful persons will, we imagine, decline to place themselves in this logical dilemma. If we cannot obtain a satisfactory and coherent philosophy of the universe as a whole, we had much better restrict ourselves to the familiar ground of science than attempt a "provisional unification" by means of 
presuppositions which involve hopeless contradictions.

Mr. Balfour observes that he has been obliged to assume the truth of theology "in order to find a basis for the only knowledge which naturalism allows." But this knowledge is relative, and it needs no basis other than the world of phenomena with which alone it is concerned. Questions of abstract philosophy, of the Absolute, of the existence of a Supreme Reason, have no practical bearing upon the work of science, and it is absurd to say that concrete knowledge must have as its basis a presupposition for which no justification can be given other than that it seems inevitable to the writer who defends it.

Turning to theology, Mr. Balfour suggests, as the second principle of his provisional philosophy, that in matters of religion mankind have been continually assisted by the Inspiration of God. Holding that all beliefs are due to divine influence, he would apparently limit the use of the word "inspiration" to those cases in which beliefs have been caused by what he calls "preferential action" on the part of God. Such a definition of inspiration is obviously no definition at all, because it fails to provide any standard whereby we may determine whether, in 


\section{MR. BALFOUR'S PROVISIONAL UNIFICATION}

any given case, there has, or has not, been direct intervention of God in the working of the human mind. Recognising the pitfalls and the uncertainties of the question, Mr. Balfour contrives to avoid precision in his statements, and takes a very broad and comprehensive view of the subject. He thinks it would "be inaccurate to say that inspiration is that, seen from its divine side, which we call discovery when seen from the human side." But, he continues :-

" It is not, I think, inaccurate to say that every addition to knowledge, whether in the individual or the community, whether scientific, ethical, or theological, is due to a co-operation between the human soul which assimilates and the divine power which inspires."

Perhaps it is not surprising, considering the weakness of his case, that Mr. Balfour should display a wonderful facility in begging the question in favour of his own theories. In the passage just quoted there are two examples of this futile method of controversy. First, he assumes that theology is a department of knowledge; and, second, he assumes that scientific discoveries are due to a co-operation between the human mind and God. The first of these assumptions has already been dealt with; and, as regards the second, we need only say that it is a piece of pure imagination, which we take 
the liberty to reject until Mr. Balfour can produce some kind of evidence on its behalf. If unfounded statements of this character may be freely made and believed, why should we hesitate to believe in witcheraft or magic, or that men, like Faust, may sell themselves to the devil? Monsters like Cæsar Borgia, dabbling in toxicology, have made scientific discoveries which they have used against the lives of their enemies. Gunpowder, and all the terrible weapons of modern warfare, are the direct results of scientific discovery. Will Mr. Balfour dare to maintain that all these discoveries are "due to a co-operation between the human soul which assimilates and the Divine power which inspires"? If not, on what principle does he draw the line where Divine inspiration ends, and human intellect works unaided by any extraneous supernatural power?

On this, as on many other points, Mr. Balfour tries to prove too much. In claiming for Divine influence a share in the production of all kinds of human belief he weakens the special claim of theology, that man has been guided by the inspiration of God in matters of religion. If, in the realm of theology, we mean by inspiration nothing more than the operation of influences which, in other spheres, have led to scientific 
and ethical discoveries, religious inspiration loses its unique character, and the last shadow of justification for Mr. Balfour's plea, that theology must not be tested by the standards of science, is destroyed. If the discovery of the law of gravitation and the "Thus saith the Lord" of the prophets are both due to the co-operation of the human soul with the Divine power, we are clearly entitled to demand from the religious teacher the same logical and circumstantial proofs of his statements as are freely offered to us by the man of science. It cannot be admitted, on this broad view of inspiration, that the prophet possesses an authority and an infallibility, apart from reason, which are denied to the exponent of science.

But while suggesting, in this general way, that inspiration covers the whole range of human thought and belief, Mr. Balfour seems inclined, as we have already said, to invest the term with a special meaning in relation to theological teachings. The difference on which he insists is one of degree rather than of kind; he merely affirms that inspiration is a "more important" matter in connection with religion than it is in connection with other departments of belief, though the grounds on which he makes this distinction are not clear. $\mathrm{He}$, however, holds. 
that religious inspiration is "limited to no age, to no country, to no people," and that "its aid has been granted not merely along the main line of religious progress, but in the sidevalleys to which there seems no issue." In other words, all religious and ethical systems possess some measure of inspiration, from the idolatrous beliefs of the ancient Semites, who surrounded the Jews in Palestine, to "the ethico-religious teaching of the great Oriental reformers." By taking this broad and charitable view Mr. Balfour avoids the Scylla of contending that Judaism and Christianity have been favoured with Divine help and guidance, to the exclusion of all the other great religions of the world. But he falls into the Charybdis of admitting that no one can tell where inspiration begins or ends, and that every man must decide for himself what particular doctrines, whether of Christianity or of any other religion, are due to the inspiration of God. If all religions possess some measure of Divine inspiration, on what ground is $\mathrm{Mr}$. Balfour entitled to declare that they do not possess an equal measure of inspiration? Clearly he can only decide the matter by the light of reason, or under the influence of personal predilections due to nationality and training. Thus he holds that, while 
Christianity is " a religion adequate to the necessities of a world," there is something, which he does not define, in the great Oriental religions which prevents them "from merging as a whole in the main stream of religious advance." But if $\mathrm{Mr}$. Balfour were of Asiatic race, he would probably reverse this statement in favour of Buddhism or Mohammedanism. That Christianity is not "adequate to the necessities of a world" is proved, first, by its status among nations of Caucasian blood; and, second, by the comparative failure of missionary enterprise. In /practice some of the plainest injunctions of the founder of Christianity are disregarded and contemned by those who most loudly call him "Lord, Lord." They will not refrain from resisting evil, offer the other cheek to the smiter, give away both cloak and coat, and sell all they have and distribute the proceeds to the poor. This kind of thing might answer very well in ancient Palestine, or with St. Francis of Assisi, and it may not be out of place as a part of the lessons read in church on the Sabbath day. But Mr. Balfour and his fellow-Christians turn with disgust and scorn from the man who, like Tolstoy, ventures to suggest that all loyal followers of Jesus are bound to carry out his injunctions in their daily lives. 
While Christians themselves thus set the essence of Christianity at naught, large numbers of thoughtful people in Europe and America have rejected its claims altogether, and have ceased to believe in any form of supernatural religion. So widespread and deeply-rooted is this religious scepticism that $\mathrm{Mr}$. Balfour has found it necessary to write two subtle and elaborate volumes for the purpose of counteracting it, and he deems the case so desperate that he is ready to destroy the foundations of all knowledge in his endeavour to prove that the doctrines of Christianity have the same claims on our credence as the doctrines of science.

In view of these facts, what becomes of the arrogant assumption that Christianity is "a religion adequate to the necessities of a world"? In the countries where alone this religion meets with acceptance on any considerable scale its professed adherents quietly, but unmistakably, set its precepts at defiance, while a large proportion of the people are altogether indifferent or hostile to its claims. On what ground, then, can it be affirmed that such a religion is "adequate to the necessities of a world "?

If these considerations are not sufficient to invalidate Mr. Balfour's statement, we may turn for its final refutation to the failure of Christian 
missions in Asia and Africa. The vast majority of Asiatics are either unmoved by the active Christian propaganda which is carried on in their midst, or they regard it with feelings of hostility and detestation. In many districts it is only the scum of the populace that can be persuaded to embrace Christianity, and these persons are influenced by the hope of pecuniary gain rather than by any conviction that the doctrines of that religion are true. If Christianity is unable to displace the great religions of the East, it is clearly, in the opinions of Asiatics themselves, not so adequate to their necessities as their own religions. We are obliged to conclude either that Christianity is not adequate to the necessities of the people of Asia, or that other Oriental religions are, at least, equally capable of ministering to their needs and aspirations. In either case the facts are fatal to Mr. Balfour's contention that Christianity is fitted, in some unique fashion, to meet the wants of the whole of the human race.

In Africa the refutation of Mr. Balfour's plea on behalf of Christianity is even more complete than in Asia. Christianity has not only failed to commend itself to the religious instincts of the negro races, but it has been hopelessly outdistanced in missionary enterprise and success 
by a rival religion. The Cross has once more been overshadowed by the Crescent, and it seems probable that before many years are past the greater portion of Africa will acknowledge the sway of Mohammed.

Taking the human race as a whole, it is clear that Christianity cannot be specially identified with " the main stream of religious advance." If by "advance" Mr. Balfour means the broadening of religious thought, it may be conceded that this is taking place on a larger scale in the Western world than in Asia and Africa. But the advance takes the form of an attenuation of doctrines and creeds, and, if it continues, must end in the destruction of Christianity rather than in such a deepening of its life and vigour as might reasonably be called an advance. And if by "advance" Mr. Balfour means an increase in the number of adherents, it is more than doubtful, as we have seen, whether in this respect Christianity can claim any superiority over the other religions of the world. The future of religion lies mainly in the hands of the coloured races, and the system which fails to engage their sympathies and command their assent is not destined to play an important part in the history of the world. No candid observer can_doubt that Christianity has lost its hold upon 
182 MR. BALFOUR'S PROVISIONAL UNIFICATION

large numbers of the most active and independent minds among races of European origin, and that, taking these races as a whole, they are already, in practice, dominated by the spirit of Rationalism. 


\section{CHAPTER XIII.}

\section{PHILOSOPHY AND CHRISTIANITY}

Continuing his "provisional unification," Mr. Balfour proceeds to inquire whether " the great body of our beliefs, scientific, ethical, theological, form a more coherent and satisfactory whole" if we consider them in a Christian setting than in a merely theistic or in a naturalistic one. Taking first the doctrine of the Incarnation, he observes that "we need neither be surprised nor embarrassed if the unique mystery of the Christian faith refuses to lend itself to inductive treatment"; that the difficulties of the subject are clearly "not scientific"; and that if "we cannot devise formulæ which shall elucidate the familiar mystery of our daily existence," we need not be astonished that the perplexities of the Incarnation will not yield to the rules of logic. He holds that this doctrine belongs to a region which " must be explored by methods other than those provided for us by the accepted canons of experimental research."

There is nothing unique in the doctrine of the 
Incarnation. In various forms it was familiar throughout the ancient world. A similar story was told of the births of Pythagoras and Plato, and the religions of Egypt and India embodied the doctrine of incarnation in the cults of Krishna and of Isis and Horos. Whether the difficulties of the subject are scientific or not, it is clear that they fall into their proper place under the head of mythology, and that only from the standpoint of this science may we hope to arrive at any satisfactory solution of the problems involved in the doctrine of incarnation. There can be no doubt that the story of the birth of Jesus has its origin in the astronomical myth which represented the sun-god as born every year at the winter solstice, on or near the 25th December, at the time when the constellation Virgo made its appearance above the horizon. It is absurd to describe as unique a doctrine which has so many striking counterparts in the myths of pagan antiquity and in the existing religions of the East.

Mr. Balfour, as we have pointed out, falls back on his familiar plea that, as we cannot elucidate the mystery of our daily existence, we need not scruple to accept the mysterious doctrine of the Incarnation. Is there any force in the argument that because we are unable to attain to a know- 
ledge of the absolute, and cannot comprehend the ultimate facts of the universe, we are entitled to believe in any prodigious miracle or in any astounding doctrine which may happen to form part of our hereditary creed? The question whether any particular man had or had not a human father belongs to the region of the relative, and has no connection whatever with the shadowy realm of the absolute. It is a question of concrete fact, and the difficulties of abstract philosophy have no more bearing upon it than they have upon the question whether there are, or have ever been, such creatures as centaurs or mermaids, or whether the story of the infancy of Cyrus the Great is literally true.

But, contends Mr. Balfour, the doctrine of the incarnation belongs to a region which "must be explored by methods other than those" of physical science. To some extent this may be true, but it is a region that must be explored by the methods of logical, historical, and mythological science; or, if this be disputed, the region must be one of pure imagination with which science has no serious concern at all. By what methods would Mr. Balfour explore this region? Apparently, he has no wish to explore it in any true sense of the words. He 
takes for granted the central fact of the incarnation, and regarding it as, in itself, a mystery too sacred for discussion, he explores the region to which it belongs by the aid of fancy and prejudice, and constructs a theory which, in the absence of any proof that the doctrine of incarnation is true, is simply worthless. Mr. Balfour can hardly hope that this method of building up theories without having first verified the facts will prove less barren in the realm of theology than it has proved in the realms of philosophy and science.

$\mathrm{He}$ admits, however, that, in part at least, the doctrine of the incarnation rests on historical evidence; but, when we seek to apply the usual methods of historic criticism to the ancient records of Christianity, he proceeds to argue that, while in the majority of instances these methods and their results may be both admirable and reliable, there are other cases,

" though they be rare, to whose consideration we must bring larger principles, drawn from a wider theory of the world; and among these should be counted as first, both in speculative interest and in ethical importance, the early records of Christianity."

It is a fact of fundamental significance that a writer possessing Mr. Balfour's extensive knowledge of philosophy and general literature, together with keen insight and great power of 
dialectic, should resort to the puerile method of begging the question in favour of Theism and Christianity whenever he comes within sight of the opposing forces of Rationalism. On what ground may the early records of Christianity be shielded from the knife and scalpel of historic criticism? And what other case is there to which Mr. Balfour would seek to apply these "larger principles, drawn from a wider theory of the world"? He can hardly wish to apply them to the records of Buddhism, Mohammedanism, or Hinduism, and it is tolerably clear that he desires to make the exemption in the sole favour of the particular religion for which he pleads. Yet neither in speculative interest nor in ethical importance have the early records of Christianity any claim to special consideration at the hands of historical criticism. The New Testament contains nothing original or important in the shape of speculation. The system which we find in its pages is mainly a compound of Jewish theology and demonology with the myths of Paganism, modified by some admixture of neo-Platonic philosophy, and the ethical maxims which had filtered slowly into the Greek and Roman world from the far East.' It is one of the commonplaces of criticism that Christianity possesses nothing of ethical importance which 
is not shared in an equal degree by other religions, such as Buddhism and Zoroastrianism. 'Thus there is no foundation for Mr. Balfour's claim that the early records of Christianity deserve a treatment altogether different from that which is accorded by ordinary critical methods to other ancient documents.

Having attempted to clear the ground by these preliminary considerations, Mr. Balfour inquires: "In what temper of mind, in what mood of expectation, ought our provisional philosophy to induce us to consider the extant historic evidence of the Christian story?" The reply must, he thinks, depend " upon the view we take of the ethical import of Christianity; while its ethical import, again, must depend on the degree to which it ministers to our ethical needs." Mr. Balfour selects, as of primary importance, the ethical need "for harmony between the interests of the individual and those of the community," and he argues that this "can be provided, with any approach to theoretical perfection, only by a future life, such as that which is assumed in more than one system of religious belief." If the fact that Christianity ministers to this supposed ethical need for a future life is to be counted as an argument in favour of the antecedent 
probability of the wonders and miracles of the New Testament, the same contention must apply with equal force in support of the credibility of the ancient records of other systems of religious belief which inculcate the doctrine of immortality. Mohammedanism lays great emphasis upon the doctrine of a future life, but Mr. Balfour would be very slow to admit that this fact lends antecedent probability to the claim that the Koran is a revelation from God, or that it forms any ground for believing all the wondrous stories that are told of the Prophet's life and mission. Yet, if the argument fails in the case of Mohammedanism, how can it be held valid on behalf of Christianity?

A still more important point remains to be considered. The ethical need to which Mr. Balfour refers is "for harmony between the interests of the individual and those of the community" in this life. How can this harmony be provided by a future life? We might as well say that the needs of a famine-stricken country, during the season of dearth, will be provided for by the plenty of years to come. It is absurd to pretend that an ethical need which is insistent. and clamorous now, and which grows out of the peculiar conditions of this life, can be provided 
for only in some other life beyond the grave. Of this future life nothing whatever is known, but the persons who affirm its reality agree in declaring that its conditions will be altogether different from those of the present life. The strife and passion which arise from material needs and surroundings will be impossible in the serene and ghostly atmosphere of heaven, and we thus see that, on Mr. Balfour's theory, the harmony of which he speaks will be established only by the removal of all the essential elements of earthly life.

Mr. Balfour asks whether we can "argue from the need for some complete correspondence between virtue and felicity, to the reality of another world than this, where such a correspondence will be completely effected?" and he seems to agree with Kant that we can. ||The need for a complete correspondence between virtue and felicity is fanciful rather than real. Other things being equal, a man's happiness is in direct proportion to his virtue, and this practical correspondence between the two is all that we actually need or may reasonably expect. Again, what ground is there for supposing that in any other world there will be a more complete correspondence between virtue and felicity than we find in the present life? On Mr. Balfour's 
theory, both worlds are subject to the same moral government, and it is difficult to see on what ground he is able to assume that the methods of the divine ruler vary in different worlds. Kant's argument, that the reality of the moral law implies the reality of a sphere where it can for ever be obeyed, does not seem to us to possess much force as an argument in favour of immortality. The moral law can be obeyed in the present sphere by any man who chooses to obey it. If it be objected that no man keeps the moral law in its entirety, it may be answered that there is no section of the law which is not observed somewhere and by some persons, and that this is sufficient to meet the difficulty raised by Kant. Probably there is no British subject who does not, in letter or in spirit, infringe some portion of British law during the course of his life. Yet no political philosopher has ventured to argue that the reality of British law "implies the reality of a sphere where it can for ever be obeyed," and that in the statute-book of the United Kingdom we may discern the promise and the hope of immortal life.

Mr. Balfour holds that " the Power which has thus produced in man the knowledge of right and wrong, and has added to it the faculty of creating 
ethical ideals, must have provided some satisfaction" for ethical needs, and he asks-

"Whether, in a universe which, by hypothesis, is under moral governance, there is not a presumption in favour of facts or events which minister, if true, to our highest moral demands? and whether such a presumption.... is not.... more than sufficient to neutralise the counter-presumption which has uncritically governed so much of the criticism directed in recent. times against the historic claims of Christianity?"

We need not stop to discuss Mr. Balfour's assumption that there is a Power which has "produced in man the knowledge of right and wrong" and "the faculty of creating ethica ideals." This knowledge and this faculty are the inevitable outcome of progressive social life, and it is not necessary to postulate the influence of some extraneous personal power in order to account for their existence. From this assumption, for which no foundation can be discovered in history or in fact, $\mathrm{Mr}$. Balfour proceeds to the hypothesis that the universe is "under moral governance." This hypothesis might be shattered from a hundred points of view, but it will be sufficient to ask how it can be reconciled with the general trend of Mr. Balfour's argument that there must be a future life, if only for the sake of righting the wrongs and smoothing away the inequalities of the life on earth. If in this life, of which alone we have any knowledge, the innocent frequently suffer for the sins of the 
guilty, and injustice often triumphs, and the moral governance of things is so doubtful and uncertain that even ardent theists like $\mathrm{Mr}$. Balfour can only urge that the Creator is guiding the universe "slowly" and "with difficulty" to higher issues, what substantial grounds can there be for the hypothesis that the universe is "under moral governance"? The black phantoms of physical and moral evil, ever stalking through the world, and blighting with their grisly fingers much that is fairest and best in human life and achievement, proclaim with grim and cruel emphasis that the idea of the moral governance of the universe is an empty dream.

On this assumption and on this hypothesis, which disappear before the breath of criticism like snow before the summer's sun, $\mathrm{Mr}$. Balfour bases his "presumption in favour of facts or events which minister, if true, to our highest moral demands." We deny that the "facts and events" recorded in the New Testament minister to man's highest moral demands. The theory that God became incarnate in human flesh, lived a sinless life, performed miracles, died by crucifixion, rose from the dead, and ascended into heaven, does not minister to any " moral demands" at all. Morality and ethical ideals demand that we shall do justice, love 
mercy, walk faithfully aud lovingly with our fellow-men. These things have no connection whatever, near or remote, with the tales of wonder and of mystery which are scattered through the gospels. Morality and moral demands have grown out of the relations between man and man; they can neither be helped nor hindered by the story of miracles of healing and prodigies of feeding which are said to have happened in Palestine nineteen hundred years ago. Mr. Balfour's presumption, then, in favour of the alleged "facts or events" which are related in the New Testament falls to the ground, and he has nothing left to neutralise "the counterpresumption" which, he affirms, "has uncritically governed" much of the recent criticism of the historical claims of Christianity.

This counter-presumption is the presumption with which Mr. Balfour himself approaches the historic claims of all the other religions of the world, but which he inconsistently denounces as uncritical when levelled against the early records of Christianity. It is the presumption that all stories of the miraculous and the supernatural are fictitious, and it is accompanied by the principle that the main business of the critic is to explain how these narratives came into existence. Applied to the stories of the lives of 
Buddha, Krishna, and Confucius, or to the myths and fables which recount the origin and deeds of the heroes and demi-gods of ancient Greece and Rome, Mr. Balfour would no doubt regard this presumption as possessing overwhelming validity and force. But if it is perfectly sound when directed against all other myths and sacred records, how does it become uncritical when used against the historic claims of Christianity? Clearly, the accident of birth, and prejudice in favour of the faith which he has inherited, alone determine Mr. Balfour's attitude on this point.

So far, then, we have to chronicle utter failure on the part of $\mathrm{Mr}$. Balfour to show that the great body of his beliefs are more coherent and satisfactory if considered in a Christian setting than in a naturalistic one. $\mathrm{He}$ has endeavoured to establish this position by means of an assumption which has no foundation in fact or reason; a hypothesis which is at variance with human knowledge; and a presumption which is false. The argument which he has carefully built upon these unsatisfactory bases can hardly be calculated to produce enthusiasm in the breasts of the most ardent adherents of the Christian faith. They will turn with disappointment from the controversialist who offers them a "provisional 
unification " supported by a chain of reasoning of which this assumption, hypothesis, and presumption form three of the most important links.

Mr. Balfour, however, does not allow his argument to rest at this negative stage. $\mathrm{He}$ carries it a step further, and, reverting to the Incarnation, affirms that this doctrine throws the whole scheme of things into a far truer proportion, and brings home to men that, " in the sight of God, the stability of the heavens is of less importance than the moral growth of a human spirit"; that faith in this doctrine enables men to believe that they are made in the likeness of God, despite the teachings and discoveries of. science which intimate that they live in a state of subjection to their own bodies; and that it enables men to face the problem of the existence of evil with renewed confidence and hope, because it teaches that God is not the " remote contriver of a universe to whose ills he is indifferent," but that, in the person of Jesus Christ, he has himself shared human woe and pain.

The first of these contentions is, we think, logically unsound. The doctrine of the Incarnation, even if true, does not throw "the whole scheme of things into a far truer proportion." 
Science has rendered this doctrine incredible, not by demonstrating the physical insignificance of man as compared with the planet Jupiter or with far-distant suns like Sirius, but by revealing the fact that the earth, as a theatre of life, has not the relative importance of a grain of sand in comparison with the innumerable orbs which are scattered throughout the endless vistas of infinite space. It is conceivable that one of the Cæsars might have sacrificed his only begotten son for the sake of some petty hamlet containing not more than twenty inhabitants. But such a sacrifice is antecedently incredible. Yet a hamlet of these dimensions would be infinitely larger in proportion to the Roman Empire than is the earth in proportion to the universe. If there be a personal being who has created all things, and who sustains them by the force of his will, it is antecedently incredible that such a being would assume the form of one of his humblest creatures, and would allow himself to suffer an ignominious death while thus transformed, in order to save these creatures from his own eternal vengeance. Compared with the universe as a whole, the earth and man sink into something of less importance than a tiny heap of sand covered with a community of busy ants. It is just as antecedently incredible 
that God should become incarnate for the benefit of the human race as that a man, if he had the power, should become incarnate as an ant for the benefit of the ant race as a whole. We agree with Mr. Balfour that "material grandeur and moral excellence are incommensurable quantities," but we would remind him that this is not the comparison which is suggested by science, and on which we desire to lay emphasis, as fatal to the doctrine of the Incarnation. The astro(nomical discovery that there are other worlds than ours carries with it the irresistible suggestion that there is an infinite number of globes which contain forms of intelligent life at least as high as those which exist on the earth. And the question is thus forced upon our minds, Is it reasonable to believe that, in a universe the keynote of which is an utter disregard of the interests and existence of sentient beings, our own insignificant planet and the unimportant race of man should have formed the occasion of so stupendous a miracle as is involved in the doctrine of the Incarnation?

This doctrine was, in truth, born of prescientific ideas as to the smallness of the universe, and of parochial notions as to the importance of the earth and man. It was the offspring of cosmic theories which affirmed that 
the sun and moon were made for the sole purpose of giving light to the earth ; which ignored the stars, or, at best, held that their primary office was to rule the destinies of men, and their secondary office to serve as ornaments of the midnight sky; and whose advocates never dreamed that the earth could be other than the stationary centre of the physical universe. Of the cosmos thus portrayed man was the only natural and intelligent denizen; in heaven, of which the blue firmament was the floor, there were gods and angels; and in Hades, beneath the surface of the earth, there were devils and the souls of departed men. But outside the narrow confines of the human race the domination of the supernatural was supreme. Mankind on the one hand, and supernatural beings on the other hand, constituted the whole population of the universe.

During the long centuries when theories of this kind held universal sway over the minds of men it was natural and, perhaps, inevitable that the notion of incarnation should arise in various forms, and should become a leading feature in some of the great religions. In scattering like chaff before the wind the dreams and fantasies of Ptolemaic astronomy, science has destroyed for ever the conditions and the mental atmosphere 
in which alone the doctrine of Incarnation could originate or survive. It is by placing the earth in its true proportion to the whole scheme of things that this result has been effected.

Mr. Balfour, however, attempts to evade the force of the scientific objection to the doctrine of the Incarnation by the simple process of assuming that the incarnation was a fact, and arguing from this "fact" that God sets greater store by the moral growth of a human spirit than upon the stability of the heavens. But a great number of well-known facts and the general trend of the universe cry aloud against this view, so convenient to Christianity, of the relation of God to man. If there be a God, we can judge of his disposition towards the human race only by the facts of nature and of daily life. Even if the Bible be the word of God, we are entitled to apply the same standard to heaven as we apply to earth, and to say that God, like man, shall be judged by his deeds rather than by his words. And if God be omnipotent, the whole universe, from the far-off galaxies of shining worlds, whose radiance is inconceivably beyond the limit of unassisted human vision, down to the savage beast of prey and the squalor and degradation of our great cities, is his deed. Does God, then, as revealed 
in nature, show more regard for the moral growth of man than for the stability of the heavens? The answer of every thoughtful and candid observer must be that he recks no more of man and his physical and moral growth than of the flies which in early autumn are swept out of existence by the blighting frost of a single night. What does God care for the moral growth of the multitudes of human beings whom he destroys by the frightful agency of earthqualies and volcanic eruptions? The efforts of many patient, toilsome years; the physical, mental, and moral development which are the result of centuries of patient seeking and upward striving, are hurled, by one swift Titanic stroke, into black oblivion. Mr. Balfour may reply that this physical destruction is not of cardinal importance in connection with his argument, and that the moral growth ceases here only to be resumed in some celestial sphere. But how does he know this? The weakest advocate could defend the poorest case with success were he allowed to pile assumption on assumption in this illogical fashion. In the absence of evidence to the contrary, we are bound to conclude that death is the end of man, and that the moral growth which is extinguished on earth is extinguished for ever. 
Nature teaches, with overwhelming force and insistence, that, if there be a God, the stability of the heavens is of far more importance in his sight than the moral growth of a human spirit. Whatever ancient fables may say, neither earth nor heaven has stood, or will stand, "at gaze like Joshua's moon in Ajalon," while man wages exterminating war against physical or moral foes. The "moral growth of a human spirit" is infinitely more precarious than the organisation of the heavens. The stability of the heavens is assured by the existence of forces which work with unerring precision towards that end. But the moral growth of man is checked by a thousand obstacles, and may be impeded or destroyed by myriad hostile influences. In our workhouses and lunatic asylums there are thousands of men and women whose lives are stunted and blighted by some physical defect or disorder which has produced mental feebleness of the most pitiable and revolting kind. What does God care for the moral growth of these poor human creatures? Their condition is the result of the interaction of physical forces which, in spite of Mr. Balfour's speculative objections, we may safely affirm to be stable and uniform in their operations. Let the moral growth of a human spirit come into collision with the Juggernaut car of these 
physical forces, whether they take the form of malformation or disease of the brain, and it is hopeless to expect that anything but the barest mockery of " moral growth" will remain. God is on the side of the physical forces, and their stability, we are obliged to infer, is of more importance in his sight than the moral growth of a human spirit. Being all-powerful and allwise, he could, if he would, change these conditions, and allow moral growth to triumph over all physical obstacles. But he does not, and of what avail is Mr. Balfour's fanciful argument against the unanimous testimony of Nature? It is absurd to suppose that this testimony can be weakened or overthrown by the suggestion that, if we could persuade ourselves of the reality of a certain astounding miracle, we might perhaps infer that the testimony in question is altogether false.

If, as Mr. Balfour's argument seems to imply, faith in the doctrine of the Incarnation is necessary in order to enable men to believe that "they are made in the likeness of God," it is clear that this belief does not possess much independent vitality. But Mr. Balfour apparently thinks that the belief will prove a valuable antidote to the teaching of science that man is, to a large extent, the product and the plaything of his body. So 
far, however, as this teaching is true, no effective antidote can be brought to bear against it, and, indeed, no antidote is necessary or desirable. Man can only work out his salvation from evil by acquiring a knowledge of the actual conditions of existence, and by accepting the truths thus discovered as the basis of his operations. It is altogether futile to appeal to the doctrine of the Incarnation against the materialistic trend of science. If, as $\mathrm{Mr}$. Balfour himself admits, mind is entirely dependent on body, and if, as we would suggest, mind is neither more nor less than a manifestation of the body, how can this dependence be neutralised or diminished by the belief that God once became incarnate in human form? The " burden of the body" is not thereby lightened in the smallest degree. Pain is just as depressing; bodily sickness and weakness are just as fatal to mental effort; and the whole gamut of emotion remains as completely under the sway of physiological causes whether we accept or reject the doctrine of the Incarnation. And the climax of Mr. Balfour's argument, which is reached in the assertion that faith in the Incarnation is the only bridge that " can be found to span the immeasurable gulf which separates infinite spirit from creatures who seem little more than physiological accidents," is inde- 
fensible from his own standpoint. Even if it be true that on one occasion God became man, it. does not follow that man is "made in the likeness of God," or that the gulf between man and God has been bridged by this solitary event. That God has passed downward to man does not./N imply that man may pass upward to God.

Mr. Balfour concludes his "provisional unification " by urging that faith in the doctrine of the Incarnation enables men to face the problem of the existence of evil with renewed hope and confidence. On the strength of this doctrine he. points to God as

"one who is no remote contriver of a universe to whose ills he is indifferent. If they suffer, did $\mathrm{He}$ not on their account. suffer also? If suffering falls not always on the most guilty, was He not innocent? Shall they cry aloud that the world is. ill-designed for their convenience when $\mathrm{He}$, for their sakes, subjected Himself to its conditions?"

The case for Theism is not made stronger by the statement that God is not indifferent to. the ills of the universe which he has created. To say that he takes an interest in the existence of evil without extinguishing it is equivalent to. declaring either that he could not destroy evil if he would, or that he would not destroy it if he could. And in what way is the problem of evil rendered less fatal to theistic theories by the suggestion that God himself, in the person. 
of Jesus Christ, has shared the suffering and injustice of earth? Does the fact of the incarnation, if it be a fact, transform wrong into right, turn pain to pleasure, and convert misery into happiness? If not, what practical bearing has the doctrine on the question of evil, and how does it lessen the difficulties of the problem when viewed from the theistic standpoint? God himself created the conditions out of which suffering and injustice have grown. If, as his worshippers affirm, he be omnipotent and allwise, he could have created a universe in which evil would have found no place. The conclusion that he is not omnipotent and all-wise, or that he is not benevolent, is irresistible, and this conclusion is in no way affected by the belief that, for the short space of a few years, he, in the person of Jesus Christ, voluntarily shared human woe and pain. If the king of France, or one of his powerful ministers, had elected to dwell for a period of, say, twelve months in one of the dungeons of the Bastille, would the fact have lessened the guilt of these rulers in consigning innocent men to a life-long entombment amid the horrors of that terrible prison? Could we listen with patience to a defender of the French Government who, in such a case, might exclaim, "Shall these wretched prisoners cry 
aloud that the Bastille is ill-designed for their convenience when the great king has subjected himseli to its conditions ?" Mr. Balfour, it is true, contends that God became incarnate, and suffered "for the sake" of man. But even if it could be contended that our hypothetical French king had entered the Bastille, and had endured its pains and privations for the sake of the wretches who might be buried alive within its walls, would that justify the king in sending innocent men to the living death of this horrible prison? We do not say that the world in general may be compared as a place of suffering and woe with the Bastille of 1789 ; on the contrary, we recognise that the earth bears upon her broad bosom at least as much pleasure as pain; but no candid observer can be blind to the fact that for large numbers of men and women life has furnished such a procession of miseries and pains as could not be outmatched by the grimmest records of the old French fortress. The guilt which is attached to the creation of pain and wrong cannot be obliterated by any voluntary sharing, on the part of the Creator, of the suffering and injustice which he has caused to be inflicted on his helpless creatures. And if any importance be attached to the argument that God became incarnate for the sake of man, we 
would ask Mr. Balfour to show us how the Incarnation has benefited, or could benefit, the human race.

The reader may perhaps object that, although this chapter is entitled "Philosophy and Christianity," the references to philosophy are extremely few, while the doctrines of Christianity are discussed in every paragraph. In extenuation of this discrepancy between title and contents, we can only urge that we have followed Mr. Balfour's line of argument as closely as possible, and that his "suggestions towards a provisional unification" of science and theology on the basis of a new philosophy are, from beginning to end, nothing more than a series of arguments in support of Christian Theism. In demolishing these arguments we think we may fairly claim to have destroyed the provisional philosophy which they were designed to support. 


\section{CHAPTER XIV.}

SUMMARY OF THE ARGUMENT

IT may now be convenient to present a short summary of the controversy as a whole, and to lay additional emphasis on certain points to which, perhaps, sufficient attention has not yet been given.

The keynote of Mr. Balfour's second book, The Foundations of Belief, is the philosophic doubt in defence of which his first work was written. Take this away, and he loses his most effective weapon, both of attack and defence. We have tried to show that the few questions, among the many raised by philosophic doubt, which it may be impossible to answer are irrelevant and inadmissible in any discussion of the respective claims of Christianity and Rationalism. These claims belong to the region of practical and relative thought, and they cannot be decided by appeals to a philosophy which destroys the foundations of all belief, whether in the natural or in the supernatural. Mr. Balfour complains that some of his critics have supposed him to 
argue: "If all creeds, whether scientific or theological, are equally irrational, all may be equally accepted," and he says that this theory is by no means the one which his essay was intended to advocate. But there can be no doubt that this is the practical outcome of his argument. He did not, of course, intend it to be carried to such a length; but, if he is entitled to press the logic of abstract philosophy to its uttermost limit against the theories of Rationalism, the sceptic is equally entitled to show that this logic inevitably leads to a self-stultification which involves the abandonment of reason, makes every impostor ling, and leaves man the helpless prey of delusion and superstition.

Leaving the dim and uncertain ground of philosophic doubt, and turning to matters of practical importance, Mr. Balfour confronts Rationalism on the subject of ethics, and urges that the downfall of supernaturalism will be followed by the decay of morality. We have shown that this fear is altogether groundless; that the moral sentiments have no necessary connection with religious beliefs; that moral precepts exist and command human reverence, not because they are the injunctions of God, but because they are essential to man's highest welfare, and have grown out of social needs. 
Rationalism means the recognition of the sovereignty of reason; and the growth of Rationalism, though fatal to theology, is favourable to everything that conduces to human advancement, and will, therefore, strengthen, and broaden, and deepen the hold of the moral sentiments upon mankind.

On the question of Art, Mr. Balfour's utterances are as fanciful as they are inconclusive. Like all other natural origins, the beginning of the æsthetic sentiments is buried in an obscurity which we may illumine to some small extent with guesses and theories, but which we cannot hope to altogether remove. It is, however, clear that theology throws no light on the subject. To say that æsthetic emotions were created by God does not add to our knowledge. The assertion itself is destitute of proof, and if it could be accepted as true it involves greater mysteries than the one which it purports to explain. Mr. Balfour's suggestion that "in Nature and in Art we see, each of us from our own standpoint, only passing gleams and stray reflections" of "an unchanging splendour of beauty" which shines in the presence of God, commits him to the absurdity that the coarse and jingling ditty of the music-halls, and the most tuneful compositions of Beethoven and 
Mozart, are alike reflections of a divine and eternal music which is heard for ever in the courts of heaven. We have suggested, on the other hand, that the explanation of the rsthetic sentiments lies deep down in the ultimate fact of Feeling, and in the physical relations which exist between man's body and the universe.

In dealing with the question of reason $\mathrm{Mr}$. Balfour takes up two contradictory positions. First, he holds that reason is a comparatively unimportant faculty, and that in most respects it is greatly inferior to instinct; while, secondly, he argues that any theory which does not recognise reason as the ground of all existence is degrading and absurd. This is an example of the self-contradiction which seems inseparable from Christian apologetics, and which arises from the attempt to force natural facts into harmony with theological dogmas. Human reason must be judged on its merits from the human standpoint, and apart from theistic speculations. So judged, even Mr. Balfour will be ready to admit that reason is the faculty of supreme importance to man. The suggestion that, in some mysterious fashion, reason is the ground of all existence seems to us absurd. In any case, it has nothing whatever to do with the question of the worth of human reason, which is the highest product of 
earthly evolution-the apex, and not the ground, of man's existence.

While admitting that there may be minor discrepancies between science and theology, $\mathrm{Mr}$. Balfour denies that there is, or need be, any serious conflict between these two departments of belief. To his argument, that the acceptance of theism lessens the philosophical difficulties of science, it may be answered that no metaphysical or theological doctrine can remove these perplexities, which arise out of the simple yet allembracing fact that man's knowledge is strictly limited to the relative by inflexible conditions which the human intellect is powerless to transcend. Theism explains no difficulties, and does not render scientific theories more intelligible. On the contrary, it is overweighted with perplexities and contradictions of its own, and would be a burden, rather than a help, to scientific thought. Mr. Balfour is not disposed to press the argument from design too far, but he holds that, "broadly speaking and in the rough," it is in harmony with the facts. Yet elsewhere he tells us that "from such beginnings famine, disease, and mutual slaughter, fit nurses of the future lords of creation, have gradually evolved, after infinite travail, a race with conscience enough to feel that it is vile, and intelligence enough to 
know that it is insignificant." Mr. Balfour, it is true, puts this statement in the mouth of science, and while he thus admits that many of the facts of evolution are, in themselves, indisputably revolting, he appears to think that in the light of Christian theories they undergo a complete transformation. This may be true, but we submit that the transformation is for the worse. The horrors of the process of evolution are not diminished, but increased, by the belief that omnipotent wisdom set these natural forces in motion, and that they will culminate in heaven and hell. Do not let us talk of design in connection with a universe which sweeps through cycles of blood and tears, of strife and suffering, of cruelty and injustice, to the awful goal of eternal punishment. Whatever Mr. Balfour may think should be our attitude towards the Creator who designed that man should traverse this fiery pathway, he cannot, at least, expect us to love and worship him.

Even to a dialectician so accomplished and subtle as $\mathrm{Mr}$. Balfour the problem of miracles is surrounded with difficulties which he evidently feels to be insuperable. Carefully avoiding all reference to any specific Christian miracle, he deals with the subject in vague and general terms, and attempts to obscure the points at 
issue by means of a cloud of words, much irrelevant philosophy, and some evasive propositions. He refers to the "extreme difficulty of the problem raised by the relation of the self to phenomena," and contends that there is an analogy between the action of man and the alleged intervention of God in the phenomena of the universe. The comparison is transparently false. There is no more analogy between the two than between the action of a man who distils wine from the juice of the grape by ordinary methods and that of one who should turn water into wine by the mere exercise of his will. Mr. Balfour attempts to destroy the position that miracles are antecedently incredible by affirming (1) that there is no general agreement as to what is meant by the uniformity of nature; (2) that the scientific view of the " natural" is "open to grave philosophical objection," and is "deficient in philosophic proof "; and (3) that a miracle may assume a character of inevitableness when considered in relation to man and the universe as a whole. All these propositions are mere evasions of the difficulties of the question. There is sufficient agreement as to what is meant by "the uniformity of nature" to render any account of such a miracle as the raising of a dead man to life antecedently incredible in the highest degree. 
The second proposition is merely an invocation of Mr. Balfour's familiar spirit, philosophic doubt, and it must be ruled out of court as an intruder which may have business elsewhere, but which is certainly not entitled to speak on the concrete question of miracles and natural law. The third proposition falls to the ground in the absence of any demonstration that some particular miracle assumes this "character of inevitableness." Such a demonstration may be safely affirmed to be impossible, because if a miracle were " inevitable" it would cease to be a miracle, and would take place according to natural law.

Mr. Balfour's "suggestions towards a provisional unification" form, perhaps, the weakest portions of his books. Here he attempts to sketch the outlines of a philosophy which shall be "applicable to the whole circuit of belief"; but while his exposition is deficient in general philosophic principles, it is characterised by elaborate special pleading on behalf of theism and the Christian religion. In fact, Mr. Balfour's provisional philosophy is neither more nor less than an endeavour to plant the mighty structure of science on the crumbling foundations of theology. He contends first that, in order to avoid the difficulties of the theory that nature is non-rational, we are obliged to accept the belief 
that there is a Supreme Reason who is guiding the universe to a rational issue, and that this belief "seems forced upon us by the single assumption that science is not an illusion." It is difficult to see on what ground this kind of reasoning may be dignified by the name of "philosophy." A satisfactory philosophic system may be beyond our reach, but in that case we had much better take the facts as we find them, and adhere to the philosophy of empiricism, than plunge blindly, after Mr. Balfour's fashion, into the contradictions of theology and the mysteries of the absolute. Observing that he has been obliged to assume the truth of theology in order to find a basis for science, Mr. Balfour proceeds to argue that "preferential Divine intervention" takes place in connection with religion, and he points out that men " have almost always claimed for their beliefs about God that they were due to God." He thus finds room in his provisional philosophy for the doctrine of inspiration, and he is charitable enough to affirm that this preferential Divine action " is limited to no age, to no country, to no people." But while the doctrine of inspiration may be very good theology, most persons will incline to the opinion that it is out of place as one of the principles of a new philosophy. The belief in inspiration 
has been a baneful factor in the history of mankind. The statement that men "have almost always claimed for their beliefs about God that they were due to God" would form an appropriate heading for one of the darkest chapters of human history-the chapter which contains the record of religious persecutions, wars, and crimes. It was on this ground that the Jew persecuted the Christian; it is on this ground that the Christian has hunted and tortured the Jew, that Christians and Mohammedans have fiercely struggled together, that Protestants have slaughtered and imprisoned Catholics, and Catholics have stretched Protestants on the rack or led them to the stake. On the religious side of human affairs inspiration is a word of evil omen, and it casts a dark and forbidding shadow over any system of philosophy which adopts it, in its theological aspect, as a fundamental principle. Mr. Balfour's " provisional unification" may be incomplete and incoherent without it, but that is a reason, not for accepting the doctrine of inspiration, but for concluding that the new philosophy is sketched on false and worthless lines. If science and theology can be unified only by means of a synthesis which includes this pernicious and peace-destroying principle, it were better that they should remain for ever apart, or 
even at discord with each other. It may be true, as Mr. Balfour affirms, that science is lacking in philosophic coherence and stability. The deficiency, we are sure, cannot be supplied by the ancient theological dogmas which Mr. Balfour marshals before us with as much pride as though they were new discoveries of his own; but, if it could, we would rather Science remained destitute of a satisfactory philosophy than that she should be indebted for theoretical completeness to a doctrine which has filled the world with bitterness and strife, and which must always tend to produce fruit of this miserable kind.

$\mathrm{Mr}$. Balfour finds the crowning principle of his new philosophy in the doctrine of the Incarnation. His arguments on this subject have already been examined in detail, and here we need only point out the futility of a scheme which professes to explain and unify the mysteries and problems of the natural world by postulating a supernatural marvel which, in the extent of its difficulties and contradictions, exceeds them all. In the course of his two volumes $\mathrm{Mr}$. Balfour advances many strange arguments and takes up many untenable positions, but we think he reaches the climax of absurdity when he puts forward as one of the main principles of his " provisional unification" a doctrine which is merely 
the application to Christianity of one of the myths of sun-worship, and which has formed an important feature of so-called heathen religions. Mr. Balfour's provisional philosophy is altogether unworthy of his acute and powerful intellect. It is a bubble that could be pricked by the hand of a child. A unification which is founded on the myths and legends of ancient religions long since outgrown by the progressive portions of the human race; which takes us back to crude theological and metaphysical explanations of natural phenomena; and which re-affirms the exploded logmas of Christianity as the cardinal principles of a new philosophy, can hardly appeal to thoughtful readers of any school, and must form a poor and ineffective breakwater against the rising flood of rationalistic science. 


\section{CHAPTER XV.}

MIR. BALFOUR'S PERSONAL POSITION

The attentive reader who has followed this analysis of Mr. Balfour's books may be prompted to ask: "How, if your criticisms be just, do you account for the fact that a man of Mr. Balfour's intellectual power and high social standing should take so much pains to defend positions which you hold to be in many respects absurd, and in all respects untenable?" The question is a. pertinent one, and, while it may be impossible to. meet it with an entirely satisfactory answer, some suggestions on the point may not be without value.

We think nothing can be clearer, both from the form and from the substance of Mr. Balfour's. books, than the fact that it is emotion and prejudice, rather than intellectual conviction, which move him to make these elaborate efforts on behalf of his hereditary faith. In no single instance does he attempt to grapple directly with any Rationalist argument or hypothesis, and although he may excuse himself on this point. 
by the plea that he has been content to write " notes introductory to the study of theology," and that he has not attempted to produce a manual of Christian evidences or a formal defence of theological doctrines, there can be no escape from the conclusion that in works whose main object is the destruction of Rationalism he has deemed it politic or necessary to proceed by way of sap and mine rather than to make a frontal attack. In physical warfare this method may be sometimes laudable; in intellectual conflict it is usually held to denote fundamental weakness on the side of the combatant who adopts it. The situation, so far as $\mathrm{Mr}$. Balfour is concerned, may, we think, be summed up in a sentence. His intellect is unwillingly on the side of Rationalism; his emotion and sentiment are passionately devoted to the religion which he has inherited from a long line of aristocratic ancestors. A thinker like Mr. Balfour could hardly avoid being profoundly influenced by the great currents of modern scientific and philosophical thought; but even if feeling joined with intellect to impel him towards Rationalism, the wrench of leaving the ancient faith would probably be too great for a man possessing the peculiar traits of character which have made his personality attractive and charming. 
It is somewhat remarkable that three British Prime Ministers who have held office in recent times have been more or less ardently devoted to the cause of the national religion. Mr. Gladstone was deeply enamoured of the obsolete theology of divines like Butler, and, if he had not been a great statesman, he would probably have been an excellent bishop. Lord Salisbury, in characteristic fashion, has thrown light shafts of ridicule at the theory of evolution, though there can be no doubt that he cares infinitely more for problems of chemistry and experiments of the laboratory than for the Thirty-nine Articles of the English Church. Mr. Balfour has shown, both by his general attitude and by the volumes which we have been discussing, that his heart is warmly engaged on the side of the faith which he knows to be intellectually insecure. Lord Beaconsfield will, no doubt, be cited as an example of another type of British Premiers. He certainly displayed no particular enthusiasm in the cause of religion, but, being a Jew, he was probably more than half a Rationalist.

Some explanation of the intensely religious attitude of men like Mr. Gladstone and $\mathrm{Mr}$. Balfour may, we think, be found in the political environment. The extensions of the franchise during recent years have brought an immense 
Nonconformist vote into the field of practical politics, and, both by its sympathies and by its antipathies, the pressure of Nonconformist feeling has forced religious and ecclesiastical questions into greater political prominence. We do not suggest that Mr. Gladstone was, or that Mr. Balfour is, in the smallest degree insincere; but no man can altogether escape the influences of his surroundings and position. And neither of these statesmen can have been oblivious of the fact that pronouncements in defence of religion were likely to find favour with a large proportion of the electors from whom they derived their power.

On the social and political side, then, apart from his personal predilections, the influences which lead Mr. Balfour to openly and actively espouse the cause of Christianity are very strong. Descended, on his father's side, from the Scottish Earl of Lauderdale, and, through his mother, from the English House of Cecil, all the ties of blood, all the historic associations of the families from which he has sprung, all the subtle streams of social intercourse, combine to make any revolt against the established religion of the land repugnant to his inmost soul. The criticisms of the historic claims of Christianity may be unanswerable; the objections to theism may be 
overwhelming; the discrepancies between science and religion may be fundamental and ineradicable ; but rather than admit that we must therefore give up theology and acknowledge the claims of Rationalism, Mr. Balfour is prepared, on the one hand, to uproot the foundations of all knowledge, and, on the other hand, to set forth the philosophical difficulties of Rationalism, and the terrible social consequences which may be expected to follow the abandonment of Christianity, in the style of the average clergyman or hired lecturer who imagines that he is charged with a special mission from heaven for the demolition of modern thought. Mr. Balfour's mind is of a type too powerful and logical to be content with shuffling compromise, and he is too earnest to hide his thoughts and feelings on religious subjects beneath the veil of outward and inarticulate conformity to theological teaching and practice. He, therefore, seeks to justify the faith in which he has been reared, and to provide some method of shielding it from the encroachments of the great tidal waves of modern thought which are engulfing it before our eyes. He clings with passionate devotion to the religion of his fathers, and he is determined, at all costs, to justify to his intellect the creed which he accepts only because of his hereditary 
bias and social environment. In the ordinary field of controversy Mr. Balfour knows that the battle of theology has been fought to the bitter end; that it has been won by Rationalism and lost by religion; and he is unwilling to add to the chaos and destruction and humiliation which Christianity has suffered in open combat with her remorseless and terrible foe.

And so, with an audacity befitting the best traditions of the aristocracy which gave him birth, with a merciless logic worthy of the dreaming metaphysicians in whose society so many of his hours have been spent, with a theoretical consistency characteristic of the philosopher who deals with words rather than with things, Mr. Balfour digs a mine, deep and broad, beneath the whole arena of controversy, fills it with philosophic gunpowder, applies his logical match, and sends both religion and Rationalism, and all the combatants on both sides, including himself, heavenward in such a blaze of fiery and magnificent ruin as even Guido Fawkes, in his most sanguine moments, could hardly have hoped to emulate. And, during this strange ascent, Mr. Balfour cheers his co-believers with the assurance that such of them as may happen to reach the earth once more will be justified in framing a philosophical, 
scientific, and religious creed to their own liking out of any fragments which may have escaped destruction, and which may be sufficiently picturesque to enchain their fancy, or sufficiently familiar to harmonise with their prejudices and sentiments.

In his practical moments even Mr. Balfour must be convinced that the struggle between reason and belief in the supernatural cannot be decided in this summary and sweeping fashion. The weapon which, if it be effective against Rationalism, is equally destructive of the theology which it is intended to protect, cannot be of real and lasting service to the cause of religion. The great problems at issue are altogether untouched by Mr. Balfour's methods. When the noise and the dust caused by the explosion of his philosophic mine have passed away, we see that he has solved no riddles, removed no doubts, smoothed away no perplexities, and that all the momentous questions of life and death present themselves with the same insistence as of old, unaffected in any essential point by the haze of speculation which he has thrown around them.

We recognise that to $\mathrm{Mr}$. Balfour the decay of religion must seem a mournful process, fraught with dire omen for the future of the human race. 
His heart is with the Past, and his intellect is warped by the conviction that the happiness of mankind is inseparably interwoven with the faith which has been dominant in Europe for more than a thousand years. But there is a positive as well as a negative side to the process which fills Mr. Balfour's mind with so much alarm. The decay of religion is the result of the great increase of knowledge and the universal growth of reason. Men are turning with disgust from the dark jungles and miasma-laden valleys of supernaturalism to the sunny plains and green hill-sides of Nature, illumined with the light of science, and glowing with the ever-expanding influence of universal brotherhood and love. In all this we see cause for rejoicing rather than for the pessimistic lamentations which flow so readily from Mr. Balfour's pen.

Towards the future, then, we look with faith and hope. Theology may perish, but humanity will survive, and will work out its salvation from ignorance and wrong, not with the aid of mystic doctrines and narrow religious dogmas, but through the magic power of science, joined with the wondrous force of human self-sacrifice and love. 


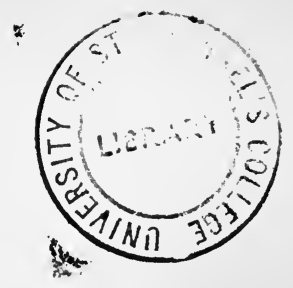

\section{INDEX}

Abrahaj, 24

Arabian Nights, 39, 128

Atheism, 42

Agnostics and the Moral Law, 42

Appetites, bodily, 46, 108

Altruistic virtues, 48

Altruism, 50, 61-2, 70

Anthropoid apes, 51

Ages of faith, 60

Anthropomorphism, 94

Author of nature, rational, 110,116

Authority is reason crystallised, 161

- human obeisance to, 163 baleful effects of unquestioned, 164

Arnold, Matthew, 171

America and Christianity, 179

Asia and Christianity, 180-1

Africa and Christianity, 180-1

Aristotle, 38

Balfodr, Mr., speech at Glasgow, 9

his theological position, 10

like a blind Samson, 26

his "need" for religion, 28

his barren negations, 33

his thesis of a lying universe, 37

brings an indictment against God, 52

shows a lack of philosophic discrimination, 58
Balfour, Mr., his arguments vitiated by prejudice, 66 dreams vain and foolish dreams, 83 reasons in a circle, 116 , 132,137 commits himself to the idea of an immoral creator, 142

- throws reason and experience overboard, 147

- his love of paradox, 152 his "provisional unification" a castle of sand, 167

- begs the question, 24, 174,187

- his attitude towards the injunctions of Christ, 178

__ his provisional philosophy unworthy of him, 220

- influenced by Nonconformist sentiment, 224

- his familiar spirit, philosophic doubt, 216

- digs a controversial mine, 226

his remedy for Rationalism overshoots the mark, 227

philosophic doubt his most effective weapon, 209

Bishop Butler, 14, 223

Byron, 33

Berkeley, 38

Book of Mormon, 39, 146

Beth-Gelert, 59 
Bride of Lammermoor, 77

Beethoven, 83, 211

Buddha, 100, 195

Buddhism, 178, 187, 188

Bradlaugh's definition natural law, 121, 125, 129

Borgia Cæsar, 175

Bastile, 206, 207

Beaconsfield, Lord, 223

Beliefs, non-rational causes of, 160

Colour a subjective phenomenon, 21, 22

Calvin, 24

Christian hearen, 49

Christian scientists, 53

Christian church, 100

Confucius, 134, 195

Cyrus the Great, 185

Christian apologeties, 212

Causation, Law of, 12, 144

Curiosity, Speculative, 88

Danwin, 20, 95

Descartes, 27, 38

Demosthenes, 51

Determinism, 55,58

Divine Reason, 86

Design, 105-8, 213-4

Evoldtion, 7, 35-6, 50, 52, 62, 89, 107, 111, 140-1, 214

Ethical truth, 28-9

Esthetic sentiments, 71-3, 211

Evil, physical and moral, 193

Empiricism, 217

Europe and Christianity, 179

Egypt, religion of, 100, 184

First Cause, 19

Feeling, 73, 82, 212

Fashion, 80, 81

"Free Reason," 112, 113

Faith and the maxims of daily life, 145-6

Frankenstein, 169

Faust, 175
Francis, St., of Assisi, 178

Fawkes Guido, 227

Force, persistence of, 112

of GoD, existence of, 102-3, 115-6

God and force identical, 117-8

God, preferential action of, 139-142

Gulliver, 148

God and the moral growth of man, 200-3

Gladstone, Mr., 223-4

God, personal, 19, 66

Historical INFEReNce, 17

Huxley, 32

Hume, 38, 122

Heroism, 47

Human race not immortal, 69

Helmholtz, 76

Handel, 83

Heaven and Hell, 146, 214

Humboldt, 148

Herculaneum and Pompeii, destruction of, 171

Historical criticism and Christianity, 186-8

Hinduism, 187

Happiness proportionate to virtue, 190

Hadles, 199

Iмmortality, $28,61,63,188$, $189,190,192$

Ivanhoe, 78

India, religions of, 100, 184

Ideals and sentiments, irherited, 99, 100

Inspiration, 173-6, 217-8

Incarnation, doctrine of, 183-6, 219

Isis and Horos, 184

Incarnation, doctrine of, and scheme of the universe, 196-9

Incarnation, doctrine of, and the materialistic trend of science, 204 
Incarnation, doctrine of, and the existence of evil, 205-8

Inspiration and persecution, 218

Jests, 10, 24, 30, 100, 123-4, $135,184,206$

Jesus, religion of, 135-6

Judaism, 100, 177

Jesus, resurrection of, 134-7

Korax, 24, 189

Kant, 38, 190-1

Krishna, 184, 195

LAPLACE, 20

Lyell, 20

Luther, Martin, 24

Llewellyn, 59

Life an ultimate fact, 110

Laws of nature, 117-8, 122-5, Orios, 70 129,138

Lewes, G. H., 121, 143

Lazarus, raising of, 123-4

Lisbon, earthquake at, 171

Livingstone, 148

Mars, 15-16

Metempirics, 21, 143-4, 147

Moses, 24

Moral sentiments, 40,42

Moral law, 41-2, 49, 50, 66, 191

Morals, evolution of, 54

Music, 75,78

Milton, 82

Means, doctrine that end justifies, 108

Matter, indestructibility of, 112

Man a phenomenon among phenomena, 117

Mill, J. S., 122-3, 161

Miracles and the twentieth century, 126

- and philosophic doubt, 130-2

— not inevitable, 136-7, 216
Munchausen, Baron, 148

Mohammed, 181, 189

Mohammedanism, 178, 187, 189

Missionary enterprise, failure of, 178

Miraculous, presumption against stories of the, 194-5

Mozart, 212

Nature, uniformity of, 14, 16, 119-121, 125, 128, 131-2, 139

Newton, 20

Natural selection, 71

Nature non-rational, 85

Natural facts not alien to reason, 114 5

New Testament, 125, 187, 189, 194

Parker, Theodore, 24

Palmer, Rugeley poisoner, 46

Protoplasm, 67, 107, 109

Plato, 77, 78, 100, 181

Pentateuch, 94

Planets, habitability of, 106

Prospero, 117

Providence, 140

Prophets, the, 176

Pythagoras, 181

Ptolemaic astronomy, 199

Paine, 226

Redentrtion, Pauline scheme of, 10

Rome, Pope of, 24

Reason, practical, 31

Robiuson Crusoe, 77

Reason not the ground of existence, 92-93, 96

Rational ground of existence, 103-4, 107

Religion not a necessary element of any adequate scheine of belief, 133

Rationalism, moral ideal of, 151 
Rationalism and authority, Sound a subjective pheno154-7, 165 menon, 21, 22

SUPERNATURALISM, $7,8,39$

Senses, evidence of, 22,26 inadequate, 89

Sense-perception, mode of interpreting, 149,150

Stephen, Sir Leslie, 32

Spencer, Herbert, 42,87

Sinai, 45

Shakespeare, 46,51

Sexual selection, 74

Symphony, ninth, 74, 81

St. Pierre, 86, 171

Solar system, formation of, 105-6

Struggle for existence, 107

Smith, Joseph, 134

Science, one and indivisible, 134-5

Supreme reason, 167-173, 217

Science, presuppositions necessary to, 169,170

Salisbury, Lord, 223

Theology not a department of knowledge, 24, 27, 103, 174

Theism, 25, 42, 112, 116-7, $187,205,208,213,224$

Theists, 42

Tennyson, 51

Treasure Island, 78

Tom-tom, the, 81

Trinity, 83

Turner, 83

Tolstoy, 178

Vedas, 24

Virgo, 184

Vanity Fair, 77

WagNer, 78

Wonder-working and ethics, 135

Witchcraft, 156-7, 175

Zoroaster, 134

Zoroastrianism, 188

Printed ly Watts \& Co., 17, Jolntson's Court, Fleet Street, London, E.C. 


$$
\text { - }
$$


Columbine

BD

Mr. Balfour's apologetics critically examined. 


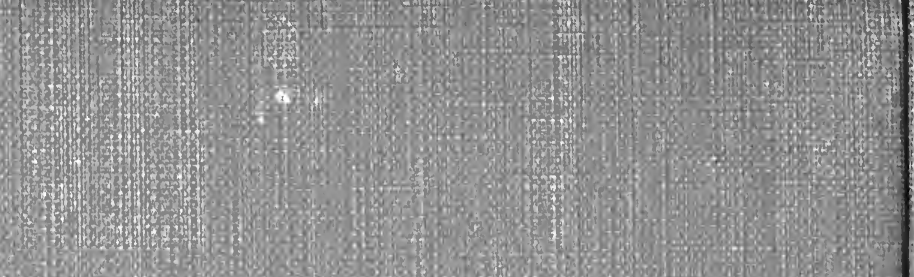

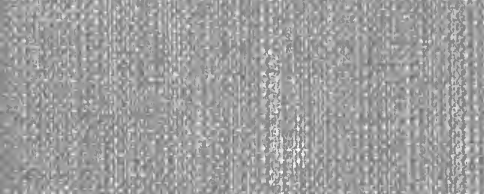

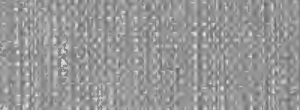

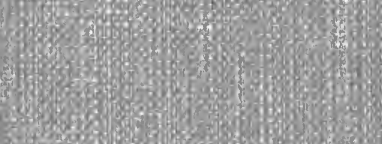

3): 350

19.

a. 5 .

40.60

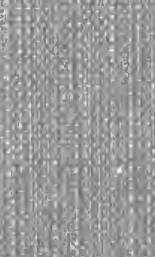

s)

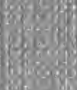

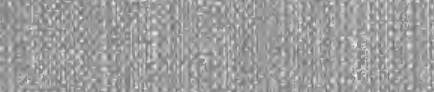

as

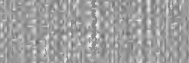

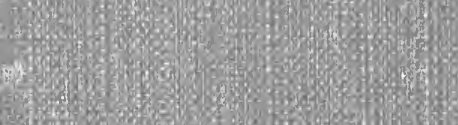

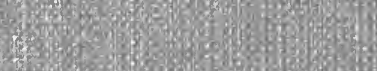

S1

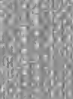

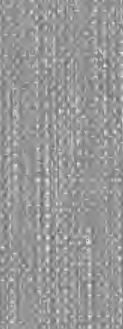
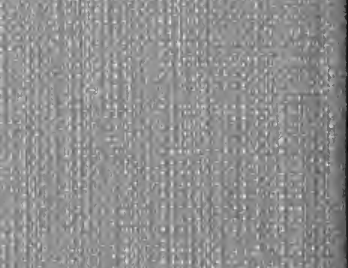